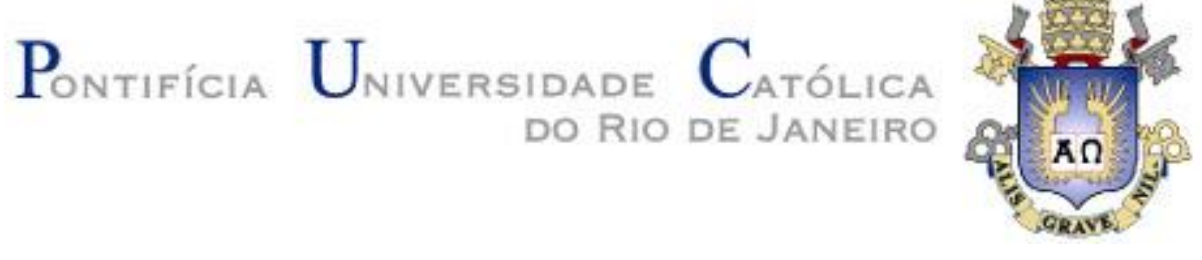

Renner Guilherme da Costa Marques

Estudo da viabilidade da substituição do anel de desgaste fixo por flutuante em bombas centrífugas

Dissertação de Mestrado

Dissertação apresentada como requisito parcial para obtenção do título de Mestre pelo Programa de PósGraduação em Engenharia Mecânica da PUC-Rio.

Orientador: Prof. Hans Ingo Weber

Rio de Janeiro

Agosto de 2015 
Renner Guilherme da Costa Marques

\section{Estudo da viabilidade da substituição do anel de desgaste fixo por flutuante em bombas centrífugas}

Dissertação apresentada como requisito parcial para obtenção do título de Mestre pelo Programa de PósGraduação em Engenharia Mecânica da PUC-Rio. Aprovada pela Comissão Examinadora abaixo assinada.

Prof. Hans Ingo Weber

Orientador

Departamento de Engenharia Mecânica - PUC-Rio

Prof. Igor Braga de Paula

Departamento de Engenharia Mecânica - PUC-Rio

Prof ${ }^{\text {a }}$ Katia Lucchesi Cavalca Dedini

UNICAMP

Prof. José Eugenio Leal

Coordenador Setorial do Centro Técnico Científico - PUC-Rio 
Todos os direitos reservados. É proibida a reprodução total ou parcial do trabalho sem autorização da universidade, do autor e do orientador.

\section{Renner Guilherme da Costa Marques}

Graduou-se em Engenharia Mecânica (UFMG) em 2007. Cursou MBA em Engenharia de Manutenção na COPPE-RJ em 2012. Trabalha na Petrobras desde 2007 na área de inspeção, fabricação e manutenção de Turbomáquinas.

Ficha Catalográfica

Marques, Renner Guilherme da Costa

Estudo da viabilidade da substituição do anel de desgaste fixo por flutuantes em bombas centrífugas / Renner Guilherme da Costa Marques ; orientador: Hans Ingo Weber. - 2015.

107 f. : il. (color.) ; $30 \mathrm{~cm}$

Dissertação (mestrado)-Pontifícia Universidade Católica do Rio de Janeiro, Departamento de Engenharia Mecânica, 2015.

\section{Inclui bibliografia}

1. Engenharia mecânica - Teses. 2. Anel de desgaste flutuante. 3. Vibração. 4. Bomba centrífuga. I. Weber, Hans Ingo. II. Pontifícia Universidade Católica do Rio de Janeiro. Departamento de Engenharia Mecânica. III. Título. 
Aos meus pais, Ademar e Conceição. Aos meus irmãos, sobrinhos e minha namorada Tammy. 


\section{Agradecimentos}

Primeiramente a Deus, pela saúde e força dada em todos os momentos da minha vida.

Aos meus pais, e aos meus irmãos e sobrinhos por todo amor, amizade, apoio e confiança nos meus estudos.

A minha namorada, pelo amor, companheirismo, incentivo e paciência.

A equipe de manutenção de equipamentos dinâmicos da Refinaria Duque de Caxias pelos ensinamentos e apoio concedidos durante o desenvolvimento do trabalho.

Ao meu orientador, Professor Hans, por toda sabedoria e pelas valiosas sugestões imprescindíveis para o desenvolvimento deste trabalho.

A todos os professores, colegas e funcionários do Programa de Pós-Graduação em Engenharia Mecânica, pelo apoio e amizade.

Aos membros da Banca Examinadora, por toda atenção ao lerem minha dissertação e participarem da minha avaliação. 


\section{Resumo}

Marques, Renner Guilherme da Costa; Weber, Hans Ingo. Estudo da viabilidade da substituição do anel de desgaste fixo por flutuante em bombas centrífugas. Rio de Janeiro, 2015. 107p. Dissertação de Mestrado Departamento de Engenharia Mecânica, Pontifícia Universidade Católica do Rio de Janeiro.

Grande parte dos sistemas de bombeamento existentes em refinarias é do tipo centrífuga com rotor em balanço. Alguns desses sistemas, que foram fabricadas antes da década de 80, ainda estão sendo usadas em refinarias no Brasil. Tipicamente estes equipamentos possuem rotores muito flexíveis. Isto ocorre devido ao alto valor da razão entre a distância entre mancais e o diâmetro do eixo e também por causa da substituição de gaxetas, que oferecem rigidez, por selos mecânicos. Como consequência, a resposta dinâmica destes equipamentos é sensível à pequenas variações da folga entre os anéis de desgaste. $\mathrm{O}$ desgaste devido a erosão e ao contato entre as superfícies aumentam a folga, causando aumento da vibração e redução de eficiência, pois aumenta a vazão através dos anéis. Visando contribuir para a solução destes inconvenientes na operação de bombas centrífugas, o presente trabalho investigou a viabilidade de substituir o anel de desgaste estático por flutuante através de análise rotodinâmica com o auxílio dos softwares ROMAC e XLTRC2. A anel flutuante proporcionaria a redução da erosão e aumento da eficiência de bombeio, proporcionado pela montagem com folga reduzida. Outra vantagem é a redução da resposta ao desbalanceamento causado pelo aumento da rigidez e amortecimento. A desvantagem de usar anel flutuante é que este deve ser projetado para cada condição operacional.

\section{Palavras-chave}

Anel de desgaste flutuante; vibração; bomba centrífuga 


\section{Abstract}

Marques, Renner Guilherme da Costa; Weber, Hans Ingo (Advisor). Study of feasibility in replacing in a centrifugal pump the static wear ring by a floating wear ring. Rio de Janeiro, 2015. 107p. MSc. Dissertation Departamento de Engenharia Mecânica, Pontifícia Universidade Católica do Rio de Janeiro.

A major pumping systems used in refineries is overhung centrifugal pump. Some of them, which were manufactured before 80 's, are still being used in refineries in Brazil. Usually theses equipments have flexible rotors since the ratio $\mathrm{L} / \mathrm{D}$ is high and the packing, that offers stiffness, was replaced by mechanical seals in order to get more safety. As consequence, the dynamic response of these pumps is very sensitive to any variation of the wear ring clearance. Weariness due to erosion and surfaces in contact increase the diametral clearance of the wear ring, that increases the vibration and reduces the efficiency of the pump since the flow through the seals rises. So, in order to solve these two concerns (vibration and efficiency) this study investigated the feasibility of replacing the static ring by the floating wear ring through rotordynamic analyses using the following software: ROMAC and XLTRC2. Floating wear ring reduces the erosion and increases the efficiency of the pump since it permits to minimize the radial clearance. The disadvantage of using floating wear ring is that each one has to be designed for a specific operation condition.

\section{Keywords}

floating wear ring; vibration; centrifugal pump 


\section{Sumário}

1 Introdução 14

1.1. Revisão Bibliográfica 19

1.2. Objetivos, justificativa do tema e resultados esperados 23

2 Introdução à rotodinâmica 24

2.1. Modelo matemático simplificado do modo de vibração lateral de um rotor isotrópico 26

3 Escoamento através do selo anular 33

3.1. Teoria de filme de óleo hidrodinâmico em selo anular 35

3.2. Anel de desgaste flutuante 43

4 Influência dos coeficientes dinâmicos do fluido na dinâmica da máquina rotativa

5 Elementos finitos para análise lateral do rotor 49

5.1. Modelo em elementos finitos 51

5.1.1. Matriz de rigidez do eixo $\quad 54$

5.1.2. Matriz de massa do eixo $\quad 57$

6 Modelagem e simulação rotodinâmica 61

7 Metodologia $\quad 69$

8 Resultados $\quad 82$

8.1. Bomba centrífuga de simples estágio 82

8.2. Bomba centrífuga de multiestágios 94

9 Conclusões 100

10 Referências bibliográficas 102 


\section{Lista de figuras}

Figura 1- Espectro de vibração de uma bomba centrífuga com rotor em balanço 14

Figura 2 - Tipos de anéis de desgaste - Block (1999) 17

Figura 3 - Modelo da bomba centrífuga analisado por Black (1969) 20

Figura 4 - Escoamento através dos selos anulares excêntricos - Black (1969) 20

Figura 5 - Bomba trabalhando com anel de desgaste flutuante - Duan et al.

Figura 6 - Modos de vibração de um rotor - Muszynska (2005) 25

Figura 7 - Modelo do rotor no modo de vibração da sua primeira crítica -

Muszynska (2005)

Figura 8 - Comparação entre movimentos com tipos diferentes de

amortecimentos - RAO (2003) 31

Figura 9 - Direita: foto da bomba em corte. Esquerda: anel de desgaste 33

Figura 10 - Volume de controle diferencial em coordenadas cilíndricas -

Childs (1993) 36

Figura 11 - Queda de pressão através do selo 39

Figura 12 - Vazão mássica através dos anéis de desgaste 41

Figura 13 - Rigidez direta 41

Figura 14 - Rigidez cruzada $\quad 42$

Figura 15 - Coeficientes de amortecimento 43

Figura 16 - Teste de convergência versus número de malhas 43

Figura 17 - Superior: Conceito do anel flutuante. Inferior: Balanço de força no anel 45

Figura 18 - Coeficientes dinâmicos das forças introduzidas pelo fluido $\quad 46$

Figura 19 - Coeficientes dinâmicos diretos da força do fluido 47

Figura 20 - Coeficientes dinâmicos cruzados da força do fluido 48

Figura 21 - Superior: Rotor representado no sistema de coordenadas cartesianas. Inferior: Subdivisão do rotor em elementos finitos - Allaire \& Castilho (2011) 49

Figura 22 - Polinômio de Hermite 53

Figura 23 - Deslocamento generalizado do elemento - Allaire \& Castilho (2011)54 
Figura 24 - Tensão normal e deslocamento axial - Allaire \& Castilho (2011) 55

Figura 25 - Desenho de Corte da bomba centrífuga multiestágios 62

Figura 26 - Dimensional e propriedades mecânicas do conjunto rotativo 62

Figura 27 - Modelagem do conjunto rotativo da bomba centrífuga multiestágios 63

Figura 28 - Mapa das frequências naturais de uma bomba centrífuga $\quad 64$

Figura 29 - Diagrama de Campbell - Mapa das frequências naturais 65

Figura 30 - Mapa de estabilidade rotordinâmica 66

Figura 31 - Simulação dos modos de vibrar de uma bomba centrífuga 67

Figura 32 - Representação "3D" do primeiro modo de vibrar de um rotor 67

Figura 33 - Representação em "3D" do segundo modo de vibrar de um rotor 68

Figura 34 - Etapa do dimensionamento do conjunto rotativo 70

Figura 35 - Representação do modelo do conjunto rotativo 72

Figura 36 - Variação da rigidez radial com o fator de velocidade - site da SKF 73

Figura 37 - Mancais hidrodinâmicos no lado acoplado e lado desacoplado 79

$\begin{array}{ll}\text { Figura } 38 \text { - Dados do óleo de lubrificação } & 79\end{array}$

Figura 39 - Selos anulares do rotor do primeiro estágio 79

Figura 40 - Dados do selo na sucção do $2^{\circ}$ ao $8^{\circ}$ estágio $\quad 80$

Figura 41 - Dados do tambor de balanceamento $\quad 80$

Figura 42 - Medição da frequência natural da bomba com suporte 82

Figura 43 - Mapa das frequências naturais não amortecidas 82

Figura 44 - Variação do coeficiente de rigidez direta $K_{x x}$ - ("g" refere-se ao selo 84 $\begin{array}{ll}\text { com superfície ranhurada) } & 84\end{array}$

Figura 45 - Variação do coeficiente de rigidez Direta $\mathrm{K}_{\mathrm{yy}} \quad 84$

Figura 46 - Variação do coeficiente de rigidez cruzada $\mathrm{K}_{\mathrm{xy}}$

Figura 47 - Variação do coeficiente de rigidez cruzada $\mathrm{K}_{\mathrm{yx}} \quad 85$

Figura 48 - Variação do coeficiente de amortecimento Direto $C_{\mathrm{xx}} \quad 86$

Figura 49 - Variação do coeficiente de amortecimento direto $\mathrm{C}_{\mathrm{yy}} \quad 86$

Figura 50 - Variação do coeficiente de amortecimento cruzado 87

$\begin{array}{ll}\text { Figura } 51 \text { - Variação do coeficiente de amortecimento cruzado } & 87\end{array}$

Figura 52 - Força resultante do fluido sobre o anel flutuante 88

Figura 53 - Razão de amortecimento versus frequência natural amortecida $\quad 89$

Figura 54 - Deslocamento do rotor na posição do selo anular $1 \quad 90$

Figura 55 - Deslocamento do rotor na posição do selo anular $2 \quad 90$ 
Figura 56 - Deslocamento do rotor na posição do selo mecânico

Figura 57 - Vazão pelos anéis de desgaste $\quad 91$

Figura 58 - Primeiro modo de vibrar da bomba centrífuga de simples estágio 92

Figura 59 - Primeiro modo de vibrar da bomba centrífuga de simples estágio em "3D" 92

Figura 60 - Segundo modo de vibrar da bomba centrífuga de simples estágio 93

Figura 61 - Segundo modo de vibrar da bomba centrífuga de simples estágio em "3D"

Figura 62 - Primeiro modo de vibrar - anéis fixos 95

Figura 63 - Segundo modo de vibrar - anéis fixos 95

Figura 64 - Terceiro modo de vibrar - anéis fixos 96

Figura 65 - Primeiro modo de vibrar - anéis flutuantes 96

Figura 66 - Segundo modo de vibrar - anéis flutuantes 96

Figura 67 - Terceiro modo de vibrar - anéis flutuantes 97

Figura 68 - Bode dos sensores no eixo horizontal 'x' - anéis fixos 97

Figura 69 - Bode dos sensores no eixo horizontal ' $x$ ' - anéis flutuantes 98

Figura 70 - Bode dos sensores no eixo vertical 'y' - anéis fixos 98

Figura 71 - Bode dos sensores no eixo vertical 'y' - anéis flutuantes 99 


\section{Lista de tabelas}

Tabela 1 - Condições de contorno do selo anular 39

Tabela 2 - Dados de entrada dos elementos da malha do eixo 71

Tabela 3 - Propriedades mecânica do eixo 72

Tabela 4 - Propriedades físicas do impelidor (34) e acoplamento (2) 74

Tabela 5 - Coeficientes dinâmicos da bucha de fundo 75

Tabela 6 - Dados de processo da bomba centrífuga simples estágio 75

$\begin{array}{ll}\text { Tabela } 7 \text { - Parâmetros do selo anular } & 76\end{array}$

Tabela 8 - Dados de entrada dos elementos da malha do eixo da bomba $\begin{array}{ll}\text { multiestágios } & 77\end{array}$

Tabela 9 - Propriedades mecânicas do eixo da bomba multiestágios 78

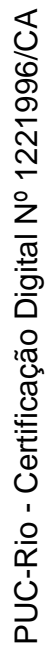

Tabela 10 - Dados dos impelidores e acoplamento ${ }^{1} \quad 81$

Tabela 11 - Distribuição de massa de desbalanceamento 81

Tabela 12 - Comparação dos resultados com anel fixo e flutuante da bomba multiestágios 


\section{Nomeclatura}

$\mathrm{C}_{\mathrm{xx}}$ - amortecimento dos termos diretos

$\mathrm{C}_{x y}$ amortecimento dos termos cruzados

$\mathrm{C}_{\mathrm{yx}}$ - amortecimento dos termos cruzados

$\mathrm{C}_{y y}$ - amortecimento dos termos diretos

E - módulo de elasticidade

e - excêntricidade

$\mathrm{e}_{\mathrm{r}}$ - rigosidade do anel rotativo

$\mathrm{e}_{\mathrm{s}}$ - rugosidade do anel estático

$\mathrm{F}$ - força

$f$ - coeficiente de atrito

$\mathrm{h}$ - folga radial

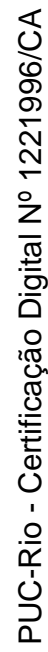

I - momento de inércia

$\mathrm{K}_{\mathrm{xx}}$ - rigidez dos termos diretos

$\mathrm{K}_{\mathrm{xy}}$ - rigidez dos termos cruzados

$\mathrm{K}_{\mathrm{yx}}$ - rigidez dos termos cruzados

$\mathrm{K}_{\mathrm{yy}}$ - rigidez dos termos diretos

$M$ - massa

$P$ - força estática

$U$ - velocidade circunferencial

W - velocidade axial

$\mathrm{x}$ - coordenada cartesiana ou deslocamento ao longo do eixo $\mathrm{x}$

$y$ - coordenada cartesiana ou deslocamento ao longo do eixo y

z - coordenada cartesiana ou deslocamento ao longo do eixo $z$

\section{Letras Gregas}

$\varepsilon$ - deformação

$\zeta$ - fator de amortecimento

$\varphi$ - fase

$\omega$ - frequência de rotação

$\Omega$ - frequência de excitação 


\section{1 \\ Introdução}

Bombas centrífugas são essenciais para as unidades de processo das refinarias de petróleo. Elas são utilizadas para deslocamento e aumento de pressão do fluido nos sistemas que são compostos por equipamentos como tanques, vasos de pressão, torre de destilação, trocador de calor, válvulas e tubulações. Sua falha pode representar a parada de uma unidade gerando, desta forma, prejuízo por lucro cessante. Portanto, devido a sua relevância, muitas vezes cada bomba possui seu par como backup, ou seja, caso uma permaneça indisponível haveria outra para manter o processo operando.

Um dos componentes de uma bomba centrífuga é o anel de desgaste, que tem como função reduzir a vazão de recirculação do fluido e aumentar a rigidez e amortecimento do conjunto rotativo. Desta forma ele reduz a vibração da bomba e melhora a sua eficiência.

Ao realizar acompanhamento preditivo de um parque de bombas centrífugas de uma refinaria de petróleo entre os anos 2008 e 2014, observou-se que algumas bombas apresentavam elevação de vibração repentina na frequência entre 1,2 a 1,4 vezes a rotação do equipamento como observado na figura 1.

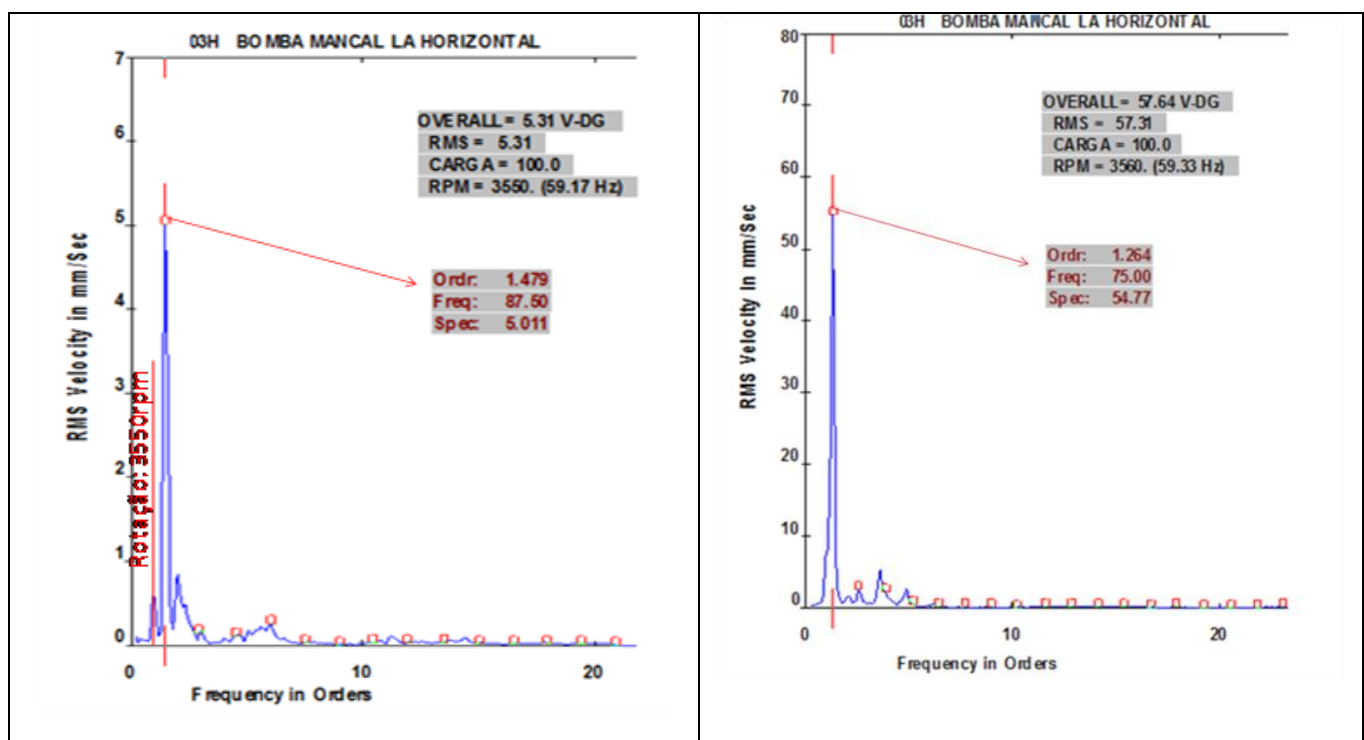

Figura 1- Espectro de vibração de uma bomba centrífuga com rotor em balanço 
Estas bombas, que foram fabricadas de acordo com a norma API 610 (American Petroleum Institute - Centrifugal Pumps for Petroleum, Petrochemical and Natural Gas Industries) em edições anteriores à $8^{\mathrm{a}}$ ed., possuem projetos semelhantes em relação ao seu coeficiente de flexibilidade (razão entre a quarta potência da distância entre mancais e o quadrado do diâmetro do eixo), utilização de gaxetas no sistema de selagem e rotor em balanço (overhung).

Em consequência destas velocidades vibrações elevadas, que chegam a ultrapassar patamares de $30 \mathrm{~mm} / \mathrm{s}-\mathrm{rms}$, ocorrem falhas prematuras dos mancais e do selo mecânico, ocasionando vazamento do produto bombeado que, por sua vez, pode iniciar um incêndio na unidade de produção. Portanto, devido a estes adventos surgiu a necessidade de pesquisar qual a causa desta anomalia presente nestes equipamentos.

Ao realizar uma análise pela causa básica de uma possível instabilidade rotodinâmica no modelo de bomba mencionado, as únicas anormalidades mecânicas encontradas foram: i) folga excessiva entre os anéis de desgaste (>1mm); ii) substituição da gaxeta de selagem por selo mecânico sem uma prévia análise do comportamento dinâmico do equipamento.

Portanto, o objetivo deste presente trabalho é analisar a influência dos anéis de desgaste no comportamento rotodinâmico de uma bomba com rotor em balanço e realizar o estudo da viabilidade da substituição do anel de desgaste estático por um flutuante. Busca-se também verificar se a frequência de vibração observada em campo de 1,2 a 1,6 vezes a rotação do rotor estava associada a alguma instabilidade do sistema. Também é avaliado qual seria a alteração do comportamento dinâmico de uma bomba centrífuga multiestágios utilizando anéis flutuantes.

A proposta da utilização de selo anular flutuante, que segue os mesmos princípios do anel flutuante em selo mecânico a óleo, seria a possibilidade da montagem com folgas mais reduzidas e sua operação em uma posição menos excêntrica que o selo fixo. Como consequência, haveria a redução da erosão, aumento do amortecimento e redução da rigidez cruzada com a possível 
eliminação da instabilidade na frequência entre 1,2 a 1,4 vezes a rotação e o aumento da eficiência da bomba centrífuga.

Uma das desvantagens de sua aplicação é que este componente deve ser projetado para cada condição operacional, dificultando sua produção em série. Portanto, este fato é um dos motivos da sua pouca utilização, sendo encontradas apenas em alguns casos específicos de turbo-bombas presente em foguetes e algumas bombas multiestágios com eixo flexível.

Estes anéis de desgaste, também chamados de selos anulares, são compostos de dois dutos anulares no qual o anel interno é rotativo e o externo é estático. Neles ocorrem um escoamento axial turbulento e um escoamento circunferencial que favorece o surgimento de instabilidade fluidodinâmica. A função principal deste selo é restringir o retorno do fluido bombeado da descarga para sucção. Este componente exibe uma diferença significativa no comportamento do rotor que depende de seu comprimento, folga, excentricidade, velocidade de entrada do fluido, queda de pressão ao longo do selo e da geometria da superfície de contato com o fluido.

Há diferentes tipos de anéis de desgaste com a finalidade de aumentar a eficiência de bombeio. Block (1999) apresenta uma tabela que correlaciona os formatos destes selos com o aumento de eficiência da bomba. 


\begin{tabular}{|c|c|c|c|c|c|c|c|}
\hline & & \multirow{2}{*}{$\begin{array}{l}a \\
\text { In. }\end{array}$} & \multirow{2}{*}{$\begin{array}{c}b \\
\text { In. }\end{array}$} & \multicolumn{4}{|c|}{$\begin{array}{l}\text { Leakage per cent } \\
\text { at r.p.m. }\end{array}$} \\
\hline & & & & 1400 & 1700 & 2000 & 2500 \\
\hline 1 & 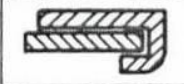 & 0.012 & $11 / 16$ & 1.52 & 1.80 & 2.00 & 2.18 \\
\hline 2 & \multirow{6}{*}{ 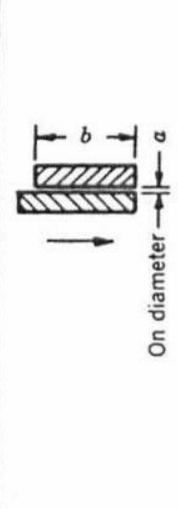 } & 0.012 & $11 / 16$ & 2.85 & 3.32 & 3.52 & 3.70 \\
\hline 3 & & 0.012 & $11 / 16$ & 3.52 & 4.03 & 4.33 & 4.50 \\
\hline 4 & & 0.017 & $11 / 16$ & 6.06 & 6.65 & 6.70 & 6.70 \\
\hline 5 & & 0.020 & $111 / 16$ & 7.92 & 8.62 & 8.86 & 8.60 \\
\hline 6 & & 0.029 & $11 / 16$ & 13.2 & 13.9 & 14.0 & 14.0 \\
\hline 7 & & 0.039 & $11 / 16$ & 18.7 & 19.6 & 19.8 & 20.0 \\
\hline 8 & \multirow{2}{*}{$\begin{array}{l}\text { DRSBA } \\
\text { Circular groove } \\
1 / 16 \times 1 / 16 \\
1 / 8 \text { apart }\end{array}$} & 0.017 & $11 / 16$ & 4.83 & 5.38 & 5.58 & 5.52 \\
\hline 9 & & 0.029 & $111 / 16$ & 12.7 & 13.5 & 13.7 & 13.6 \\
\hline 10 & $\frac{00000}{201 / 1 / 8}$ & 0.011 & $111 / 16$ & 3.18 & 3.68 & 3.94 & 4.08 \\
\hline 11 & & 0.021 & $11 / 16$ & 8.53 & 9.04 & 9.15 & 9.19 \\
\hline 12 & 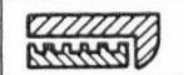 & 0.011 & $11 / 16$ & 2.52 & 2.88 & 2.92 & 2.98 \\
\hline 13 & $\begin{array}{l}1 / 16 \times 1 / 16 \\
\text { spiral groove }\end{array}$ & 0.021 & $11 / 16$ & 6.24 & 6.68 & 6.89 & 6.82 \\
\hline 14 & 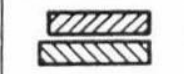 & 0.010 & $11 / 16$ & 2.55 & 3.03 & 3.28 & 3.44 \\
\hline 15 & En: & 0.010 & $111 / 16$ & 2.07 & 2.34 & 2.45 & 2.52 \\
\hline
\end{tabular}

Figura 2 - Tipos de anéis de desgaste - Block (1999)

Quando ocorre a passagem do fluido através deste selo, há geração de força no impelidor. Portanto, ele também influencia a resposta à força externa e/ou desbalanceamento do conjunto eixo-impelidor-mancal, sendo, então, necessário estudar sua característica fluido-dinâmica. Logo, o estudo da influência destes anéis de desgaste pode ser focado em dois aspectos: a) eficiência no bombeio; b) efeito da força gerada pelo fluido no comportamento dinâmico do rotor devido aos seus coeficientes dinâmicos de rigidez e de amortecimento. Apesar do foco do presente trabalho ser segunda categoria, será citado nos resultados das simulações a influência do anel de desgaste flutuante na eficiência da bomba.

O modo de vibração do conjunto rotativo de uma bomba é devido a um efeito combinado da interação das partes rotativa/estática / fluido. Frequentemente, 
o espectro de vibração pode ser analisado e quantificado com métodos apropriados de medição. Entretanto, há situações em que os dados requisitados não podem ser adquiridos devido a restrições de acesso físico ou custos proibitivos. No entanto, para realizar o diagnóstico do equipamento pode-se iniciar a investigação comparando os dados de vibração medidos nos mancais com o comportamento previsto da máquina. Para esta situação, o desenvolvimento e utilização de modelos matemáticos para simulação do sistema mecânico é mandatório.

Portanto, para elaboração do modelo matemático para estudo da vibração da estrutura (conjunto rotativo) induzida pelo fluido, foi realizada uma revisão bibliográfica que engloba a análise modal de vibração de vigas, cálculos de frequências naturais, região de instabilidade influenciada amortecimento do conjunto rotativo, elementos finitos, escoamento em dutos anulares e vibrações para o desenvolvimento de simulações para analisar a resposta do modelo.

Em posse do modelo do sistema mecânico foram realizadas simulações utilizando programas comerciais como XLTRC2T e Romac para quantificar as seguintes variáveis:

- Frequência natural do conjunto rotativo

- Frequência natural amortecida

- Modo de vibração

- Velocidade crítica, na qual a amplitude de resposta ao desbalanceamento é máxima.

- Variação da rigidez e amortecimento com a folga entre selos anulares.

- Variação da rigidez e amortecimento com a excentricidade do selo rotativo.

- Variação da vazão axial através do selo anular com a folga

- Variação da força induzida pelo fluido com a excentricidade e folga do selo.

O software XLTRC2T é um programa desenvolvido pela Texas $A \& M$ University para análise rotodinâmica. Ele utiliza código em elementos finitos e possui interface com Excel. Este programa foi utilizado para cálculo das 
frequências naturais, modo de vibração, resposta ao desbalanceamento, frequências naturais amortecidas, velocidades críticas e fatores de amortecimentos do conjunto rotativo com um impelidor.

O Romac (Rotating Machinery and Controls), código desenvolvido pela universidade de Virginia, foi utilizado para cálculo dos coeficientes dinâmicos do anel de desgaste, bucha de fundo da bomba, mancais e comportamento dinâmico do rotor multiestágios. Estes programas já são amplamente utilizados por empresas que trabalham com equipamentos rotativos (bombas, compressores, turbinas e etc.) para análise lateral dos rotores fabricados.

Como foi utilizado um programa comercial para efetuar as simulações, as equações presentes no escopo deste trabalho têm a finalidade de explicitar quais as variáveis envolvidas e como elas interferem na dinâmica do sistema mecânico. Esta dissertação não apresentou a parte experimental, pois a bomba centrífuga de simples estágio utilizada como modelo da pesquisa teve que ser sucateada devido à ocorrência de um incêndio causado pelo vazamento do seu selo mecânico em decorrência da vibração elevada, antes da alteração dos anéis de desgaste.

\section{1. \\ Revisão Bibliográfica}

Devido à relevância e complexidade do assunto, desde os anos 1960 vêm sendo elaborados artigos sobre o comportamento fluidodinâmico através de selos anulares no qual o anel interno é rotativo.

Inicialmente, o estudo da rotodinâmica englobava apenas a análise da dinâmica da estrutura do rotor, sem se preocupar, no entanto, com a influência dos mancais. Entretanto, em meados de 1960, Lund, Sterlicht e Gunter desenvolveram trabalhos focando a influência dos mancais hidrodinâmicos na frequência natural amortecida e estabilidade do rotor. Já nos anos 70's maior atenção era dada nos estudos sobre a influência da força de iteração fluidoestrutura que ocorria nos selos à gás e a óleo e nos impelidores.

Black (1969) em seu artigo "Effects of Hydraulic Forces in Annular Pressure Seals on the Vibrations of Centrifugal Pump Rotor" cita que os anéis de desgaste trabalham como um mancal hidrostático com escoamento em regime turbulento. Ele considerava que o do fluxo principal era na direção na axial, 
apesar da rotação do anel interno. Entretanto, o efeito rotacional do fluido não poderia ser desprezado. No artigo citado, a superfície do anel é lisa, como utilizado pela bomba a ser modelada nesta dissertação. Black correlaciona a influência da rotação, da velocidade circunferencial do fluido, da folga e da excentricidade do anel interno na estabilidade rotodinâmica da bomba. Ele concluiu que o efeito rotacional do fluido tende a reduzir a força devido ao amortecimento e a redução da folga tende a reduzir a amplitude de resposta ao desbalanceamento. As figuras 3 e 4 ilustram o modelo da bomba e selo analisados em seu artigo:

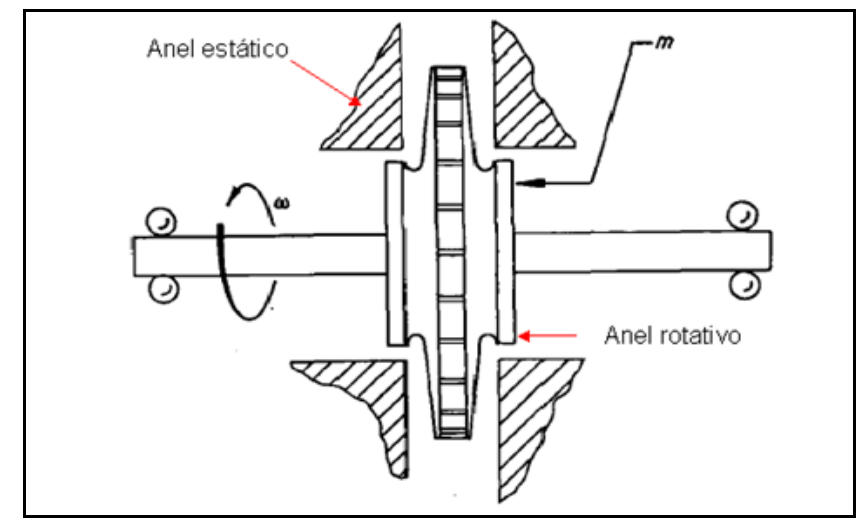

Figura 3 - Modelo da bomba centrífuga analisado por Black (1969)

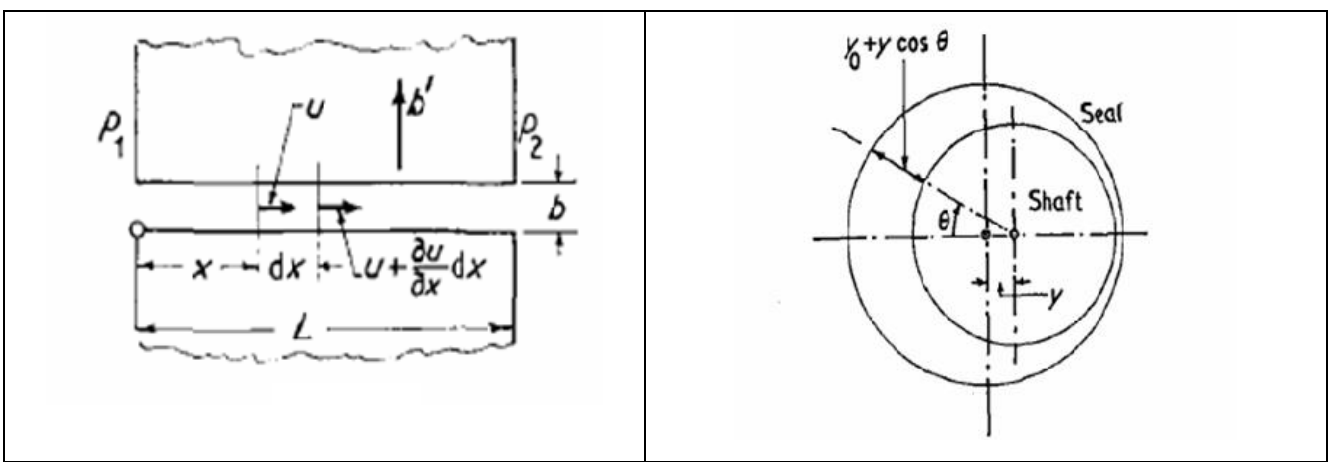

Figura 4 - Escoamento através dos selos anulares excêntricos - Black (1969)

Antunes (1996), diferentemente de Black, desenvolveu em seu artigo "Dynamics of Rotors Immersed in Eccentric Annular Flow" o equacionamento da dinâmica do fluido através de cilindros anulares excêntricos enfatizando o fluxo circunferencial em detrimento do seu fluxo na axial. O trabalho de Antunes inclui o efeito força de inércia que, diferente dos mancais, podem ter influência 
considerável em situações em que a razão entre largura e diâmetro seja maior que 0,5. Antunes obteve resultados satisfatórios ao comparar os resultados do seu modelo teórico com seus dados experimentais. Assim como Black, ele também correlacionou a influência da excentricidade do anel interno na estabilidade dinâmica da bomba. Ele afirmou que o aumento da excentricidade tende a aumentar a região de instabilidade.

Duan et al., (2006) apresenta em seu artigo "A bulk-flow analysis of static and dynamic characteristics of floating ring seals" a influência da velocidade de operação da bomba nos valores dos coeficientes dinâmicos do fluido (amortecimento e rigidez). O trabalho por ele apresentado foi para turbo-bomba e o objetivo da utilização do anel flutuante era a possibilidade de trabalhar com folgas mais reduzidas, melhorando desta forma a performance da bomba. A figura 5 mostra o modelo da turbo-bomba e do anel flutuante: 


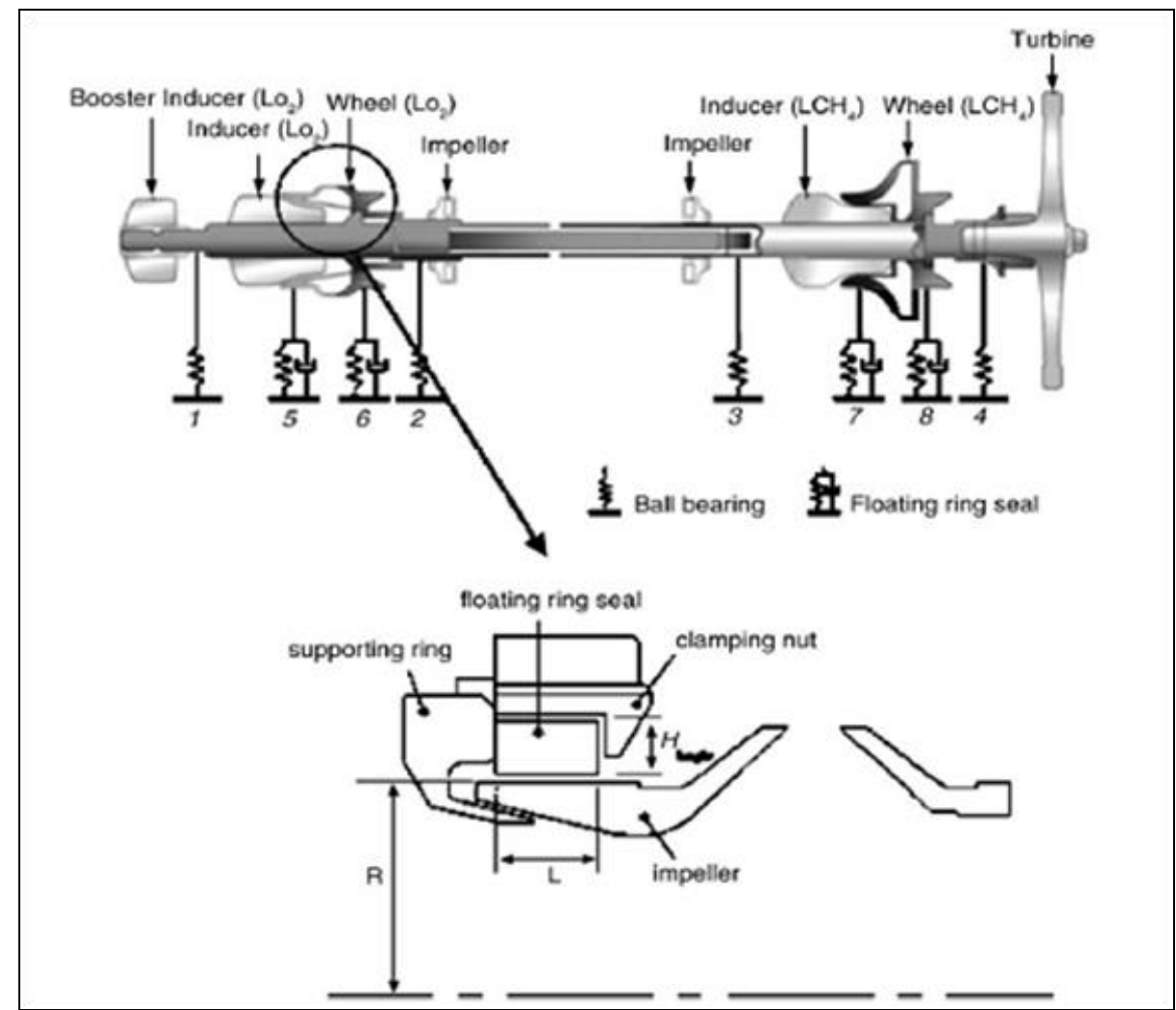

Figura 5 - Bomba trabalhando com anel de desgaste flutuante - Duan et al. (2006)

Allaire et al., (1987) em seu artigo "Subsynchronous Vibration Problem and Solution in Multistage Centrifugal Compressor" descreve que o anel flutuante de um selo a óleo pode gerar altas vibrações subsíncronas, caso este seja travado em uma posição excêntrica elevada em relação ao eixo. A causa desta vibração é devida à rigidez cruzada criada pelo filme de óleo. Para minimizar o valor da rigidez cruzada ele propôs a substituição da superfície do selo plano por uma com ranhuras ("groove"). No entanto, esta proposta de solução nem sempre é viável do ponto de vista da estabilidade, pois pode causar redução de alguma frequência natural amortecida, deslocando este valor para a faixa operacional da máquina. Neste mesmo artigo, é informada a inexistência da rigidez cruzada caso o anel não seja travado na condição operacional, ou seja, não haveria instabilidade causada pelo fluxo através do selo caso este trabalhe com a liberdade de orbitar, sem, entretanto, rotacionar. A utilização de ranhuras minimiza os valores da rigidez cruzada, mas não permite menor folga de montagem com a finalidade de minimizar o desgaste por erosão e aumentar a eficiência de bombeio. 


\section{2. \\ Objetivos, justificativa do tema e resultados esperados}

\section{$\underline{\text { Objetivos }}$}

> Estudar a viabilidade da substituição do anel de desgaste estático por um anel flutuante do ponto de vista da dinâmica e eficiência, aplicada a bombas centrífugas de simples e multiestágios.

> Analisar a possível causa da vibração elevada na frequência entre 71,4 a $96 \mathrm{~Hz}$ no modelo analisado de uma bomba centrífuga com rotor em balanço.

\section{Justificativa do tema}

Alguns projetos de bombas centrífugas com rotor em balanço apresentam uma excitação com frequência supersíncrona quando as folgas dos anéis de desgaste aumentam, desestabilizando o sistema, além de reduzir a eficiência do equipamento. Isto acarreta a falha precoce do selo mecânico e mancais, causando desta forma o vazamento do produto bombeado que, por sua vez, pode causar um incidente ou acidente.

\section{$\underline{\text { Resultado esperado }}$}

A utilização de anel de desgaste flutuante em detrimento ao estático pode proporcionar aumento da eficiência da bomba, melhoria na resposta ao desbalanceamento do conjunto rotativo e a supressão da instabilidade supersíncrona entre $71,4 \mathrm{~Hz}$ e $96 \mathrm{~Hz}$. A característica de mobilidade do selo anular flutuante permite que a influência da rigidez cruzada seja minimizada, melhorando a estabilidade do conjunto rotativo. A sua montagem com folga reduzida, sem risco de roçamento, em comparação ao anel estático, acarretaria um aumento na eficiência do bombeio. 


\section{2 \\ Introdução à rotodinâmica}

Rotodinâmica é o estudo da dinâmica de máquinas rotativas como bombas, compressores, turbinas, ventiladores e etc. Diferentemente da vibração estrutural, na rotodinâmica há a presença de efeitos giroscópios, forças cruzadas (crosscoupled forces) e instabilidade no movimento de precessão (whirling instability). Essas diferenças são devido ao movimento de rotação da máquina.

A análise rotodinâmica objetiva auxiliar o especialista da área de projeto, operação e/ou manutenção nos seguintes itens:

- Determinação da velocidade crítica: Velocidade na qual a resposta ao desbalanceamento do rotor é máxima, devendo desta forma ser evitada durante a condição de operação normal do equipamento.

- Determinar modificações do projeto para alterar a velocidade crítica. Quando a faixa operacional da máquina coincidir com a velocidade crítica, devem ser realizadas modificações no projeto do equipamento de modo a obter uma margem mínima de separação por segurança.

- Calcular a massa e a posição do centro de massa para reduzir o efeito de desbalanceamento.

- Predizer a amplitude de vibração síncrona causada pelo desbalanceamento.

- Predizer a frequência de vibração em caso de instabilidade nos mancais e a velocidade na qual esta se inicia.

- Determinar modificações no projeto de modo a atrasar o limiar da instabilidade dinâmica.

O movimento rotacional dos rotores, associado ao seu trabalho operacional, é acompanhado de efeitos "colaterais" como vibração e ruído. Devido a vários fatores que contribuem para a transferência de energia - rotação para outras formas de movimentos - a rotação do rotor pode ser acompanhada de vários modos de vibração - ver figura 6. Os três principais modos de vibração do rotor - lateral, torsional, e axial - podem estar presentes durante a operação do 
equipamento. Entre eles, o modo lateral (ou flexional) do rotor é o que será utilizado para modelar o comportamento das bombas centrífugas.

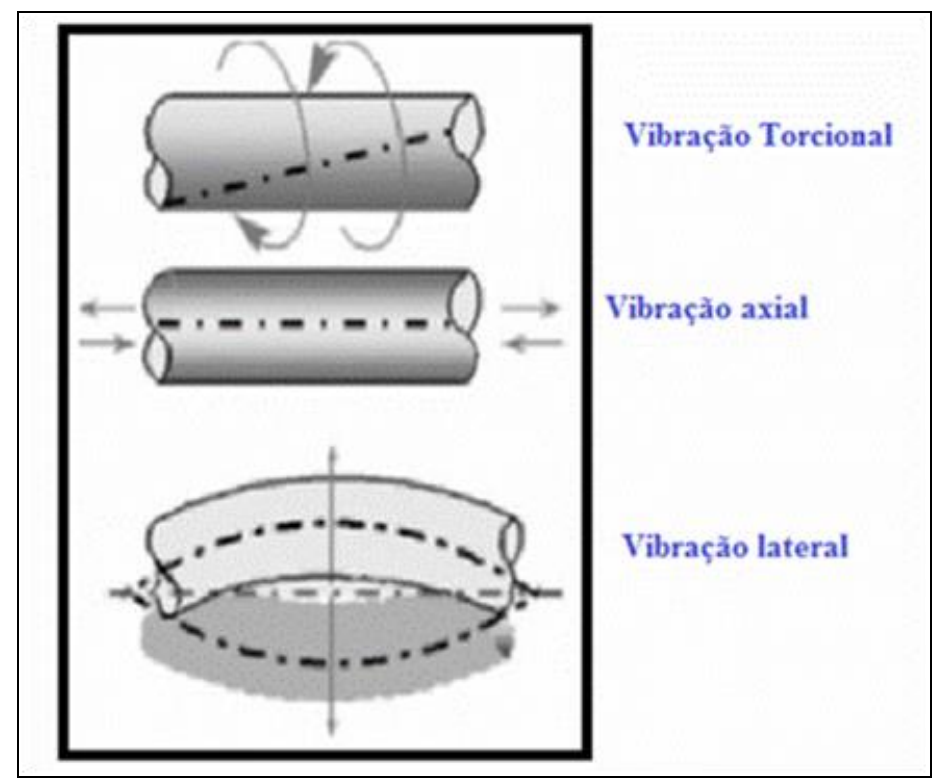

Figura 6 - Modos de vibração de um rotor - Muszynska (2005)

Através do mancal e do fluido de trabalho do equipamento, a vibração lateral do rotor é transmitida para a parte estática do equipamento. Entre as diversas causas de vibração do rotor destacam-se desalinhamento, passagem de pás, mancal "frouxo", instabilidade no mancal hidrodinâmico, desbalanceamento dinâmico. Dentre estas causas, o desbalanceamento estático é o mais recorrente. Este ocorre quando o centro de massa não coincide com o eixo de rotação do rotor gerando uma força de magnitude m.r. $\omega^{2}$ orientada no sentido perpendicular ao eixo de rotação.

A força de desbalanceamento atua em uma condição estacionária, sem variação de fase, como uma força centrífuga com a mesma frequência de rotação do rotor. Logo, resultam forças alternativas nos mancais estacionários que equilibram a força centrífuga, levando a uma resposta vibratória com a mesma frequência da força de excitação, considerando o sistema linear. Quando o sistema do rotor/mancais não puder ser tratado como linear, a frequência de vibração em resposta a uma força de excitação com uma única frequência, contêm componentes harmônicos múltiplos da frequência de excitação. Também há casos em que uma força com uma única frequência pode gerar vibração com frequências 
subsíncronas como 1/2X, 1/3X,.., sendo estas acompanhadas pelas suas harmônicas.

Além das causas de vibração citadas acima, também existem as vibrações auto-excitadas, que são permanentes, normalmente com amplitude, fase e frequência constante. Sua frequência de vibração é próxima de umas das frequências naturais do sistema e a vibração é sustentada por uma fonte de energia constante que normalmente provém da rotação do rotor.

\section{1.}

\section{Modelo matemático simplificado do modo de vibração lateral de um rotor isotrópico}

O modelo apresentado diferencia-se do modelo conhecido como "Jeffcott Rotor" introduzido por H.H. Jeffcott em 1919, por não considerar a massa de desbalanceamento igual à massa do disco rotativo.

Para elaboração do modelo rotodinâmico do rotor representado na figura 7 , as seguintes considerações foram feitas:

a. Rotação constante do rotor, $\omega$.

b. Considerando a similaridade da rigidez em todas as direções perpendiculares ao eixo, os movimentos ortogonais ao eixo de rotação do rotor podem ser representados em um único "modo complexo".

c. Efeito giroscópio é desprezado.

d. Condições de linearidade são satisfeitas para pequenos deslocamentos laterais. Portanto, as forças atuantes no rotor são constantes ou função do tempo, ou são proporcionais à aceleração lateral do rotor e/ou velocidade e/ou deslocamentos.

e. O rotor está submetido a uma carga radial constante e a uma força externa não-síncrona.

f. Rotação do rotor abaixo da segunda crítica. 


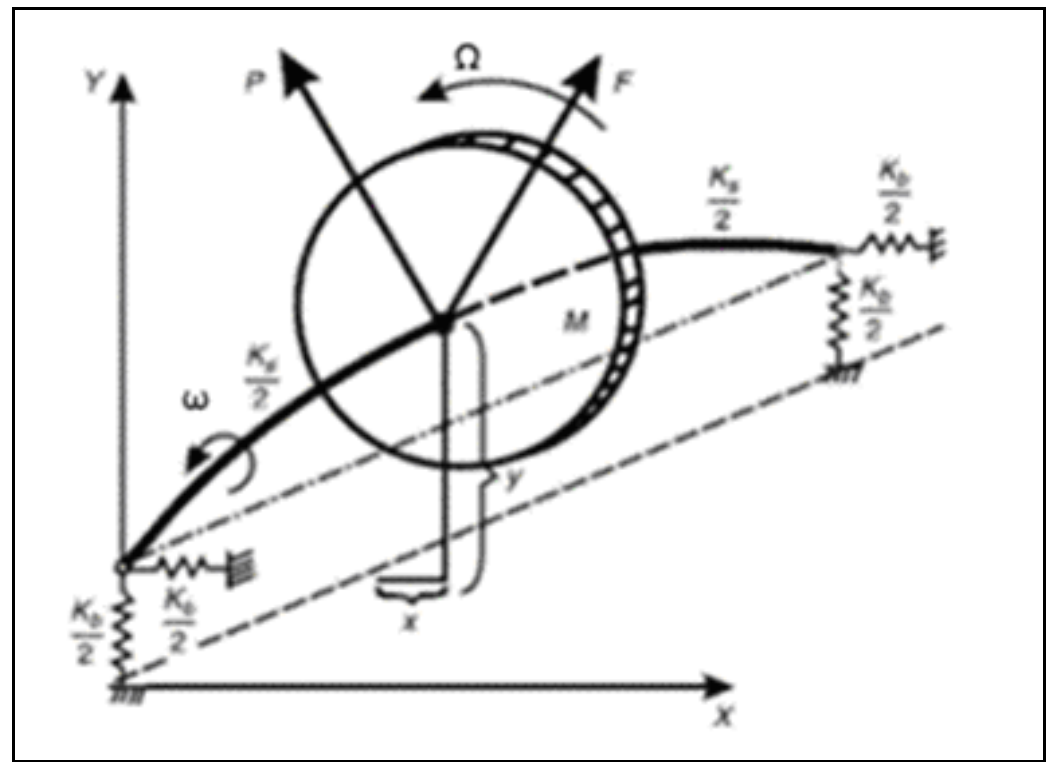

Figura 7 - Modelo do rotor no modo de vibração da sua primeira crítica -

Muszynska (2005)

Como o modelo considerado é isotrópico, pode-se fazer o uso da notação com números complexos para combinar os deslocamentos na horizontal ' $x$ ' $\mathrm{e}$ vertical ' $y$ ' na variável complexa ' $z(t)$ ' e sua conjugada ' $z *(t)$ ', resultando nas equações diferenciais de movimento 2.2 e 2.3 :

$$
\begin{aligned}
& z=x+j \cdot y \\
& z^{*}=x-j \cdot y \\
& j=\sqrt{-1}
\end{aligned}
$$

$M \cdot \ddot{z}+C \cdot \dot{z}+K \cdot z=F \cdot e^{j(n \cdot t+\delta)}+P \cdot e^{j \cdot \phi}$

$M \cdot \ddot{z}^{*}+C \cdot \dot{z}^{*}+K \cdot z^{*}=F \cdot e^{-j(n \cdot t+\delta)}+P \cdot e^{-j \cdot \phi}$

Os termos das equações de movimento acima possuem os seguintes significados, na sequência do primeiro termo da esquerda para direita:

$1^{\circ}$. Força de inércia

$2^{\circ}$. Força devido ao amortecimento

$3^{\circ}$. Força devido à rigidez 
$4^{\mathrm{o}}$. Força externa síncrona/não-síncrona aplicada de magnitude $\mathrm{F}$, frequência de excitação $\Omega$ e fase $\delta$

$5^{\circ}$. Força radial constante de magnitude $P$ e fase $\varphi$

Os coeficientes $M, K, C$ descrevem respectivamente a massa do rotor, a rigidez lateral isotrópica equivalente e o amortecimento lateral externo. A rigidez equivalente é formada pela associação em série da rigidez do eixo $\left(K_{s}\right)$ e do mancal $\left(K_{b}\right)$ :

$$
K=\frac{1}{\frac{1}{K_{s}}+\frac{1}{K_{b}}}
$$

A equação 2.2 refere se ao modo "forward" (quando a órbita descrita pelo centro do rotor devido à vibração lateral está no mesmo sentido da rotação do rotor) e a equação 2.3 descreve o modo "backward" (quando a órbita está no sentido oposto ao da rotação).

Como a equação diferencial é linear, as soluções particulares correspondentes a cada força de excitação podem ser adicionadas para representar a resposta total de vibração do rotor. Portanto, a solução geral da equação de movimento é composta por:

- Uma solução homogênea, que representa a vibração livre governada pela frequência natural.

- Uma solução particular correspondente à força radial estática aplicada externamente.

- Uma solução particular correspondente à força não-síncrona/síncrona oriunda, por exemplo. do desbalanceamento ou de esforços no impelidor.

As três componentes da solução são descritas a seguir: 


\section{$\underline{\text { Solução homogênea - Vibração Livre }}$}

A importância da análise da vibração livre do rotor é a determinação dos autovalores que fornecem informações sobre a frequência natural e a condição de estabilidade do modo de vibração.

Como no caso de vibração livre o rotor não está sujeito a forças externas, o lado direito das equações 2.2 e 2.3 são iguais a zero. Logo, estas equações admitem soluções do tipo:

$$
\begin{aligned}
& z=A \cdot e^{s . t} \\
& z^{*}=A \cdot e^{s . t}
\end{aligned}
$$

onde " $A$ " é uma constante de integração obtidas pelas condições iniciais e os valores de " $s$ " são os autovalores da equação característica.

A substituição das soluções nas equações de movimento, resulta na seguinte equação característica com seus autovalores:

$$
M \cdot s^{2}+C \cdot s+K=0 \rightarrow \text { Equação característica }
$$

$$
s_{1,2}=-\frac{c}{2 \cdot M} \pm j \sqrt{\frac{K}{M}-\frac{c^{2}}{4 \cdot M^{2}}}=s_{3,4} \rightarrow \text { Autovalores }
$$

A parte imaginária do autovalor representa a frequência natural amortecida, $\omega_{d}$, o sinal de "+" representa a frequência natural do modo "forward" e o sinal “_“ representa a frequência natural do modo "backward". Caso o radical da equação 2.7 seja igual a zero, tem-se o amortecimento crítico:

$$
C_{c}=2 \cdot \sqrt{K \cdot M}=2 \cdot M \cdot \omega_{n} \rightarrow \text { Amortecimento crítico }
$$


Para qualquer sistema amortecido, o fator de amortecimento $\zeta$ é definido como a razão entre a constante de amortecimento e a constante de amortecimento crítico:

$$
\zeta=\frac{c}{c_{e}}
$$

Utilizando a definição do fator de amortecimento, o autovalor pode ser representado da seguinte forma:

$$
s_{1,2}=\left(-\zeta \pm \sqrt{\zeta^{2}-1}\right) \cdot \omega_{n}=s_{3,4}
$$

A natureza das raízes dos autovalores e, por consequência, o comportamento das soluções das equações diferenciais de movimento, dependem da magnitude do amortecimento. Caso $\zeta=0$, tem-se uma vibração não amortecida, ou seja, a amplitude de vibração permaneceria constante, pois não há dissipação de energia por amortecimento. Se $\zeta \neq 0$, pode haver os seguintes casos:

Caso A: Sistema sub-amortecido $\left(\zeta<1\right.$ ou $\left.C<C_{c}\right)$. Para essa condição, $\left(\zeta^{2}-1\right)$ é negativo e os autovalores podem ser expressos como:

$$
s_{1,2}=\left(-\zeta \pm j \sqrt{1-\zeta^{2}}\right) \cdot \omega_{n}=s_{3,4}
$$

No movimento sub-amortecido a amplitude de vibração diminui exponencialmente com o tempo - ver figura 8.

Caso B: Sistema criticamente amortecido $\left(\zeta=1\right.$ ou $\left.C=C_{c}\right)$. Neste caso, as duas raízes $s_{1}, s_{2}$ e $s_{3}$ e $s_{4}$ são iguais conduzindo a um movimento não periódico.

Caso C: Sistema superamortecido $(\zeta>1$ ou $C>C c$ ). Neste caso os autovalores $s_{1, s_{2}}$ e $s_{3, s_{4}}$ são distintos e menores que zero, resultando no movimento representado na figura 8 . 


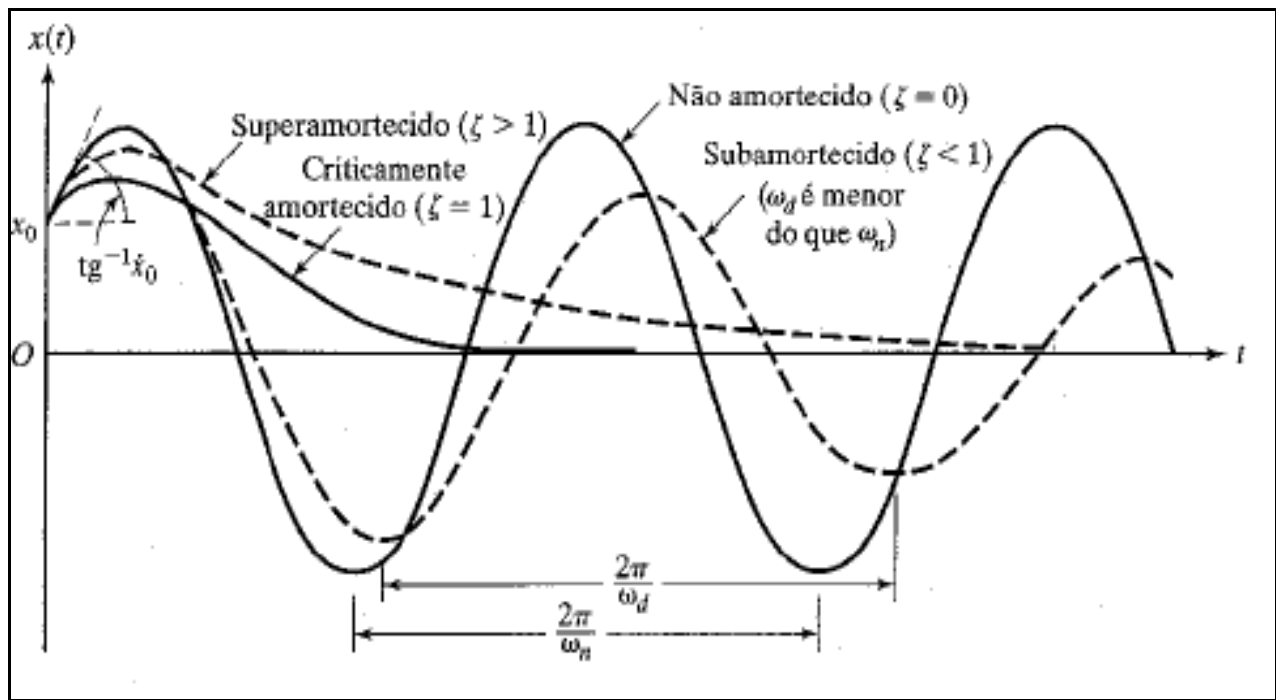

Figura 8 - Comparação entre movimentos com tipos diferentes de amortecimentos

- RAO (2003)

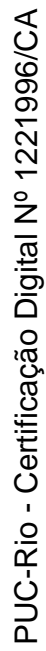

Solução Particular - Resposta à força estática radial aplicada

Considerando uma força externa radial e constante, $P_{\cdot} e^{ \pm j \cdot \phi}$, as equações 2.2 e 2.3 , admitem as seguintes soluções:

$$
\begin{aligned}
& z=A \cdot e^{j \cdot \beta} \\
& z^{*}=A \cdot e^{-j \cdot \beta} \\
& z=\frac{p_{\cdot} \cdot e^{j \cdot \phi}}{K} \text { e } z^{*}=\frac{p_{\cdot e}-j \cdot \phi}{K}
\end{aligned}
$$

Onde $\beta$ é a orientação da amplitude de deflexão do rotor em resposta a força aplicada.

Portanto, a solução particular referente à carga estática aplicada é um deslocamento com a magnitude igual à razão da força radial pela rigidez do rotor e com a mesma direção do vetor da força. 
$\underline{\text { Solução Particular - Resposta à força de excitação não-síncrona }}$

Caso o rotor esteja submetido apenas a uma força de excitação não síncrona, as equações diferenciais de movimento admitem soluções do tipo:

$$
\begin{aligned}
& z=B \cdot e^{j(\mathrm{n} . t+\psi)} \\
& z^{*}=B \cdot e^{-j(\mathrm{n} . t+\psi)}
\end{aligned}
$$

nos quais $B$ e $\psi$ são a amplitude e a fase, respectivamente, da resposta a força externa aplicada. Inserindo as soluções apresentadas nas equações de movimentos, tem-se:

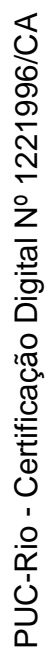

$$
\begin{aligned}
& B=\frac{F}{\sqrt{\left(K-M \Omega^{2}\right)^{2}+C^{2} \Omega^{2}}} \\
& \Psi=\delta+\arctan \left(\frac{-C \Omega}{K-M \Omega^{2}}\right)
\end{aligned}
$$




\section{3 \\ Escoamento através do selo anular}

A função principal dos anéis de desgaste, conforme já dito, é melhorar o rendimento da bomba reduzindo o retorno do fluido bombeado para a sucção da bomba de simples estágio ou para o estágio anterior nos casos de bombas com múltiplos estágios. Em geral, os selos anulares também contribuem para alteração do fator de amplificação e da frequência crítica. Diferente dos mancais, estes selos anulares possuem a vantagem de estarem localizados em uma posição estratégica do ponto de vista da rotodinâmica, pois estão localizados nos impelidores que são a principal fonte de desbalanceamento.

O modelo da bomba de simples estágio analisada e a localização do anel de desgaste são apresentado na figura abaixo. Este é um anel denominado plano devido à geometria de sua superfície.

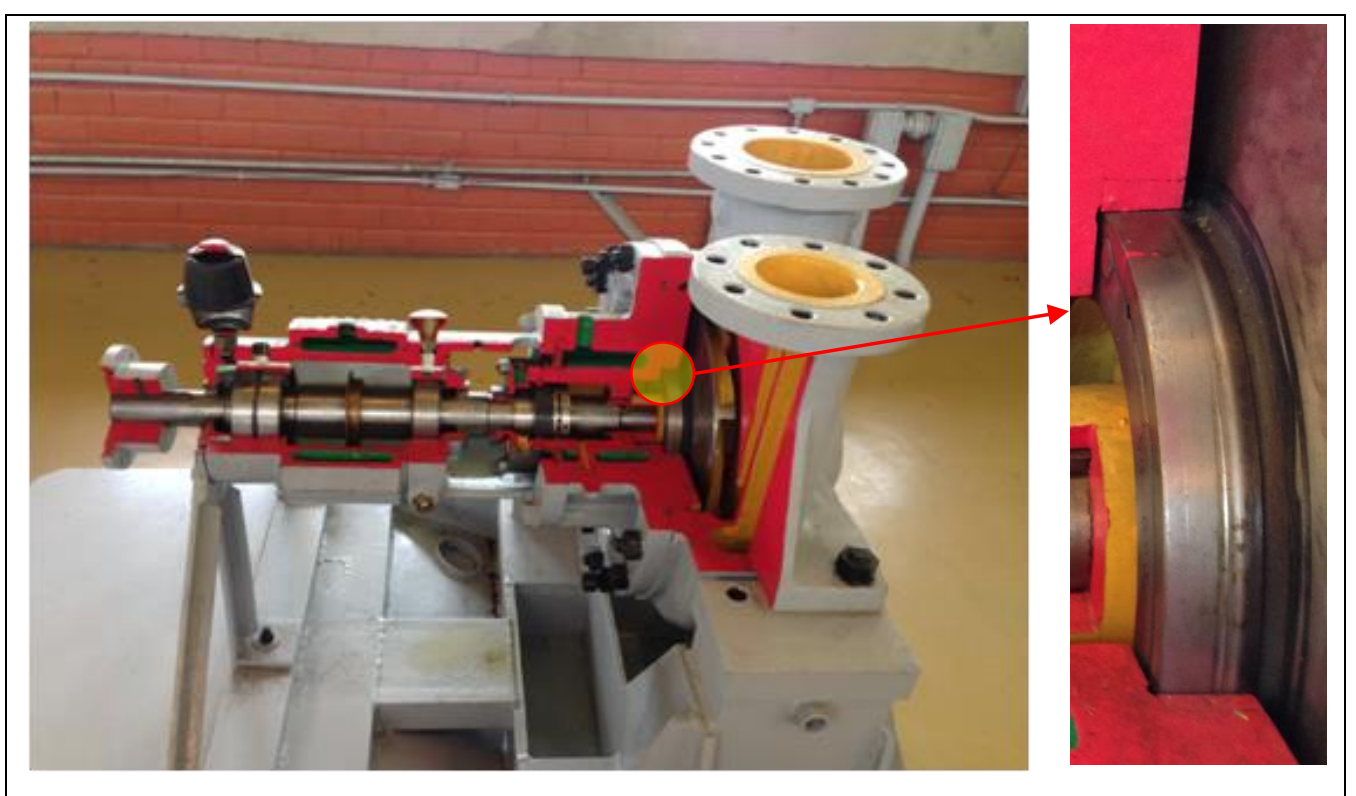

Figura 9 - Direita: foto da bomba em corte. Esquerda: anel de desgaste

As vantagens esperadas da utilização do selo anular flutuante em detrimento ao fixo são a possibilidade da sua montagem com folgas menores sem ocorrência de roçamento e a operação com uma menor excentricidade. A principal 
desvantagem é que este deve ser projetado de acordo com a condição operacional, ou seja, o mesmo modelo de bomba teria anéis de desgaste diferente.

Caso seja viável a operação do selo flutuante em uma posição com baixa excentricidade, onde a influência dos coeficientes dinâmicos é menor, este pode ser balanceado de forma a evitar seu travamento em uma posição indesejada.

A utilização de anéis flutuantes é muito comum em selos mecânicos a óleo (selos molhados) de compressores. No entanto, apesar do princípio físico de funcionamento ser similar ao proposto neste trabalho, em compressores estes componentes podem induzir vibrações subsíncronas reduzindo o limite de estabilidade, sendo que o mesmo dificilmente é identificado em bombas devido à baixa rotação. Por outro lado, em modelos de bomba centrífuga semelhantes ao analisado nesta dissertação, foram observados vários casos de ocorrência de instabilidade supersíncrona quando a folga diametral dos anéis de desgaste ultrapassou valores de $0.9 \mathrm{~mm}$, apesar de não ter sido identificado nenhum sinal de contato entre parte estática e rotativa, podendo, portanto, esta excitação ser induzida pelo fluido.

O método empregado para calcular a rigidez e amortecimento do anel flutuante é o mesmo do anel fixo, lembrando que o anel flutuante estará travado em uma determinada excentricidade que vai depender do balanceamento de força projetado. Caso seja almejado que o anel de desgaste esteja sempre flutuante, ou seja, não trave em nenhuma condição operacional, os coeficientes dinâmicos podem ser desprezados e as únicas forças radiais que irão atuar sobre o anel são o seu peso e a força de atrito. As variáveis que influenciam na determinação dos coeficientes dinâmicos dos selos anulares são:

- Rotação do eixo

- Excentricidade

- Diferencial de pressão

- Perda de pressão na entrada do selo

- Coeficiente de atrito entre o anel e a carcaça da bomba

- Viscosidade e densidade de fluido

- Comprimento axial

- Diâmetro externo do anel rotativo 
- Folga entre os anéis estático e rotativo

- Número de ranhuras na superfície dos anéis quando utilizado

- Rugosidade das superfícies dos anéis

- Coeficiente de recuperação de pressão na saída do selo

- Pré-rotação do fluido na entrada do selo

\section{1.}

\section{Teoria de filme de óleo hidrodinâmico em selo anular}

Devido ao elevado gradiente de pressão e a folga elevada em comparação ao praticado em mancais, o fluxo no selo anular é turbulento. Os números de Reynolds axial e circunferencial são altos devido à baixa viscosidade do fluido bombeado e a alta velocidade tangencial causada pela rotação do eixo, por isto não é utilizada a equação de Reynolds como usual em mancais hidrodinâmicos.

Para pequenos deslocamentos do rotor em relação a um ponto de equilíbrio, a força de reação do fluido sobre o rotor pode ser representada por coeficientes dinâmicos linearizados resultando na seguinte fórmula:

$$
-\left\{\begin{array}{l}
F_{X} \\
F_{Y}
\end{array}\right\}=\left[\begin{array}{cc}
K_{x x} & k_{x y} \\
-k_{y x} & K_{y y}
\end{array}\right] \cdot\left\{\begin{array}{l}
x \\
y
\end{array}\right\}+\left[\begin{array}{cc}
C_{x x} & c_{x y} \\
-c_{y c} & C_{y y}
\end{array}\right] \cdot\left\{\begin{array}{l}
\dot{x} \\
\dot{y}
\end{array}\right\}+M\left\{\begin{array}{l}
\ddot{x} \\
\ddot{y}
\end{array}\right\}
$$

A teoria de bulk flow para fluxo turbulento, incompressível e espessura reduzida de filme, aplicada na equação de Navier-Stokes, é utilizada para análise do escoamento através do selo anular e na determinação dos coeficientes dinâmicos introduzidos pelo fluido, conforme proposto por Hirs (1970). Em resumo, a premissa desta teoria é que a variação da velocidade através da folga do selo anular é desprezível, ou seja, a velocidade média é considerada. Hirs também desconsiderou a variação da tensão viscosa cisalhante dentro da folga e apenas as tensões atuando na superfície do selo estático e rotativo são consideradas.

Portanto, aplicando as premissas proposta por Hirs nas equações de conservação de massa e quantidade de movimento, obtém-se (ver figura 10): 
Equação de conservação de massa

$$
\frac{\partial h}{\partial t}+\frac{1}{R} \frac{\partial(h U)}{\partial \theta}+\frac{\partial(h W)}{\partial Z}=0
$$

Equação da quantidade de movimento linear na direção axial

$$
-h \frac{\partial P}{\partial Z}=\tau_{r z}+\tau_{s z}+\rho \cdot h \cdot\left(\frac{\partial W}{\partial t}+\frac{U}{R} \frac{\partial W}{\partial \theta}+W \frac{\partial W}{\partial Z}\right)
$$

Equação da quantidade de movimento linear na direção circunferencial

$$
-\frac{h}{R} \frac{\partial P}{\partial Z}=\tau_{r \theta}+\tau_{s \theta}+\rho \cdot h \cdot\left(\frac{\partial U}{\partial t}+\frac{U}{R} \frac{\partial U}{\partial \theta}+W \frac{\partial U}{\partial Z}\right)
$$

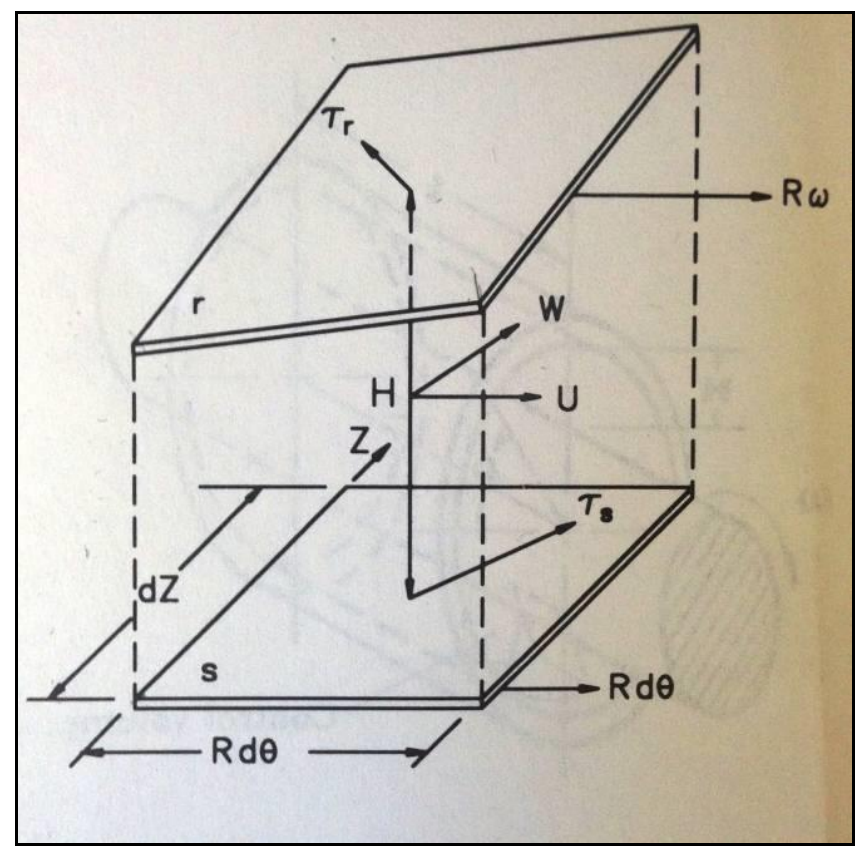

Figura 10 - Volume de controle diferencial em coordenadas cilíndricas - Childs (1993) 
As tensões cisalhantes nas paredes são definidas segundo Hirs, como:

$$
\begin{aligned}
& \tau_{s}=\frac{\rho \cdot f_{s^{*}} U_{s}^{2}}{2} \\
& \tau_{r}=\frac{\rho \cdot f_{r^{*}} U_{r}^{2}}{2}
\end{aligned}
$$

Onde $f_{s}, f_{r}$ são os coeficientes de atrito do anel estático e rotativo respectivamente, e $U_{s}$ e $U_{r}$ são as velocidades médias definidas como:

$$
\begin{aligned}
& U_{s}=\left(W^{2}+U^{2}\right)^{1 / 2} \\
& U_{s}=\left(W^{2}+U^{2}\right)^{1 / 2}
\end{aligned}
$$

Logo, as componentes das tensões $\tau_{s}, \tau_{r}$ são dadas por:

$$
\begin{array}{ll}
\tau_{r z}=\tau_{r}\left(\frac{W}{U_{r}}\right) & \tau_{r \theta}=\frac{\tau_{r}(U-R \omega)}{U_{r}} \\
\tau_{s z}=\tau_{s}\left(\frac{W}{U_{s}}\right) & \tau_{r \theta}=\tau_{s}\left(\frac{U}{U_{s}}\right)
\end{array}
$$

Substituindo as equações 3.6 nas equações de quantidade de movimento linear, resulta se em:

\section{Direção axial}

$$
-h \frac{\partial p}{\partial z}=\frac{\rho}{2} W U_{s} f_{s}+\frac{\rho}{2} W U_{r} f_{r}+\rho h\left(\frac{\partial W}{\partial t}+\frac{U}{R} \frac{\partial W}{\partial \theta}+W \frac{\partial W}{\partial z}\right)
$$

Direção circunferencial

$$
-\frac{h}{R} \frac{\partial P}{\partial \theta}=\frac{\rho}{2} U U_{s} f_{s}+\frac{\rho}{2}(U-R \omega) U_{r} f_{r}+\rho h\left(\frac{\partial U}{\partial t}+\frac{U}{R} \frac{\partial U}{\partial \theta}+W \frac{\partial U}{\partial Z}\right)
$$

De acordo como os fatores de atrito do modelo de Moody, os coeficientes de atritos $f_{s}$ e $f_{r}$ são dados por: 


$$
\begin{array}{ll}
f_{s}=a_{1}\left[1+\left(\frac{b_{2} e_{r}}{2 h}+\frac{b_{3}}{R_{s}}\right)^{1 / 3}\right] & R_{s}=\frac{2 U_{s} h \rho}{\mu} \\
f_{r}=a_{1}\left[1+\left(\frac{b_{2} e_{s}}{2 h}+\frac{b_{3}}{R_{r}}\right)^{1 / 3}\right] & R_{r}=\frac{2 U_{r} h \rho}{\mu}
\end{array}
$$

Nos quais: $a_{1}=1.375 \times 10^{-3} ; b_{2}=2 \times 10^{4} ; b_{3}=10^{6}$ e $e_{r}, e_{s}$ são as rugosidades absolutas do anel rotativo e estático, respectivamente.

Portanto, através das equações de conservação de massa e da quantidade de movimento linear apresentadas acima, e inserindo uma pequena perturbação no deslocamento $(h=h o+\Delta h 1)$, na velocidade circunferencial $(U=U o+\Delta U 1)$, na velocidade axial $(W=W o+\Delta W 1)$ e na pressão $(P=P o+\Delta P 1)$, o código do programa Romac, através de métodos numéricos, determina os coeficientes dinâmicos dos selos anulares e mancais apresentado neste trabalho.

A perturbação no deslocamento em relação à posição de equilíbrio serve para calcular as rigidezes providas pelo fluido, já que esta é igual à reação entre a força e o deslocamento. E a perturbação na velocidade serve para calcular os coeficientes de amortecimento que é a razão entre a força e a velocidade.

Softwares comerciais, como o utilizado nesta dissertação, simulam os coeficientes dinâmicos sem carga e são considerados independentes da frequência de excitação. De acordo com Andrés (2010) esta consideração introduz incerteza no modelo, pois é de conhecimento que os selos anulares em bombas contribuem para a distribuição de carga.

O termo da adição de massa ou coeficiente de inércia do fluido, que pode ser calculado de forma simplificada pela equação abaixo segundo Andrés (2010) que, diferentemente dos mancais, não é desprezível para situação na qual se tem a razão entre $\mathrm{L} / \mathrm{D}>0.5$, alto número de Reynolds e densidade elevada. Como os anéis aqui analisados possuem uma razão entre largura e diâmetro menor que 0.2 , o termo de inércia será desprezado na simulação.

$$
M_{y y}=M_{x x}=\rho \cdot \pi \cdot\left(\frac{D}{2}\right)^{3} \cdot \frac{L}{c} \cdot\left(1-\frac{\tanh (L / D)}{\frac{L}{D}}\right)
$$


As condições de contorno de entrada e saída do volume de controle, conforme demonstrado pela figura 11, são dadas por:

Tabela 1 - Condições de contorno do selo anular

\begin{tabular}{|l|l|}
\hline Condição de contorno na entrada & Condição de contorno na saída \\
$1: \quad P_{e}=P_{d}-\frac{1}{2} \rho(1+\eta) W^{2}$ & $3: \mathrm{P}=\mathrm{P}_{\mathrm{s}}=$ Pressão de sucção \\
2: $\mathrm{U}=\alpha \omega R$ & \\
\hline
\end{tabular}

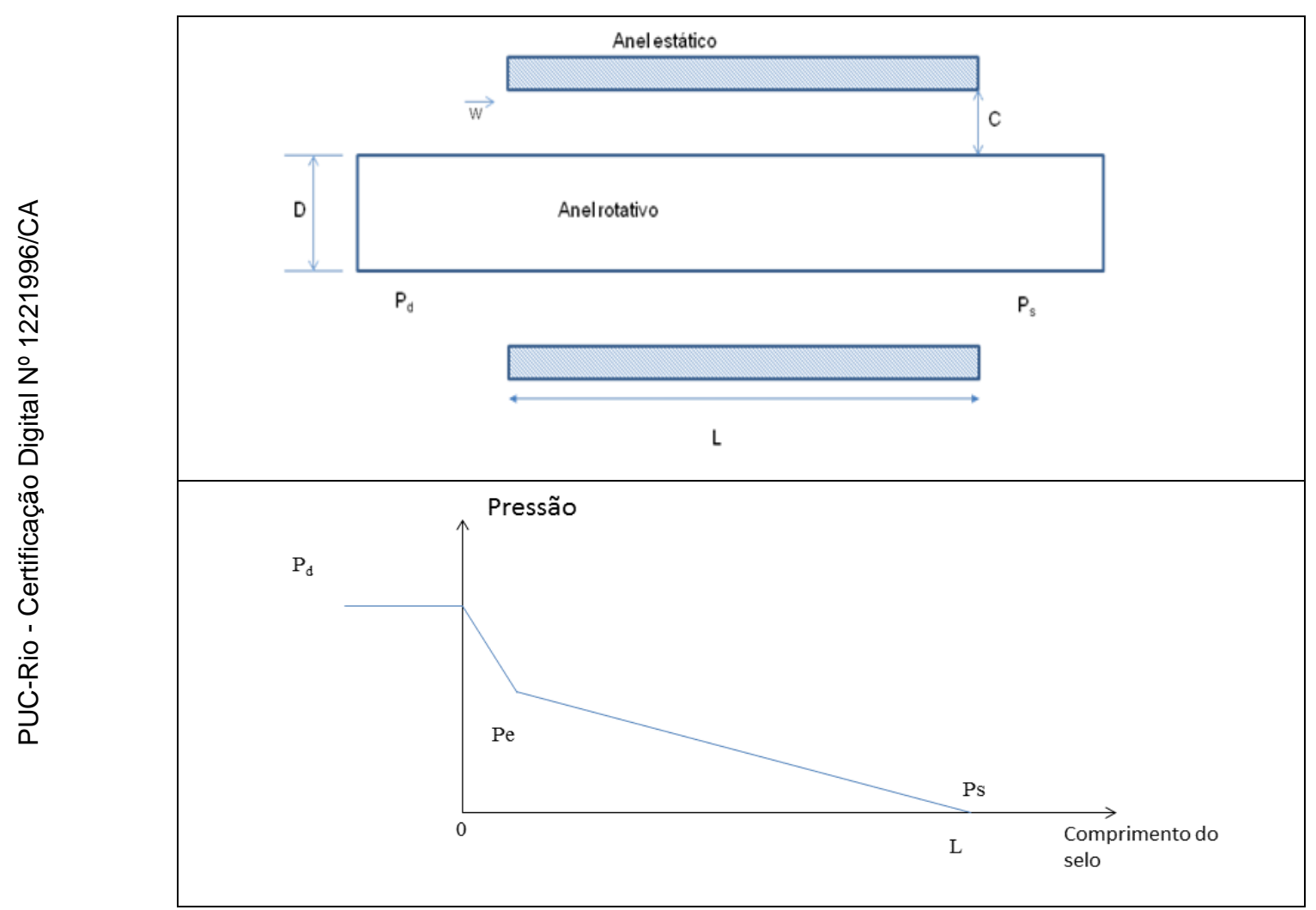

Figura 11 - Queda de pressão através do selo

A velocidade circunferencial na entrada $(U)$ é uma fração da rotação do rotor $(\omega \mathrm{R})$. $\alpha$ igual a 0.5 é normalmente utilizado para selo interestágio ou pistão de balanceamento e $\alpha$ igual a 0.6 é mais apropriado para o selo presente na sucção do impelidor. Quanto maior o valor de $\alpha$ maior será o coeficiente de rigidez cruzada do fluido devido ao aumento da velocidade circunferencial, contribuindo 
desta forma para desestabilizar o sistema rotativo. No presente trabalho será utilizado alfa igual a 0.5 .

O segundo termo do lado direito da condição de contorno 1 , é devido à perda de pressão causada pela transformação da energia potencial de pressão em energia cinética do fluido. O terceiro termo é a perda de carga na entrada, no qual o coeficiente $\eta$ normalmente varia entre zero e 0.25 , segundo informação encontrada em literatura. Portanto, a queda de pressão entre $P_{d}$ e $P_{e}$ é causada pela queda repentina de pressão e aumento da aceleração. $\mathrm{O}$ valor de $W$ é constante durante a passagem pelo anel conforme a teoria da continuidade.

A perda de pressão entre $P_{e}$ e $P_{s}$ causado pelo efeito viscoso é dado por:

$$
P_{e}-P_{a}=\frac{\mu k_{z}}{c^{2}} \cdot W \cdot L
$$

O valor de $k_{z}$, segundo Hirs (1970) é igual a:

$$
\begin{aligned}
& k_{z}=f_{z} \cdot R_{a}=\left(n \cdot R a^{m}\right) \cdot R a=n R a^{m+1} \\
& R a=\frac{\rho \cdot W \cdot c}{\mu}: \text { Reynolds axial }
\end{aligned}
$$

onde " $n "$ e " $m$ " são constantes empíricas, e segundo Yamada (1962) seus valores para selos lisos são iguais a 0.079 e -0.25 , respectivamente.

Com o objetivo de "calibrar" o programa em relação ao número de malhas e critério de erros, foram obtidos os coeficientes de um anel de desgaste com dimensões e condições operacionais semelhantes ao da bomba centrífuga analisada neste trabalho. Os coeficientes deste mesmo selo foram calculados por Andrés (2010) e os dados e resultados são mostrados abaixo:

$>$ Diâmetro do selo: $152,4 \mathrm{~mm}$

$>\mathrm{L} / \mathrm{D}=0.2$

$>$ Folga radial nominal: $0.19 \mathrm{~mm}$

$>$ Coeficientes de perda na entrada: 0.1

$>$ Anel estático e rotativo com superfícies lisas
$>$ Coeficiente de pré rotação $(\alpha)=0.5$

$>$ Fluido: água

$>$ Densidade $=995 \mathrm{~kg} / \mathrm{m}^{3} \mathrm{e}$

> viscosidade dinâmica:0.792cPoise

> Rotação=3600rmp

> Pressão Diferencial $\left(\mathrm{P}_{\mathrm{d}}-\mathrm{P}_{\mathrm{s}}\right)=34.4 \mathrm{bar}$ 
Resultados plotados com o eixo horizontal representando a rotação em rpm:

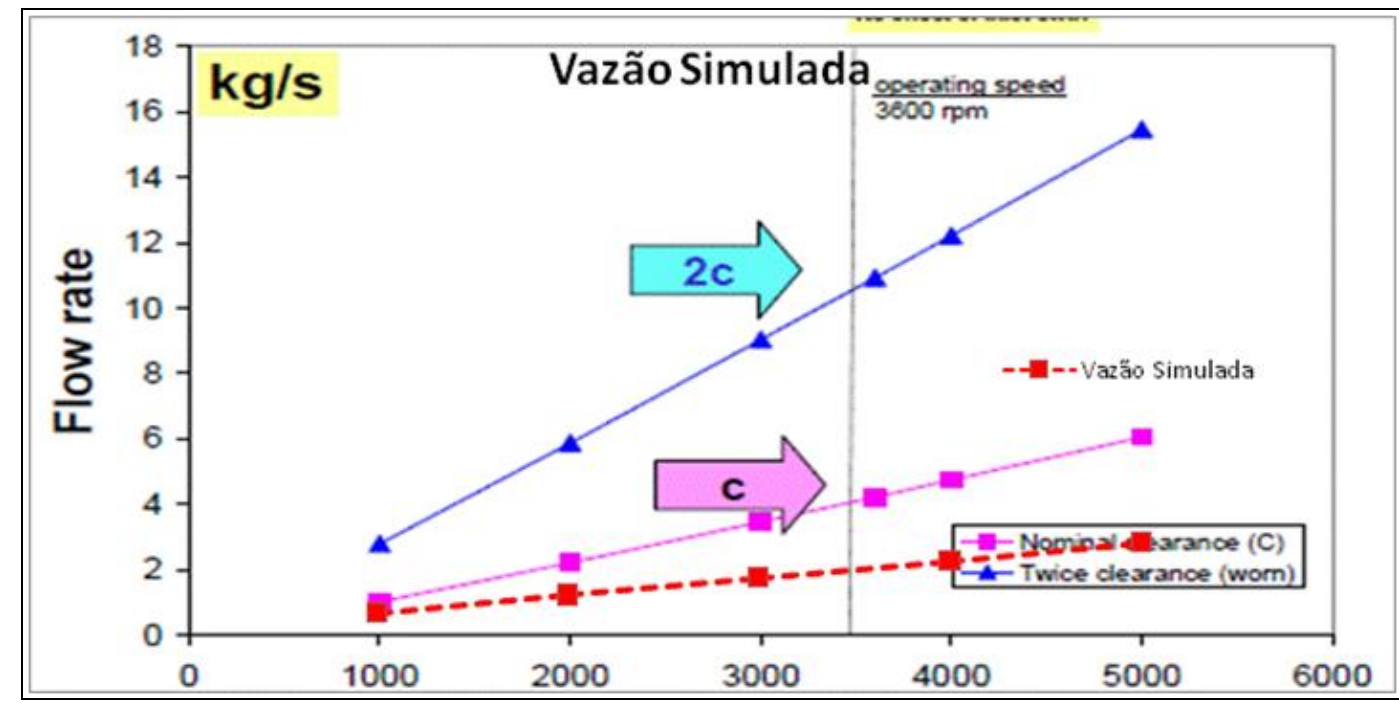

Figura 12 - Vazão mássica através dos anéis de desgaste

A vazão mássica apresentou resultados mais conservadores que o obtido por Andrés. Um dos motivos da diferença entre os resultados pode ser a diferença entre a rugosidade das superfícies dos anéis e o coeficiente de recuperação na saída do selo.

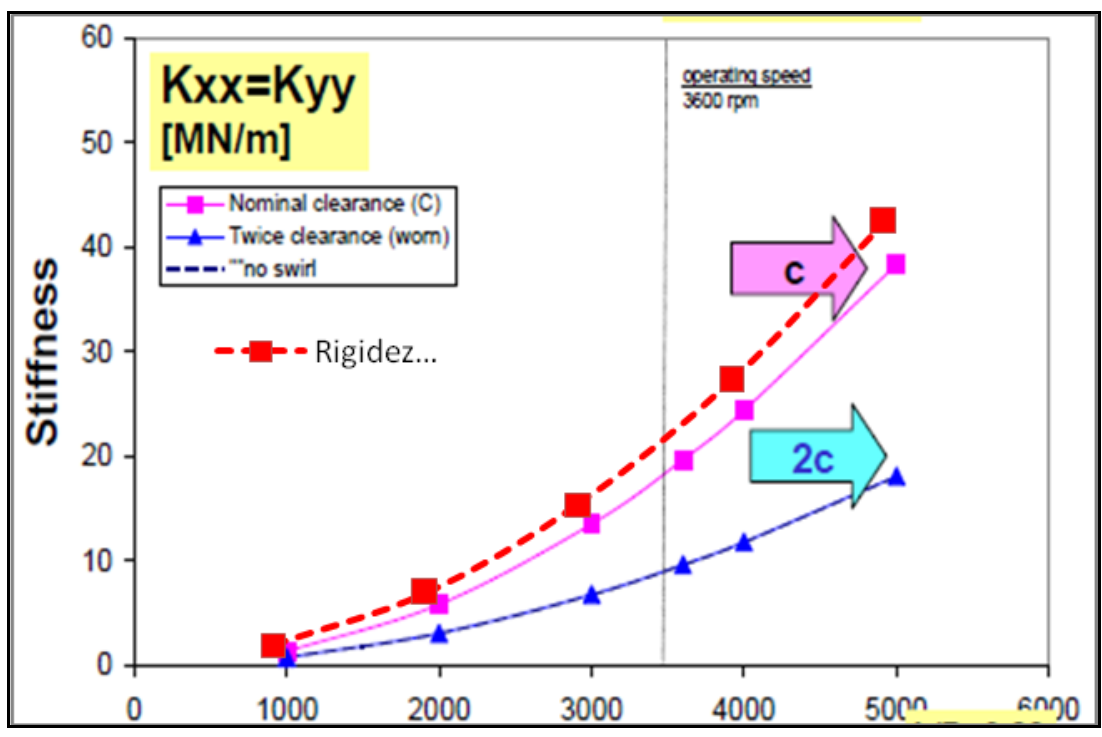

Figura 13 - Rigidez direta 


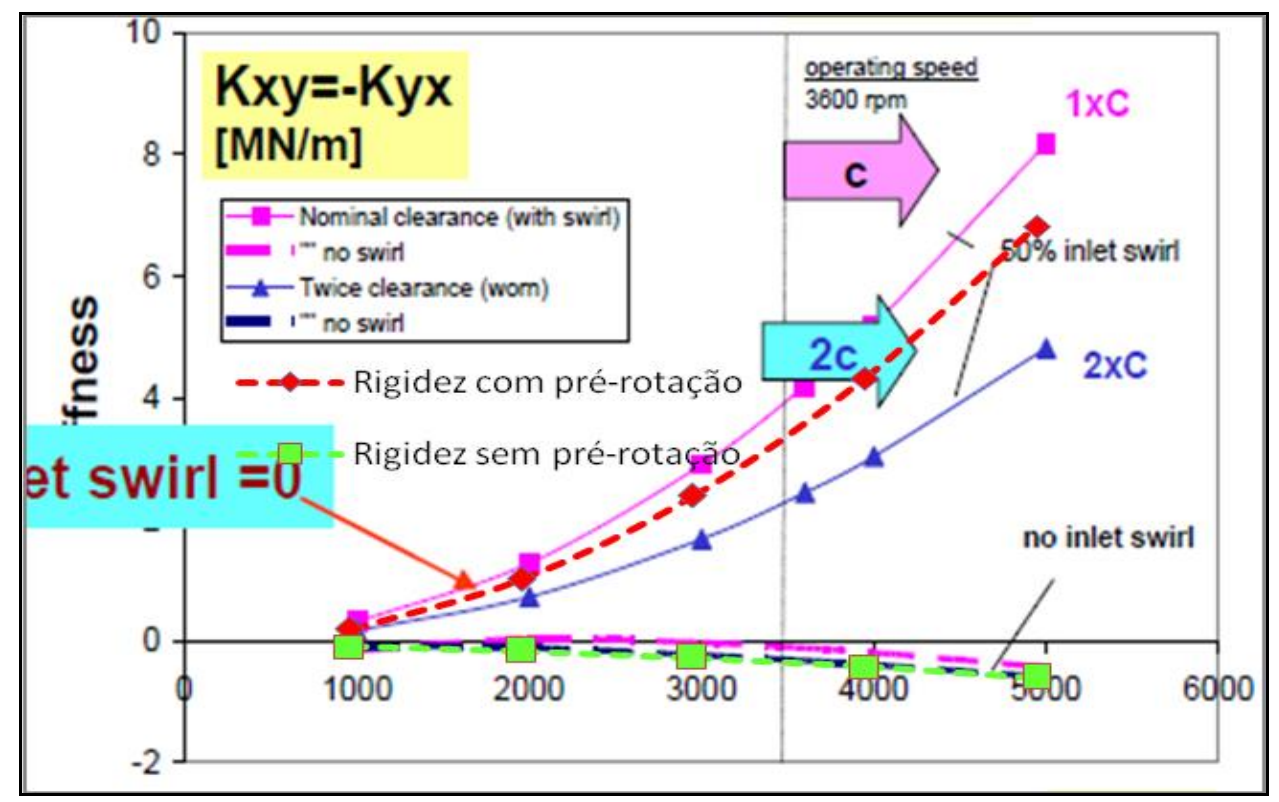

Figura 14 - Rigidez cruzada

Os valores da rigidez direta obtidos são semelhantes, no entanto a rigidez cruzada apresentou valores com diferença máxima de $15 \%$, sendo esta dada como razoável, devido a diferentes considerações envolvidas nos cálculos. Através do gráfico de rigidezes cruzadas pode ser verificada a influência do valor de $\alpha$ na estabilidade do sistema rotativo. Baixos valores de $\alpha$ são conseguidos instalando aletas ("swirlbrake") para "quebrar" a rotação na entrada do selo.

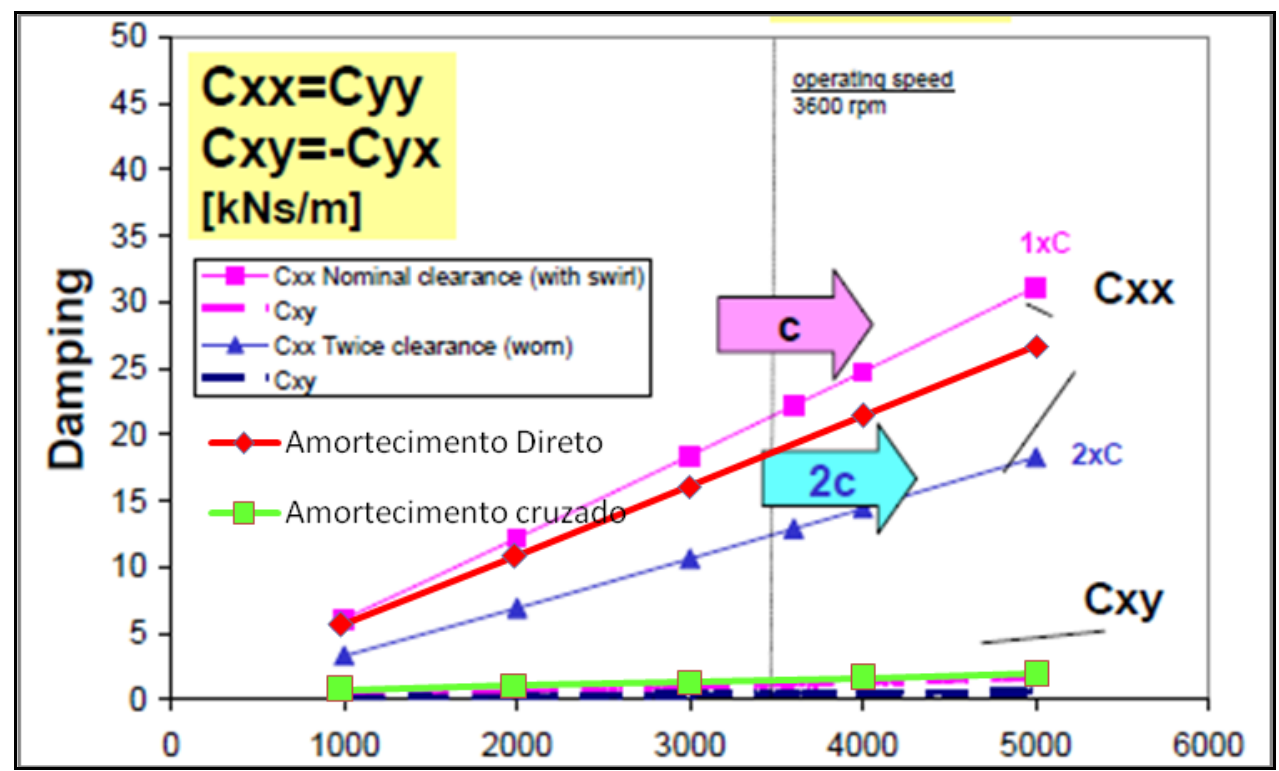


Figura 15 - Coeficientes de amortecimento

Os coeficientes de amortecimento acusaram uma diferença máxima de 6.5\%. As igualdades dos valores entre $C_{x x}$ e $C_{y y}$ e entre $C_{x y}$ e $-C_{x y}$ referem-se a posição concêntrica considerada do anel rotativo em relação ao estático.

O número de elementos de malha utilizado para simulação do selo anular foi de 100 , apesar da convergência abaixo de $2 \%$ ter sido atingida com número de malha igual a 50 conforme gráfico abaixo:

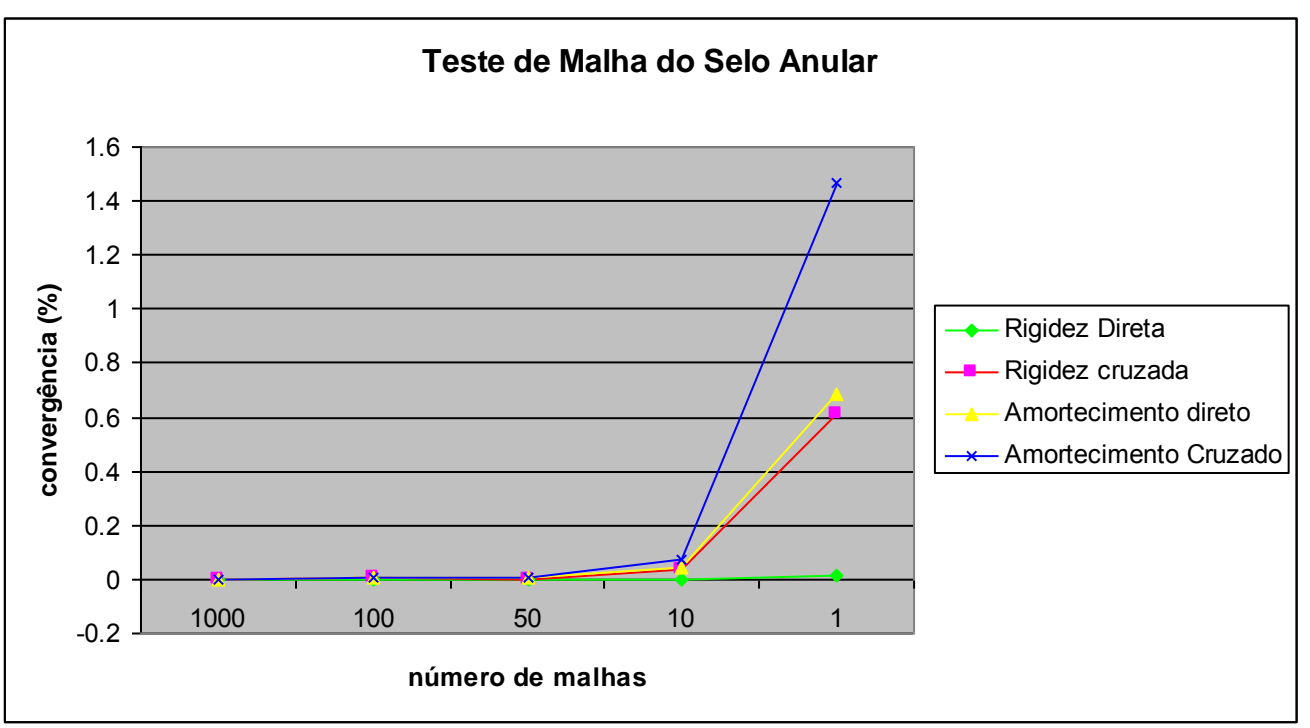

Figura 16 - Teste de convergência versus número de malhas

\section{2.}

\section{Anel de desgaste flutuante}

Como dito anteriormente, as vantagens propiciadas pela aplicação do anel flutuante ocorrem devido à viabilidade de realizar a sua montagem com folgas menores que a recomendada pela API 610 aplicadas a anéis estáticos. A sua aplicação em bombas centrífugas multiestágios também poderia vir a viabilizar a substituição do mancal hidrodinâmico por rolamento, pois os anéis flutuantes com folgas reduzidas diminuiriam os esforços sobre os mancais.

A utilização de material não metálico no lugar do aço para fabricação dos anéis de desgaste também permite uma redução de até $50 \%$ da folga recomenda pela norma API 610. Entretanto, o anel flutuante aumentaria a vida útil dos anéis, pois não haveria o contato entre as partes. 
A filosofia do comportamento físico do anel flutuante é a mesma empregada para o anel flutuante do selo mecânico molhado (a óleo) utilizado em compressores centrífugos, como demonstrado pela figura 17. O anel flutuante é capaz de se mover apenas radialmente, pois seu movimento axial é restringido por um pino anti-rotacional. $\mathrm{O}$ diferencial de pressão vezes a área de contato e a força da mola induzem a uma força normal $F_{N}$. Por sua vez, a força normal vezes a coeficiente de atrito entre a área de contato do anel e a carcaça tende a travar o selo. Enquanto a força resultante do fluido $\left(F_{L}\right)$, que é gerada de forma semelhante em mancais hidrodinâmicos, mais o peso do anel $\left(P_{\text {anel }}\right)$ forem maiores que a força de atrito $\left(F_{\text {atrito }}\right)$, o anel flutuará radialmente reduzindo sua posição excêntrica, até atingir uma posição de equilíbrio no qual o anel ficará travado. Portanto, a posição excêntrica de operação do anel flutuante depende da condição operacional, coeficiente de atrito entre anel e carcaça, parâmetro geométricos do anel e a influência do anel "O". Desprezando a influência do anel "O" e considerando a área de contato perfeitamente lapidada, a equação do equilíbrio de força é dada através do seguinte equacionamento:

\section{Força normal}

$$
\begin{aligned}
F_{N}= & k_{\text {mola }} \cdot d_{\text {mola }}+P_{d} \cdot \frac{\pi}{4} \cdot\left(D_{a e}^{2}-D_{a i}^{2}\right)+P_{d} \cdot \frac{\pi}{4} \cdot\left(D_{b e}^{2}-D_{b i}^{2}\right)+ \\
& \left(P_{d}-P_{s}\right) \cdot \frac{\pi}{4} \cdot\left(D_{b i}^{2}-D^{2}\right)
\end{aligned}
$$

Força de atrito

$$
F_{\text {atrito }}=\mu_{\text {atrito }} . F_{N}
$$

Equilíbrio de forças

$$
F_{\text {atrito }}=F_{L}+P_{\text {anel }}
$$


Durante o instante que o anel flutuante estiver travado, ele irá trabalhar como um anel fixo até que a força do fluido aumente durante um transiente e uma nova posição de equilíbrio seja estabelecida. Logo, apesar do anel ser flutuante, ele deverá operar como travado durante o regime permanente, ou seja, seu movimento radial deve ocorrer apenas durante a iminência do contato com o anel rotativo.

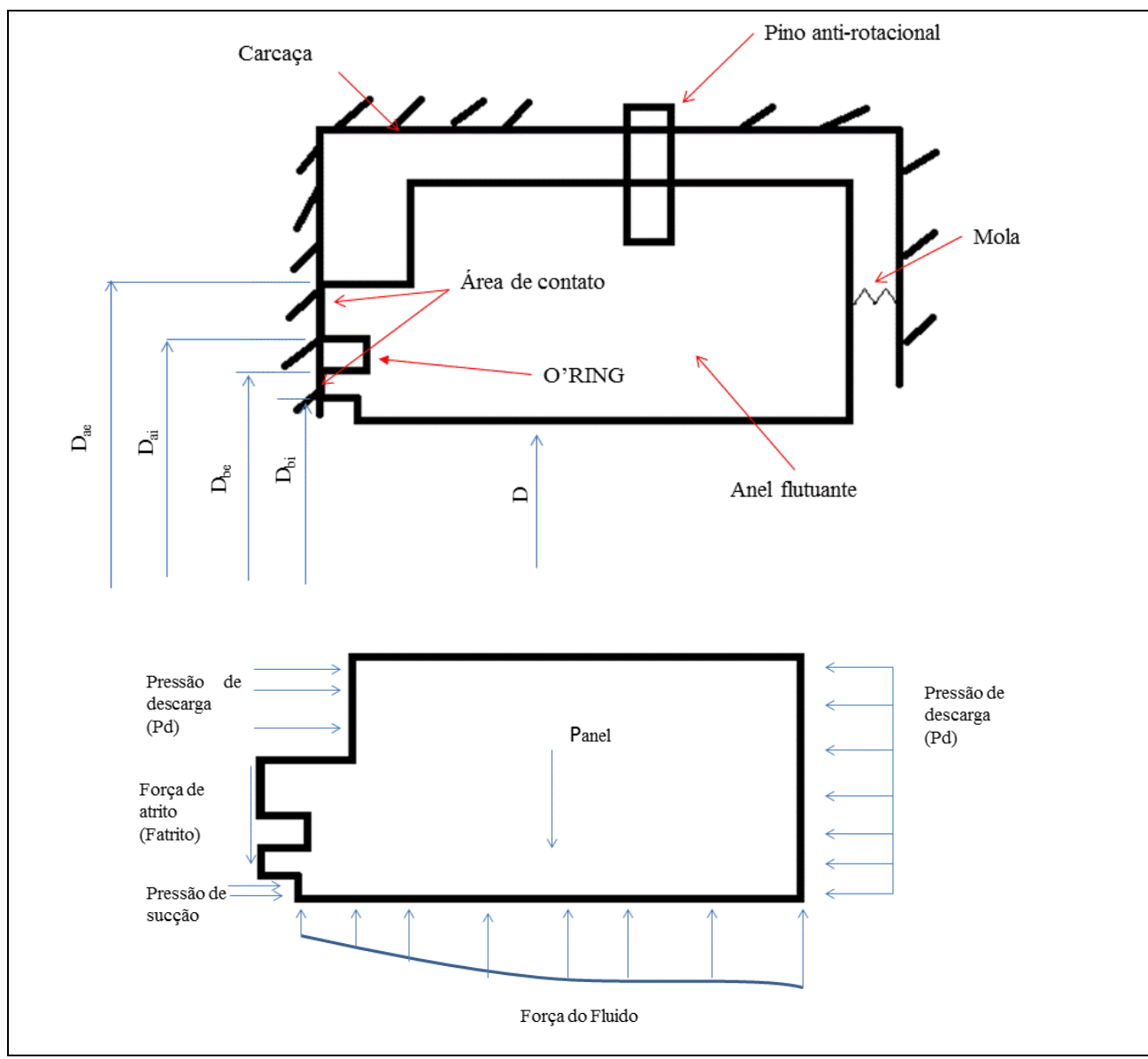

Figura 17 - Superior: Conceito do anel flutuante. Inferior: Balanço de força no anel

Ao serem estabelecidos os coeficientes dinâmicos providos pelo fluido, o sistema rotor/fluido acoplado resulta em um modelo dinâmico representado pela seguinte equação:

$$
\left[\left[M_{r}\right]+\left[M_{f}(\varepsilon)\right]\right]\left\{\begin{array}{l}
\ddot{X} \\
\ddot{Y}
\end{array}\right\}+\left[\left[C_{r}\right]+\omega[G] \cdot\left[C_{f}(\omega)\right]\right]\left[\begin{array}{l}
\dot{X} \\
\dot{Y}
\end{array}\right]+\left[\left[K_{r}\right]+\left[K_{f}(\varepsilon, \omega)\right]\right]\left\{\begin{array}{l}
X \\
Y Y
\end{array}\right\}=[F]
$$

eq. (3.17)

onde $\omega[G], \omega$ representam o efeito giroscópio e a rotação do eixo respectivamente, e os subscritos " $r$ " e " $f$ " referem-se ao rotor e ao fluido. 


\section{4 \\ Influência dos coeficientes dinâmicos do fluido na dinâmica da máquina rotativa}

Devido a sua importância, é apresentada a influência das propriedades de rigidez e amortecimento no sistema rotativo conforme figura 18.

As componentes $X$ e $Y$ de uma força no rotor podem ser expressas em forma linearizada para pequenas perturbações em relação a um equilíbrio estacionário para uma dada rotação do eixo. Os coeficientes desta força linearizada resultam da derivada parcial da força em relação ao deslocamento e velocidade do rotor. Desta forma, de acordo com a equação 4.1, estas forças são expressas como:

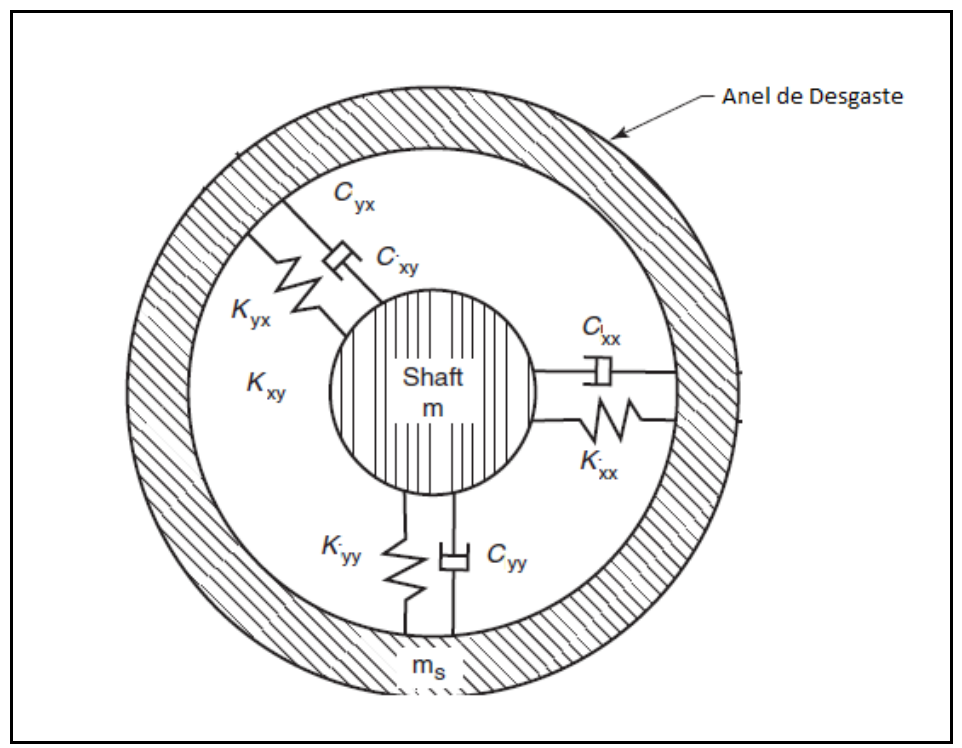

Figura 18 - Coeficientes dinâmicos das forças introduzidas pelo fluido

$$
\begin{aligned}
& F_{x}=-K_{x x^{*}} x-K_{x y^{*}} Y-C_{x x^{*}} \dot{x}-C_{x y^{*}} \dot{y} \\
& F_{y}=-K_{y x^{*}} x-K_{y y^{*}} Y-C_{y x^{*}} \dot{x}-C_{y y^{*}} \dot{y}
\end{aligned}
$$

onde $\dot{x}$ e $\dot{y}$ são velocidades. 
Considerando uma órbita circular, são apresentadas as seguintes análises:

\section{Coeficientes diretos (Direct Coefficients)}

Os coeficientes de rigidez positivos $K_{x x}=K_{y y}$, no selo de fluxo, produzem uma força radial direcionada para o centro da órbita e colinear com o vetor de deflexão do rotor, como mostrado na figura 19. Se estes coeficientes forem negativos a direção da força se inverte. Já os coeficientes de amortecimento $C_{x x}=C_{y y}$ produzem uma força tangencial normal ao vetor de deflexão do rotor e oposta à velocidade de precessão. Se estes coeficientes forem negativos o sentido da força será o mesmo da velocidade de precessão.
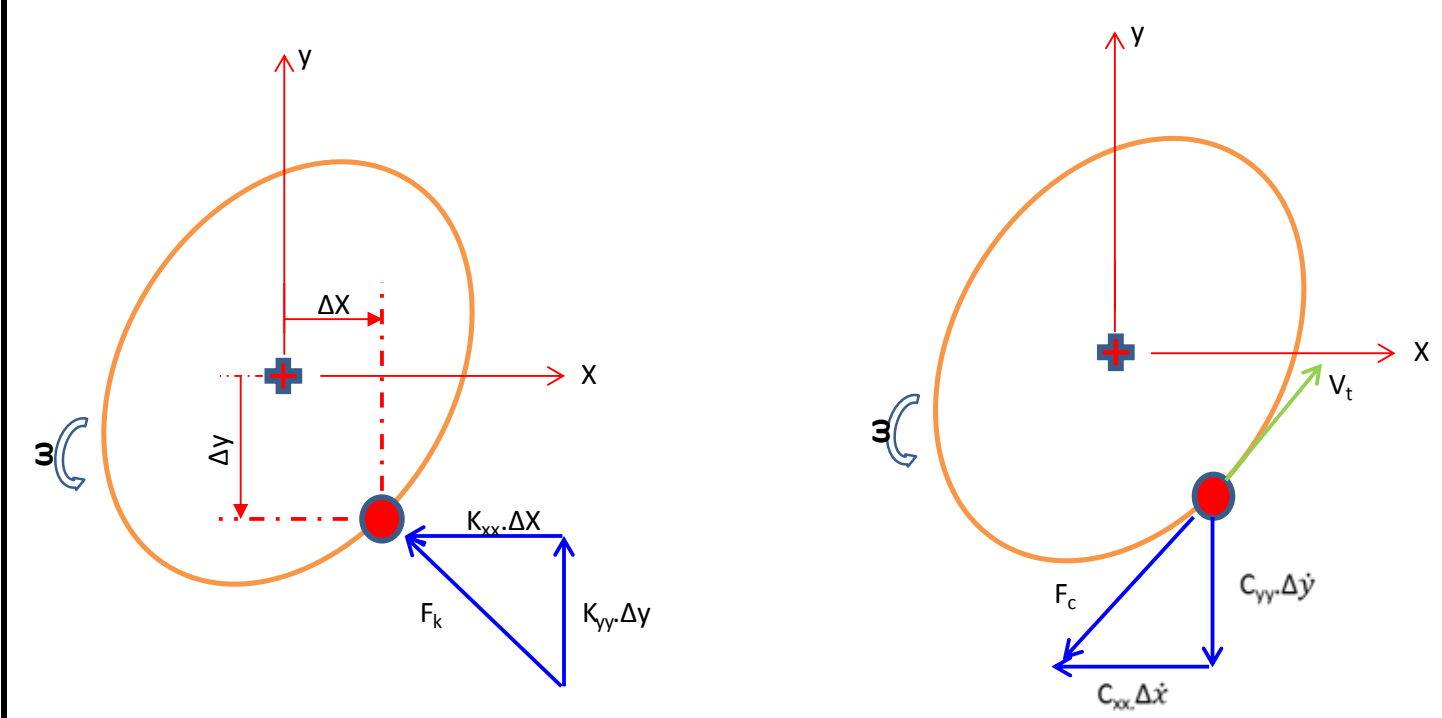

Figura 19 - Coeficientes dinâmicos diretos da força do fluido

\section{Coeficientes acoplados cruzados (Cross-coupled Coefficients)}

Os coeficientes de rigidez cruzados $K_{x y}=-K_{y x}$ produzem uma força tangencial normal ao vetor de deflexão do rotor e sua direção depende do sinal algébrico, como representado pela figura 20. A combinação $\mathrm{K}_{\mathrm{xy}}>0, \mathrm{~K}_{\mathrm{yx}}<0$ empurra o rotor no sentido da velocidade de precessão e pode desestabilizar o sistema. Caso $K_{x y}$ e $K_{y x}$ tenham o mesmo sinal eles tendem a estabilizar o movimento fazendo uma órbita elíptica. 
Os coeficientes de amortecimento cruzados $C_{x y}=-C_{y x}$, no selo de fluxo, produzem uma força radial colinear com o vetor de deflexão do eixo e sua direção depende do sinal algébrico. Caso $C_{x y}>0, C_{y x}<0$, a força fica direcionada para o centro da órbita.

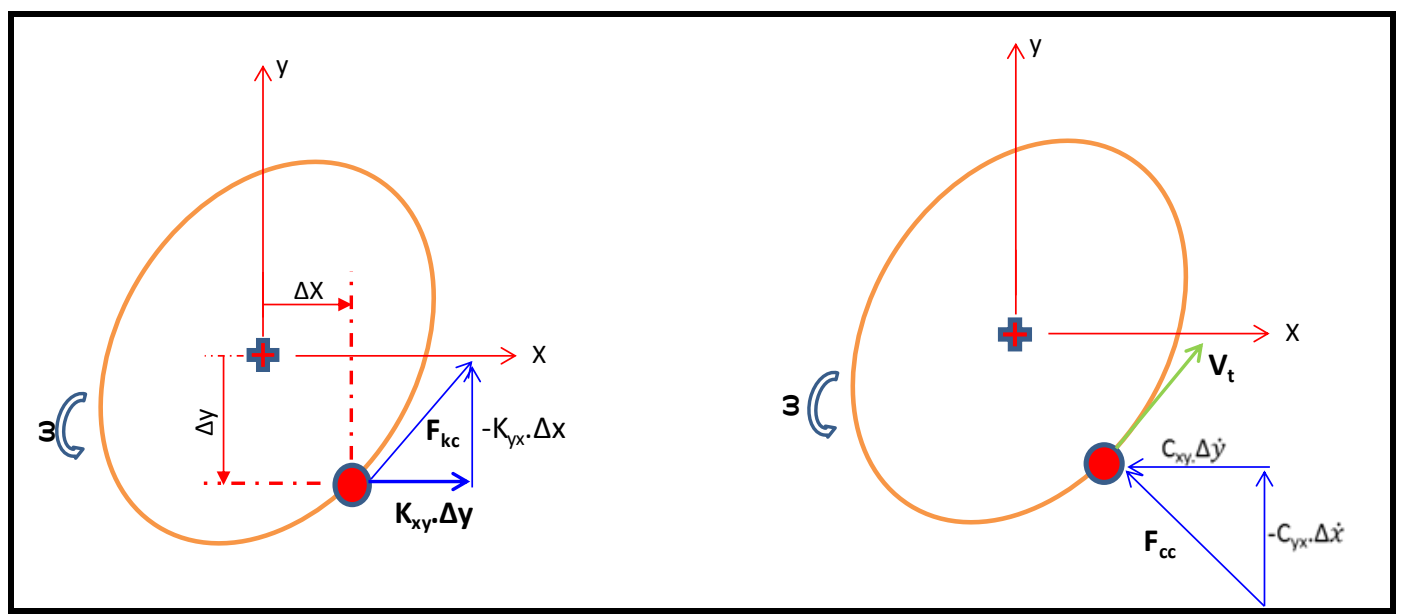

Figura 20 - Coeficientes dinâmicos cruzados da força do fluido

Os coeficientes dinâmicos cruzados são característicos de mancais (ou selos anulares) de geometria fixa e aparecem devido à rotação do fluido. Quando submetidos a uma força direcionada para baixo, o fluido responde com uma força não exatamente na direção oposta, mas sim formando um ângulo no sentido da rotação do eixo, conhecido como "ângulo de atitude".

Os coeficientes que produzem força radial (rigidez direta e amortecimento cruzado) tendem a ter pouco efeito na estabilidade. Entretanto, eles têm grande influência na frequência natural e na localização da velocidade crítica. Já os coeficientes que produzem força tangencial ao movimento orbital têm pouco efeito na frequência natural, porém têm grande influência na estabilidade e no fator de amplificação na velocidade crítica.

Duas razões são usadas para verificar o efeito na estabilidade do mancal e selo baseado nos coeficientes da força. O amortecimento efetivo $C_{e f f}=C_{x x}-K_{x y} / \omega_{n}$, no qual $\omega_{n}$ é a frequência natural e não a de operação do rotor, informa se o componente (mancal ou selo) atua desestabilizando o movimento do rotor caso o valor de $C_{\text {eff }}$ seja negativo. A $W F R=K x y / C x x . \omega$ (WhirlFrequencyRatio) informa a razão esperada entre $\omega_{n} / \Omega$ no início da estabilidade, no qual $\Omega$ representa a rotação do rotor. Caso $K_{x y}$ não seja igual a $-K_{y x}$ estas razões não têm significado. 


\section{5 Elementos finitos para análise lateral do rotor}

Programas de análise de rotodinâmica como Romac e XLTRC2 utilizam a teoria da viga de Bernoulli-Euler ou Timoshenko para simulação e análise do movimento vibratório e determinação das frequências naturais de rotores. Portanto, será demonstrado como é formada a matriz de massa e rigidez nas equações de movimentos. O desenvolvimento desta seção segue as notas de aula do prof. Paul Allaire e Adhemar Castilho, realizada em 2011.

A figura 21 abaixo mostra um rotor representado no sistema de coordenadas cartesianas 'xyz' e sua subdivisão em elementos finitos. Como a ênfase do estudo é a análise lateral, apenas as seguintes variáveis serão analisadas:

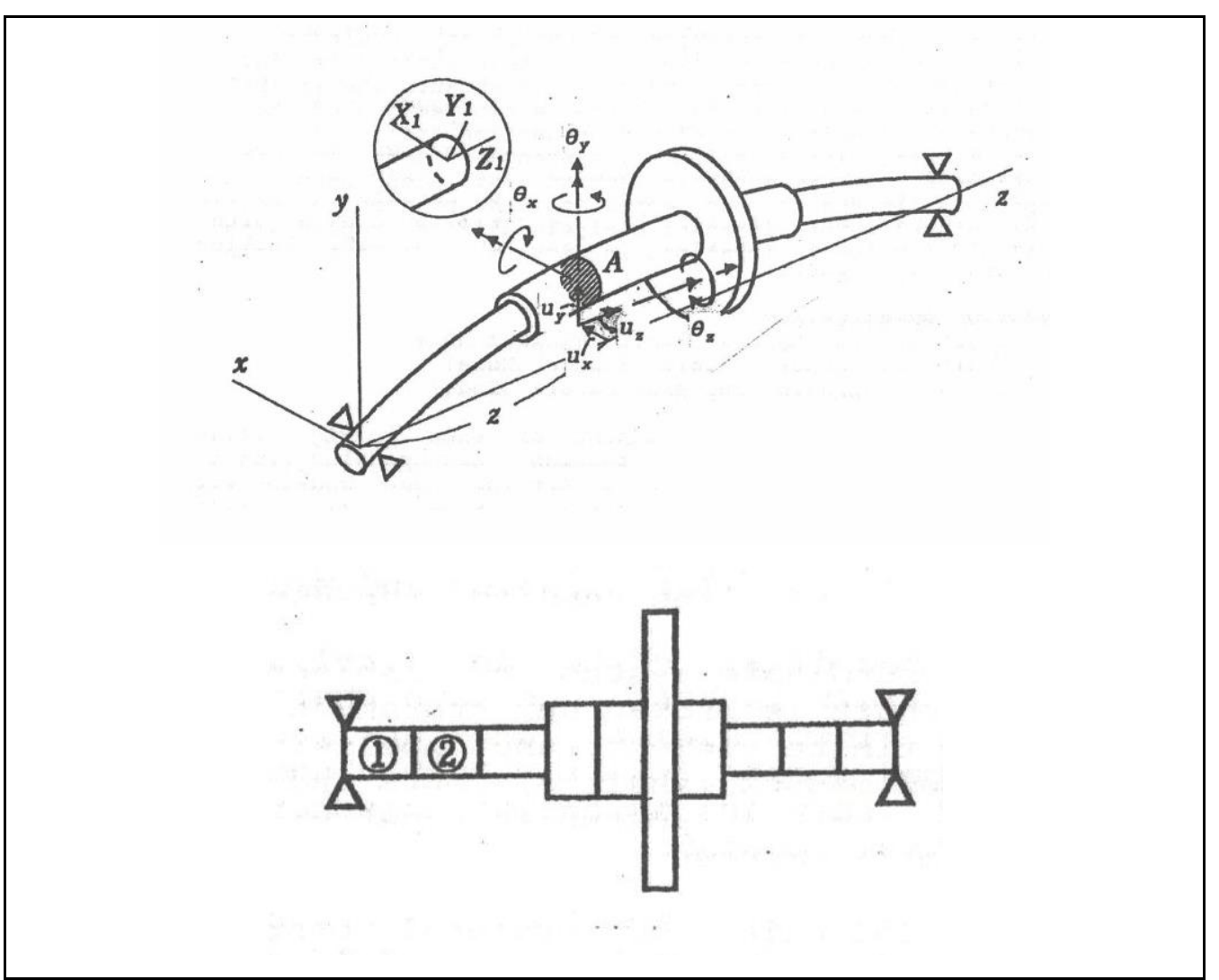

Figura 21 - Superior: Rotor representado no sistema de coordenadas cartesianas. Inferior: Subdivisão do rotor em elementos finitos - Allaire \& Castilho (2011) 
Onde:

$u_{x}$ : deslocamento lateral horizontal

$u_{y}$ : deslocamento lateral vertical

$\theta_{y}=\frac{\partial u_{x}}{\partial z}:$ deslocamento angular no plano $x z$
$\theta_{x}=\frac{\partial u_{y}}{\partial z}:$ deslocamento angular no plano $y z$

O modelo de viga de Euler-Bernoulli é uma simplificação da teoria linear da elasticidade, que fornece meios de calcular as características de deflexão de uma viga sob um determinado carregamento estático ou dinâmico, a qual é constituída pela seguinte equação diferencial parcial linear no plano ' $y z$ ':

$\frac{\partial^{2}}{\partial z^{2}}\left(E \cdot I \frac{\partial^{2} u_{y}}{\partial z^{2}}\right)-\frac{\partial}{\partial t}\left(\rho \cdot A \cdot \frac{\partial u_{y}}{\partial t}\right)=f_{y}$

onde:

$1^{\circ}$ termo $=$ flexão da barra

$2^{\circ}$ termo $=$ inércial/massa lateral

$3^{\circ}$ termo $=$ força lateral por unidade de comprimento

As condições de contorno da equação acima podem ser:

a) Barra apoiada

$$
\begin{gathered}
\mathrm{u}_{\mathrm{y}}=0 \\
M_{y}=E \cdot I_{y y} \cdot \frac{\partial^{2} u_{y}}{\partial y^{2}}=0 \\
I_{y y}=I_{x x}=\frac{\pi \cdot D^{4}}{64} \Rightarrow \text { para seção circular }
\end{gathered}
$$

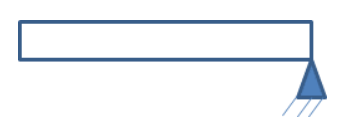


b) Engastada

$$
\begin{aligned}
& \mathrm{u}_{\mathrm{y}}=0 \\
& \theta_{x}=\frac{\partial u_{y}}{\partial z}=0
\end{aligned}
$$

c) Livre

$$
\begin{aligned}
& V_{y}=E \cdot I_{y y^{*}} \frac{\partial^{3} u_{y}}{\partial y^{3}}=0 \\
& M_{y}=E \cdot I_{y y} \cdot \frac{\partial^{2} u_{y}}{\partial y^{2}}=0
\end{aligned}
$$

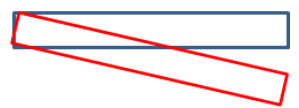

A energia potencial $\left(E P_{L y}\right)$ da viga (eixo) submetida a deformação interna devido a flexão no plano ' $y z$ ' é dado por:

$$
E P_{L_{y}}=U_{y}=\int_{V}\left(\frac{1}{2} \cdot \epsilon_{z z}, \sigma_{z z}\right) d V=\int_{L}\left(A, E_{z z}, \sigma_{z z}\right) d z
$$

onde,

$\epsilon_{z z}:$ deformação axial

$\sigma_{z z}:$ Tensão normal

A: área da seção transversal

\section{1.}

\section{Modelo em elementos finitos}

Para análise em elementos finitos, o rotor primeiramente é subdivido em elementos, no qual estes estão entre dois nós - ver figura 21. A solução para obter o deslocamento do rotor é dada para cada ponto nodal. 
As principais propriedades do eixo/rotor para elaboração do modelo em elementos finitos são:

L: comprimento do elemento

$D_{k}$ : diâmetro do elemento que oferece rigidez ao sistema

$D_{m}$ : diâmetro do elementos que oferece massa ao sistema

E: Módulo de elasticidade

$I_{x x}$ : momento de inércia de área na direção $x$

$I_{y y}$ : momento de inércia de área em y

$I_{z z}$ : momento de inércia polar

$\rho$ : densidade do material do rotor

A: área na seção transversal

O formato de deflexão de cada elemento é representado por uma função interpolação que segue os conceitos do polinômio de Hermite (ver figura 22). Considerando um elemento do rotor que possui um diâmetro uniforme, suas coordenadas generalizadas podem ser descritas conforme ilustrada na figura 23. Cada nodo possui dois graus de liberdade em cada plano ' $x z$ ' e ' $y z$ '. E a função interpolação é dada por:

$$
U_{y}^{(e)}=\left[N_{1} q_{5}+N_{2} q_{6}+N_{3} q_{7}+N_{4} q_{8}\right]^{(e)}=\left[N_{1} N_{2} N_{3} N_{4} N_{5}\right]\left[\begin{array}{l}
q_{5} \\
q_{6} \\
q_{7} \\
q_{8}
\end{array}\right]
$$

onde $\mathrm{N}_{1}, \mathrm{~N}_{2}, \mathrm{~N}_{3}$ e $\mathrm{N}_{4}$ representam funções da forma do elemento e $\mathrm{q}_{5}, \mathrm{q}_{6}, \mathrm{q}_{7}$ e $\mathrm{q}_{8}$ representam os deslocamentos dos nodos definidos como:

$$
\begin{array}{ll}
N_{1}=\frac{1}{L^{3}}\left(L^{3}-3 \cdot z^{2} \cdot L+2 \cdot z^{3}\right) & N_{2}=\frac{1}{L^{2}}\left(z \cdot 2-2 \cdot z^{2} \cdot L+z^{3}\right) \\
N_{3}=\frac{1}{L^{3}}\left(3 \cdot z^{2} \cdot L-2 \cdot z^{3}\right) & N_{4}=\frac{1}{L^{2}}\left(-z^{2} \cdot L+z^{3}\right)
\end{array}
$$


$Q_{y z}^{(e)}=\left[\begin{array}{l}q_{5} \\ q_{6} \\ q_{7} \\ q_{8}\end{array}\right]^{(e)}=\left[\begin{array}{l}u_{y i} \\ \theta_{x i} \\ u_{y j} \\ \theta_{x j}\end{array}\right]$

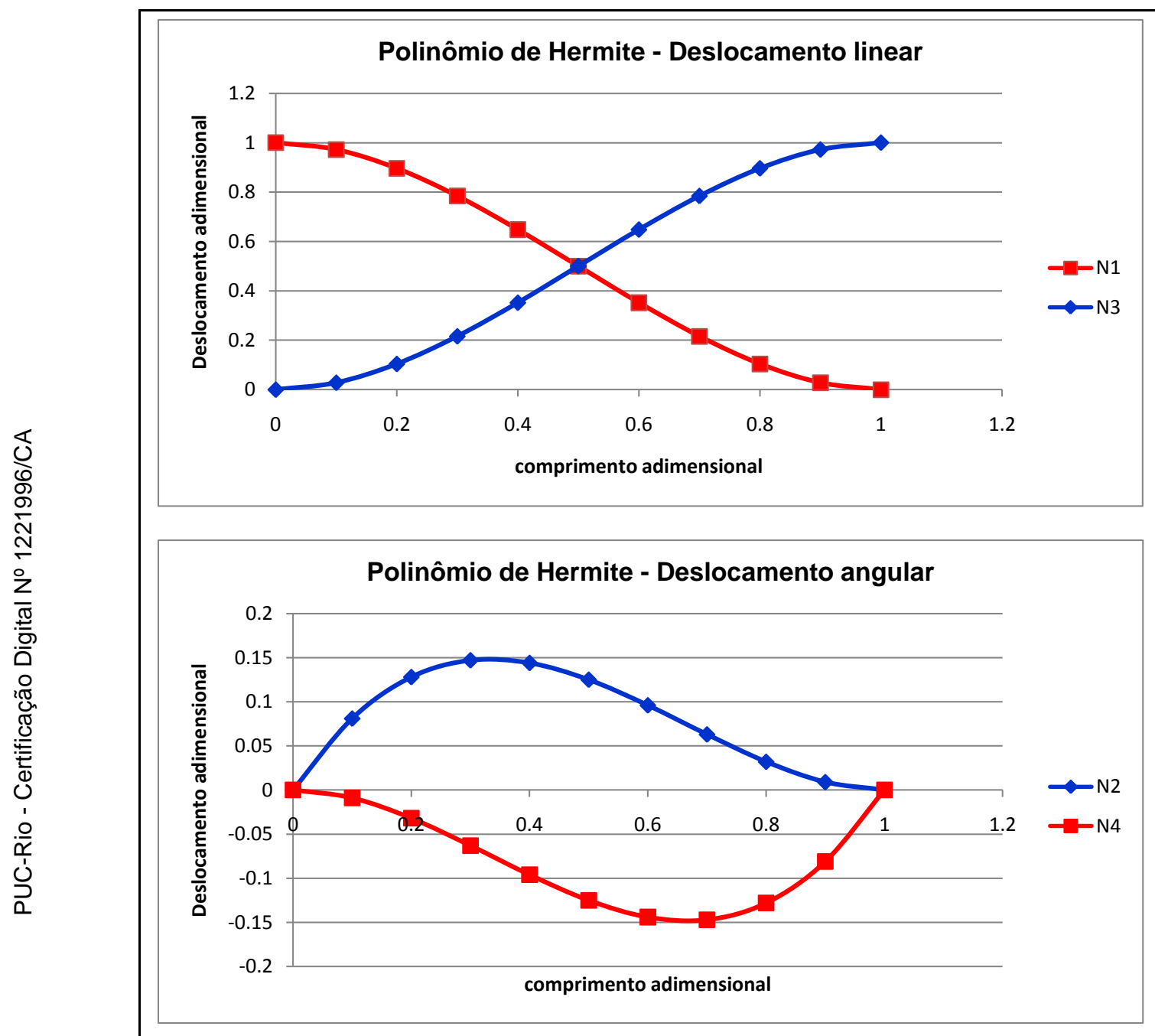

Figura 22 - Polinômio de Hermite 


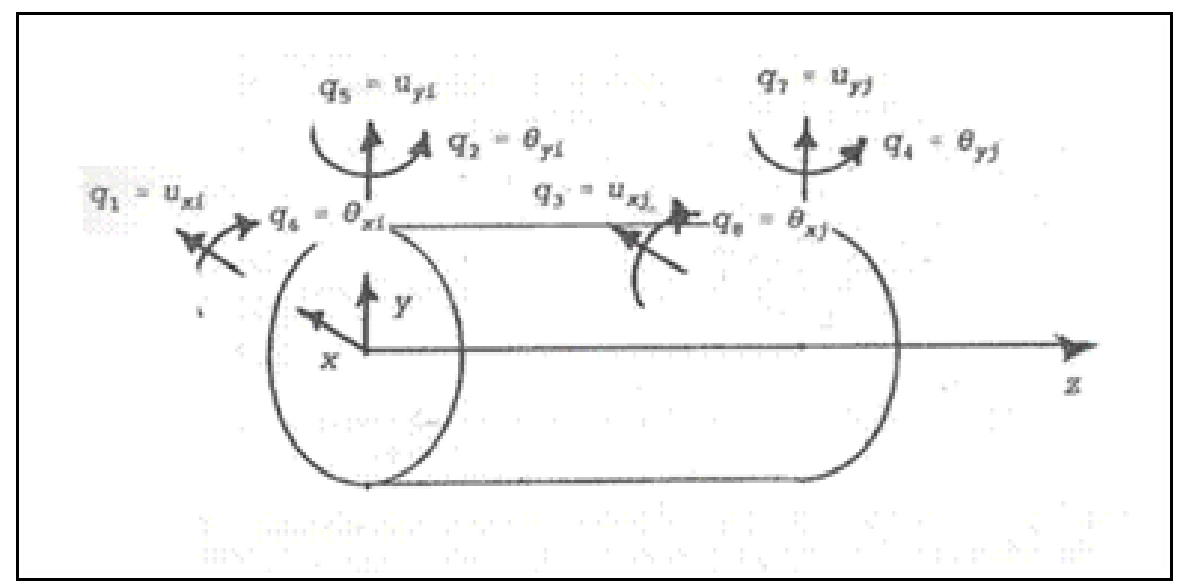

Figura 23 - Deslocamento generalizado do elemento - Allaire \& Castilho (2011)

\subsection{1.}

\section{Matriz de rigidez do eixo}

Dadas as definições acima, a matriz de rigidez do eixo pode ser definida conforme descrito abaixo.

Como o deslocamento lateral no plano ' $y z$ ' é dado por $u_{y}$, o deslocamento axial do eixo " $u_{z}$ ” é representado por

$$
u_{z}=-y \cdot \frac{\partial u_{y}}{\partial z}
$$

Portanto, a deformação axial $(\varepsilon)$ e sua relação com a tensão normal $\left(\sigma_{z z}\right)$, considerando propriedade linear do material, são dadas por (ver figura 24):

$$
\begin{aligned}
& \varepsilon_{z z}=\frac{\partial u_{z}}{\partial z}=-y \frac{\partial^{2} u_{y}}{\partial z^{2}} \\
& \varepsilon_{z z}^{(e)}=-y \frac{\partial^{2} N^{(e)}}{\partial z^{2}} Q^{(e)}=B^{(e)} \cdot Q^{(e)} \\
& \boldsymbol{B}^{(e) T}=-\frac{y}{L^{3}}[-6 L+12 z ;-4 L+6 l ; 6 L-12 z ;-2 L+6 z]
\end{aligned}
$$

B: Forma de flexão do elemento 


$$
\begin{aligned}
& \sigma_{z z}=E \cdot \varepsilon_{z z}=E \frac{\partial u_{z}}{\partial z}=-E \cdot y \cdot \frac{\partial^{2} u_{y}}{\partial z^{2}} \\
& \sigma_{z z}^{(e)}=-E \cdot y \cdot \frac{\partial^{z} N^{(e)}}{\partial z^{(e)}} \cdot Q^{(e)}=E \cdot B^{(e)} \cdot Q^{(e)}
\end{aligned}
$$

\section{$\sigma_{\mathrm{zz}:}$ Tensão de flexão do elemento}

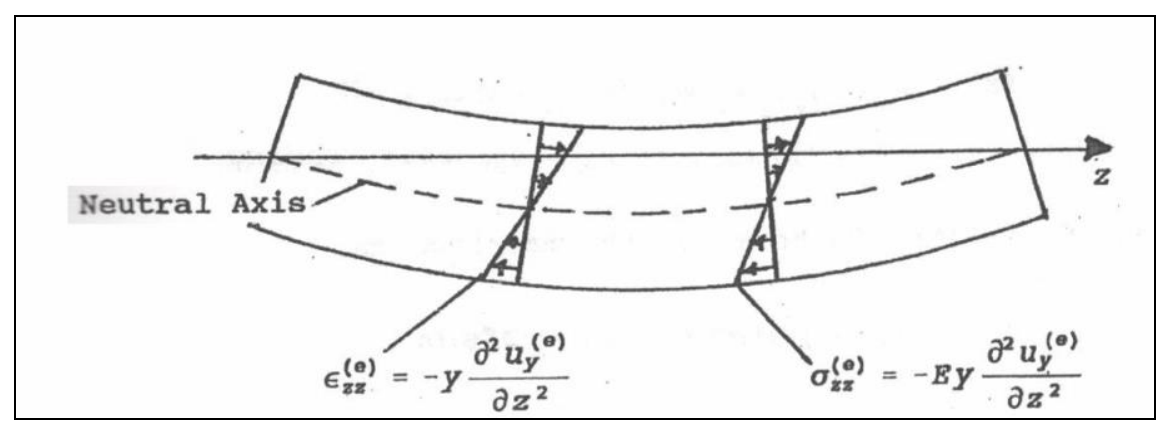

Figura 24 - Tensão normal e deslocamento axial - Allaire \& Castilho (2011)

Inserindo as equações acima na equação da energia potencial 5.2, resulta em:

$$
\begin{aligned}
& E P_{L_{y}}^{(e)}=E \int_{L^{(e)}}\left[\int_{A^{(e)}} B^{(e) T} B^{(e)} d A\right] d z \\
& E P_{L_{y}^{(e)}}^{(e)}=E \int_{A^{(e)}} y^{2} d A \int_{L^{(e)}}\left(\frac{\partial^{2} N^{(e) T}}{\partial z^{2}}\right)\left(\frac{\partial^{2} N^{(e)}}{\partial z^{2}}\right) d z
\end{aligned}
$$

nos quais o primeiro termo da equação 5.9 é o momento de inércia $I_{y y}$ e o segundo termo é a matriz de rigidez dada por:

$$
\begin{aligned}
& K_{y z}=\int_{L^{(e)}}\left(\frac{\partial^{2} \boldsymbol{N}^{(e) T}}{\partial z^{2}}\right)\left(\frac{\partial^{2} \boldsymbol{N}^{(e)}}{\partial z^{2}}\right) d z=
\end{aligned}
$$

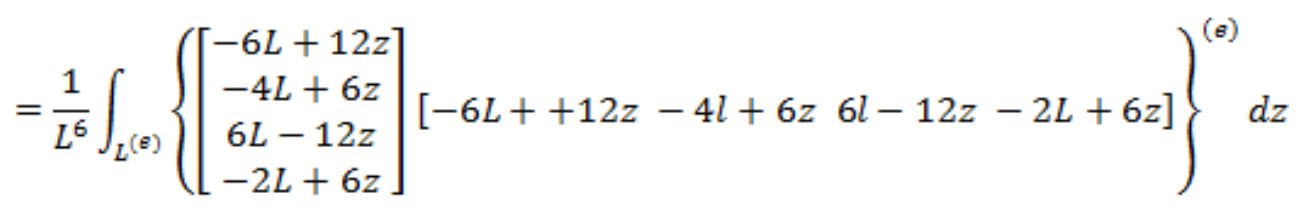

Usando a formulação de Lagrange, a matriz de rigidez do elemento no plano ' $y z$ ' é dada por: 


$$
\frac{\partial \mathcal{L}_{L_{y}^{(e)}}^{(e)}}{\partial Q_{y z}^{(e)}}=\frac{\partial E P_{L y}^{(e)}}{\partial Q_{y z}^{(e)}}=K_{y z}^{(e)} Q_{y z}^{(e)}=\frac{E \cdot I_{y y}}{L^{3}}\left[\begin{array}{cccc}
12 & 6 L & -12 & 6 L \\
6 L & 4 L^{2} & -6 L & 2 L^{2} \\
-12 & -6 L & 12 & -6 L \\
6 L & 2 L^{2} & -6 L & 4 L^{2}
\end{array}\right]\left[\begin{array}{c}
u_{y i} \\
\theta_{x i} \\
u_{y j} \\
\theta_{x j}
\end{array}\right]
$$

eq. (5.11)

Devido à simetria, a matriz de rigidez pode ser representada como:

$$
\boldsymbol{K}_{y z}^{(e)} \boldsymbol{Q}_{y z}^{(e)}=\left[\begin{array}{cccc}
k_{y 1} & k_{y 2} & -k_{y 1} & k_{y 2} \\
k_{y 2} & k_{y 3} & -k_{y 2} & k_{y 4} \\
-k_{y 1} & -k_{y 2} & k_{y 1} & -k_{y 2} \\
k_{y 2} & k_{y 4} & -k_{y 2} & k_{y 3}
\end{array}\right]\left[\begin{array}{c}
u_{y i} \\
\theta_{x i} \\
u_{y j} \\
\theta_{x j}
\end{array}\right]
$$

Onde:

$$
\begin{array}{ll}
k_{y 1}=\frac{d F}{d u}=\frac{12 E L_{y y}}{L^{3}} & k_{y 2}=\frac{d F}{d u}=\frac{6 E L_{y y}}{L^{2}} \\
k_{y 3}=\frac{d M}{d \theta}=\frac{4 E L_{y y}}{L} & k_{y 4}=\frac{d M}{d \theta}=\frac{2 E L_{y y}}{L}
\end{array}
$$

Sendo, $k_{y 1}$ e $k_{y 2}$ correspondentes à variação de força com o deslocamento $(\mathrm{N} / \mathrm{m})$ e $k_{y 3}$ e $k_{y 4}$ à variação de momento com o deslocamento angular (N.m/rad).

A matriz de rigidez no plano ' $x z$ ' é obtida da mesma forma que foi descrita para o plano ' $y z$ '. Logo, a matriz generalizada do deslocamento nos planos ' $x z$ ' e ' $y z$ ' é:

$$
Q_{x y z}^{(e)}=\left[\begin{array}{l}
q_{1} \\
q_{2} \\
q_{3} \\
q_{4} \\
q_{5} \\
q_{6} \\
q_{7} \\
q_{8}
\end{array}\right]=\left[\begin{array}{l}
u_{x i} \\
\theta_{y i} \\
u_{x j} \\
\theta_{y j} \\
u_{y i} \\
\theta_{x i} \\
u_{y j} \\
\theta_{x j}
\end{array}\right]
$$


onde as primeiras quatro entradas representam o plano ' $x z$ ' e as quatro últimas o plano ' $y z$ '. Portanto, a matriz de rigidez dos dois planos combinados é dada por:

$$
\begin{aligned}
K_{x y z^{*}}^{(e)} Q_{x y z}^{(e)} & =\left[\begin{array}{cccccccc}
k_{x 1} & k_{x 2} & -k_{x 1} & k_{x 2} & 0 & 0 & 0 & 0 \\
k_{x 2} & k_{x 3} & -k_{x 2} & k_{x 4} & 0 & 0 & 0 & 0 \\
-k_{x 1} & -k_{x 2} & k_{x 1} & -k_{x 2} & 0 & 0 & 0 & 0 \\
k_{x 2} & k_{x 4} & -k_{x 2} & k_{x 3} & 0 & 0 & 0 & 0 \\
0 & 0 & 0 & 0 & k_{y 1} & k_{y 2} & -k_{y 1} & k_{y 2} \\
0 & 0 & 0 & 0 & k_{y 2} & k_{y 3} & -k_{y 2} & k_{y 4} \\
0 & 0 & 0 & 0 & -k_{y 1} & -k_{y 2} & k_{y 1} & -k_{y 2} \\
0 & 0 & 0 & 0 & k_{y 2} & k_{y 4} & -k_{y 2} & k_{y 3}
\end{array}\right]\left[\begin{array}{c}
u_{x i} \\
\theta_{y i} \\
u_{x j} \\
\theta_{y j} \\
u_{y i} \\
\theta_{x i} \\
u_{y j} \\
\theta_{x j}
\end{array}\right] \\
K_{x y z^{*}}^{(e)} Q_{x y z}^{(e)} & =\left[\begin{array}{cc}
k_{x z} & 0 \\
0 & k_{y z}
\end{array}\right]^{e}\left[\begin{array}{l}
Q_{x z} \\
Q_{y z}
\end{array}\right]
\end{aligned}
$$

\subsection{2.}

\section{Matriz de massa do eixo}

A matriz de massa do rotor subdividido em elementos finitos é modelada utilizando a energia cinética total do rotor devido ao seu movimento lateral. Considerando apenas o plano ' $y z$ ', a energia cinética é definida como:

$$
\begin{aligned}
& E C_{L_{y}}=\int_{V} \frac{1}{2} \rho \dot{u}_{y z}^{T} \dot{u}_{y z} d V \\
& \dot{u}_{y z}=N \cdot \dot{Q}_{y z} \\
& \dot{Q}_{y z}^{(e)}=\left[\begin{array}{l}
\dot{q}_{5} \\
\dot{q}_{6} \\
\dot{q}_{7} \\
\dot{q}_{8}
\end{array}\right]^{(e)}=\left[\begin{array}{c}
\dot{u}_{y i} \\
\dot{\theta}_{x i}^{(e)} \\
\dot{u}_{y j} \\
\dot{\theta}_{x j}
\end{array}\right]^{(e)}
\end{aligned}
$$

onde,

$\dot{u}:$ vetor velocidade

$\dot{Q}_{y z}:$ velocidade generalizada nodal no plano " yz" 
Portanto, a energia cinética de cada elemento e a total são:

$$
\begin{aligned}
& E C_{L_{y}}^{(e)}=\int_{V^{(e)}} \frac{1}{2} \rho \dot{Q}_{y z}^{(e) T} \cdot N^{(e) T} \cdot N^{(e)} \cdot \dot{Q}_{y z}^{(e)} \cdot d V^{(e)} \\
& E C_{L y}=\sum_{\theta=1}^{E} E C^{(e)}=\frac{1}{2} \sum_{\theta=1}^{E} \dot{Q}_{y z}^{T} \int_{V^{(e)}}\left(\rho \cdot N^{T} \cdot N\right)^{(e)} \cdot d V^{(e)} \cdot \dot{Q}_{y z}
\end{aligned}
$$

De maneira similar à matriz de rigidez, a matriz de massa pode ser obtida através da formulação de Lagrange como:

$$
\frac{d}{d t}\left(\frac{\partial \mathcal{L}_{L_{y z}}}{\partial Q_{y z}^{(e)}}\right)=\frac{\partial E C_{L_{y z}^{(e)}}^{(e)}}{\partial Q_{y z}^{(e)}}=M_{y z}^{(e)} Q_{y z}^{(e)}
$$

$$
\frac{\partial E C_{L y z}^{(e)}}{\partial \dot{Q}_{y z}^{(e))}}=\left[\int_{V^{(\theta)}} \rho \cdot N^{(\theta) T} \cdot N^{(\theta)} \cdot d V^{(e)}\right] \ddot{Q}_{y z}^{(e)}=M_{y z}^{(e)} \ddot{Q}_{y z}^{(e)}
$$

Considerando a área da seção transversal do elemento constante, tem se:

$$
M_{y z}^{(\theta)}=\int_{V^{(\theta)}} \rho \cdot N^{(e) T} \cdot N^{(\theta)} \cdot d V^{(\theta)}=(\rho \cdot A)^{(e)} \cdot \int_{L^{(\theta)}} N^{(\theta) T} N^{(\theta)} d L^{(e)}
$$

onde:

$M_{y z}^{(e)}:$ matriz consistente de massa do elemento do eixo

$\rho^{(e)}:$ densidade constante do elemento do eixo

$A^{(e)}$ : área constante do elemento do eixo

$L^{(e)}$ : comprimento do elemento do eixo

Integrando no intervalo do comprimento do elemento $\left(\mathrm{L}_{\mathrm{e}}\right)$, resulta em: 


$$
\boldsymbol{M}_{y z}^{(e)} \ddot{\boldsymbol{Q}}_{y z}^{(e)}=\left(\frac{\rho \cdot A \cdot L}{420}\right)^{(e)}\left[\begin{array}{cccc}
156 & 22 L & 54 & -13 L \\
22 L & 4 L^{2} & 13 L & -3 L^{2} \\
54 & 13 L & 156 & -22 L \\
-13 L & -3 L^{2} & -22 L & 4 L^{2}
\end{array}\right]^{(e)}\left[\begin{array}{c}
\ddot{u}_{y i} \\
\ddot{\theta}_{x i} \\
\ddot{u}_{y j}^{(e)} \\
\ddot{\theta}_{x j}
\end{array}\right]^{(13}
$$

Portanto, a matriz consistente de massa vezes o vetor aceleração pode ser representado no plano ' $y z$ ' por:

$$
\boldsymbol{M}_{y z}^{(e)} \ddot{\boldsymbol{Q}}_{y z}^{(e)}=\left[\begin{array}{cccc}
m_{1} & m_{2} & m_{3} & -m_{4} \\
m_{2} & m_{5} & m_{4} & -m_{6} \\
m_{3} & m_{4} & m_{1} & -m_{2} \\
-m_{4} & -m_{6} & -m_{2} & m_{5}
\end{array}\right]^{(e)}\left[\begin{array}{c}
\ddot{u}_{y i} \\
\ddot{\theta}_{x i}^{(e)} \\
\ddot{u}_{y j} \\
\ddot{\theta}_{x j}
\end{array}\right]^{(e)}
$$

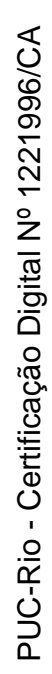

onde:

$$
\begin{aligned}
& \mathrm{m}_{1}=156 \mathrm{a} \\
& \mathrm{m}_{4}=13 . \mathrm{L} \cdot \mathrm{a} \\
& a=\left(\frac{\rho \cdot A \cdot L}{420}\right)^{(e)}
\end{aligned}
$$$$
>\mathrm{m}_{2}=22 \mathrm{~L} \cdot \mathrm{a}
$$$$
>\mathrm{m}_{3}=54 . \mathrm{a}
$$$$
>\mathrm{m}_{5}=4 \cdot \mathrm{L}^{2} \cdot \mathrm{a}
$$$$
>\mathrm{m}_{6}=3 \cdot \mathrm{L}^{2} \cdot \mathrm{a}
$$

Novamente, de forma similar a matriz de rigidez, a matriz de massa combinada nos planos ' $x z$ ' e ' $y z$ ' é representada por:

$$
\begin{aligned}
M_{x y z}^{(e)} \cdot \ddot{Q}_{x y z}^{(e)} & =\left[\begin{array}{cccccccc}
m_{1} & m_{2} & m_{3} & -m_{4} & 0 & 0 & 0 & 0 \\
m_{2} & m_{5} & m_{4} & -m_{6} & 0 & 0 & 0 & 0 \\
m_{3} & m_{4} & m_{1} & -m_{2} & 0 & 0 & 0 & 0 \\
-m_{4} & -m_{6} & -m_{2} & m_{5} & 0 & 0 & 0 & 0 \\
0 & 0 & 0 & 0 & m_{1} & m_{2} & m_{3} & -m_{4} \\
0 & 0 & 0 & 0 & m_{2} & m_{5} & m_{4} & -m_{6} \\
0 & 0 & 0 & 0 & m_{3} & m_{4} & m_{1} & -m_{2} \\
0 & 0 & 0 & 0 & -m_{4} & -m_{6} & -m_{2} & m_{5}
\end{array}\right]\left[\begin{array}{c}
\ddot{u}_{x i} \\
\ddot{\theta}_{y i} \\
\ddot{u}_{x j} \\
\ddot{\theta}_{y j} \\
\ddot{u}_{y i} \\
\ddot{\theta}_{x i} \\
\ddot{u}_{y j} \\
\ddot{\theta}_{x j}
\end{array}\right] \\
\boldsymbol{M}_{x y z}^{(e)} \cdot \boldsymbol{Q}_{x y z}^{(e)} & =\left[\begin{array}{cc}
M_{x z} & 0 \\
0 & M_{y z}
\end{array}\right]^{e}\left[\begin{array}{l}
\ddot{Q}_{x z} \\
\ddot{Q}_{y z}
\end{array}\right]^{(e)}
\end{aligned}
$$


Desta forma, a representação da equação de movimento lateral do rotor em elementos finitos torna-se igual à:

$$
\begin{aligned}
& \boldsymbol{K}_{x y z}^{(e)} \boldsymbol{Q}_{x y z}^{(e)}+\boldsymbol{M}_{x y z}^{(e)} \ddot{Q}_{x y z}^{(e)}=\boldsymbol{F}^{(e)} \\
& {\left[\begin{array}{cc}
k_{x z} & 0 \\
0 & k_{y z}
\end{array}\right]^{(e)}\left[\begin{array}{l}
Q_{x z} \\
Q_{y z}
\end{array}\right]^{(e)}+\left[\begin{array}{cc}
M_{x z}^{(e)} & 0 \\
0 & M_{y z}^{(e)}
\end{array}\right]^{(e)}\left[\begin{array}{c}
\ddot{Q}_{x z}^{(e)} \\
\ddot{Q}_{y z}^{(e)}
\end{array}\right]^{(e)}=\left[\begin{array}{c}
F_{x}^{(e)} \\
F_{y}^{(e)}
\end{array}\right]}
\end{aligned}
$$




\section{6 Modelagem e simulação rotodinâmica}

Para realização da simulação rotodinâmica de um conjunto rotativo de uma bomba, compressor, turbina, etc. é necessário desenhar todo o rotor subdividindo em elementos. É preciso também obter as propriedades do material do rotor como módulo de elasticidade e cisalhamento, momento de inércia transversal e polar dos impelidores, acoplamento e de outros componentes rotativos que podem influenciar o modelo. Outras propriedades importantes são a rigidez e amortecimento dos mancais, selos, tambor de balanceamento e suporte do mancal (pedestal), caso este seja muito flexível. De acordo com a norma API 684 - $2^{\circ} \mathrm{ed}$. (Rotordynamic Tutorial: Lateral Critical Speeds, Unbalance Response Stability, Train Torsionals, and Rotor Balancing), os cincos passos para modelagem de um equipamento rotativo são:

a. Criar o modelo lateral massa-mola de toda a unidade rotativa

b. Calcular as reações estáticas nos rolamentos

c. Calcular os coeficientes dinâmicos linearizados dos mancais

d. Calcular os coeficientes dinâmicos dos selos a óleo. Neste trabalho este item refere-se aos anéis anulares.

e. Calcular a influência de outras excitações externas (como efeitos aerodinâmicos, labirintos etc).

As figuras 25, 26 e 27 demonstram respectivamente o desenho de corte da bomba centrífuga multiestágios analisada, o dimensional do conjunto rotativo com as propriedades mecânicas do eixo e impelidores e o modelo do conjunto rotativo. 


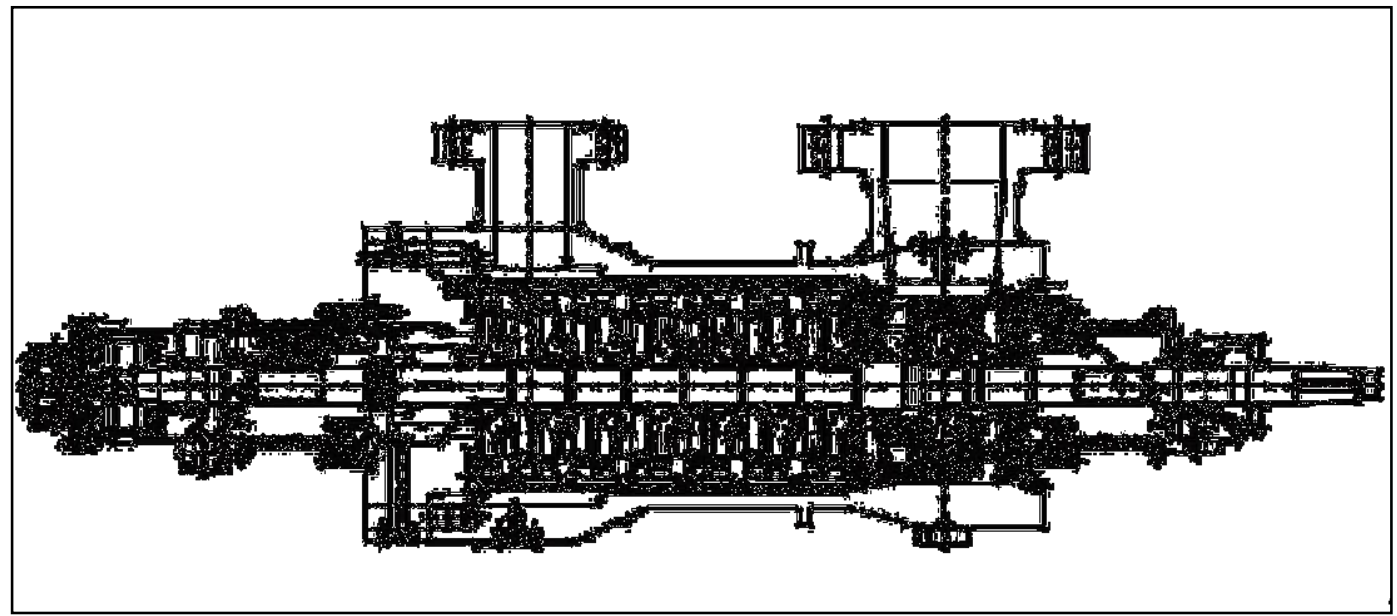

Figura 25 - Desenho de Corte da bomba centrífuga multiestágios

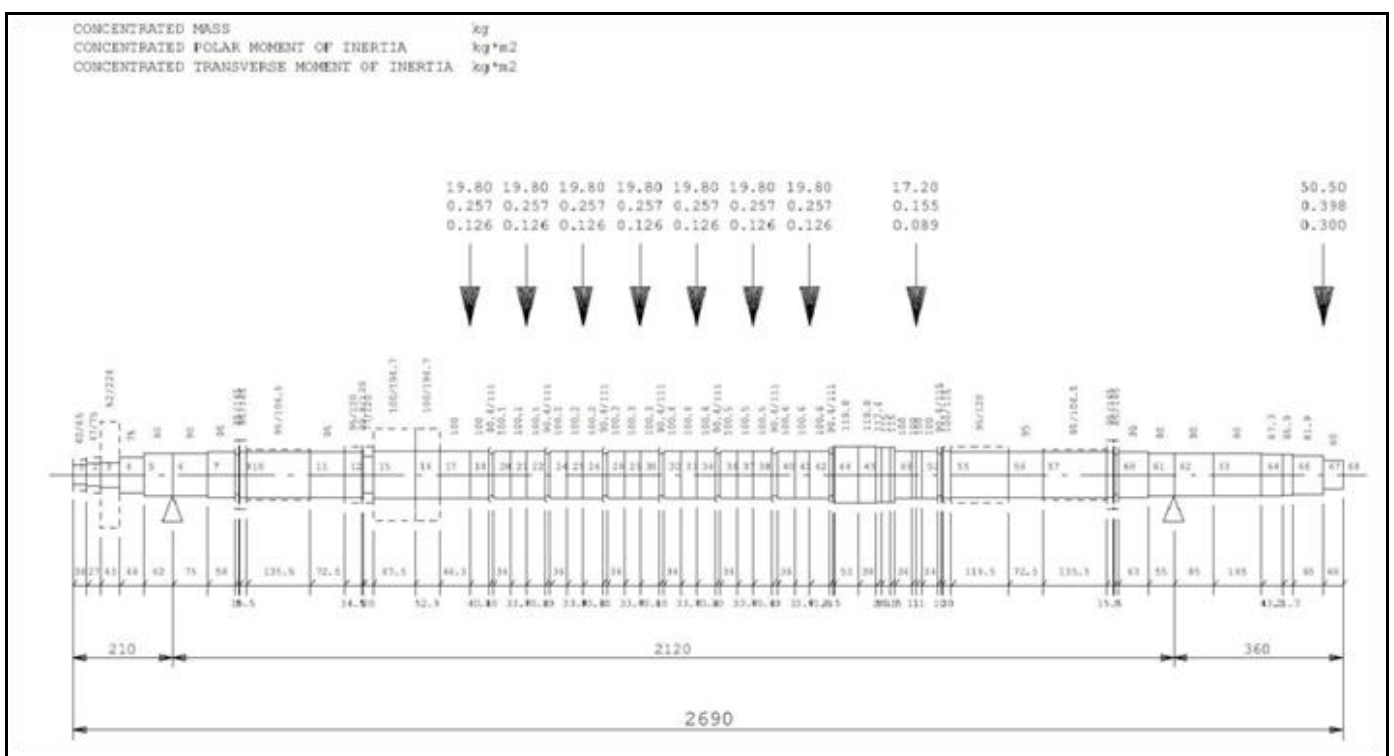

Figura 26 - Dimensional e propriedades mecânicas do conjunto rotativo 


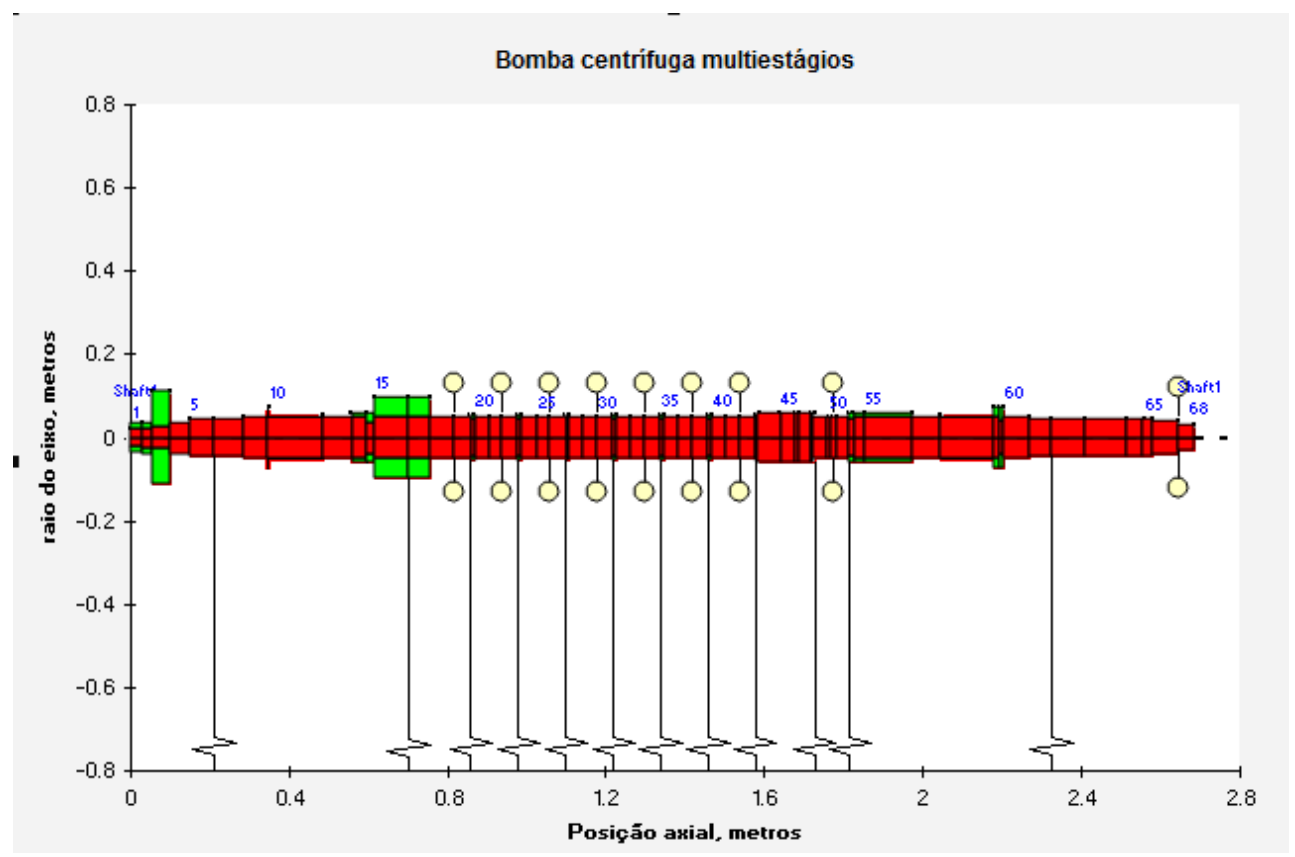

Figura 27 - Modelagem do conjunto rotativo da bomba centrífuga multiestágios

O número de estações (discretizações) necessárias para representar o conjunto rotativo depende do número de modos de vibração pretendido na análise. Como o código utilizado na simulação é baseado no método matriz de transferência ("transfer matrix"), a quantidade mínima usual de estações (malha) é de quatro vezes o número de modos desejados.

Os impelidores podem ser representados simplesmente pela adição de sua propriedade de inércia no eixo. A sua influência na rigidez do rotor pode ser desprezada, caso estes não sejam montados com muita interferência no eixo.

O acoplamento (cubo e a metade do espaçador), assim como o impelidor, também pode ser representado apenas pela adição de suas propriedades de inércia ao eixo.

Os mancais, selos, tambores de balanceamento normalmente são modelados separadamente para que seja efetuado o cálculo da rigidez e amortecimento fornecidos por estes componentes ao sistema mecânico. Estes componentes que conectam o conjunto rotativo a base do equipamento ou pedestal. Para efetuar o cálculo de seus coeficientes dinâmicos são necessárias as seguintes informações: folga, diâmetro, largura, propriedades do fluido (viscosidade, densidade, vazão e pressão etc.) dentre outros fatores que dependem do componente a ser modelado.

Durante a determinação dos coeficientes dinâmicos dos mancais, selos, tambores de balanceamento, para análise lateral, podem ser considerados quatro 
graus de liberdade por nó do sistema discretizado em elementos finitos. Conforme visto anteriormente, existe a possibilidade do deslocamento em ' $x$ ' e a rotação em torno do eixo ' $\mathrm{x}$ ', deslocamento em ' $y$ ' e rotação em ' $y$ '. Portanto, coeficientes dinâmicos destes componentes podem ser representados na forma matricial como:

$$
[K]=\left[\begin{array}{cccc}
K_{x x x} & K_{x y} & K_{x \beta x} & K_{x \beta y} \\
K_{y x} & K_{y y} & K_{y \beta x} & K_{y \beta y} \\
K_{\beta x x} & K_{\beta x y} & K_{\beta x \beta x} & K_{\beta x \beta y} \\
K_{\beta y x} & K_{\beta y y} & K_{\beta y \beta x} & K_{\beta y \beta y}
\end{array}\right] \quad[\boldsymbol{C}]=\left[\begin{array}{cccc}
c_{x x x} & c_{x y} & c_{x \beta x} & c_{x \beta y} \\
c_{y x} & c_{y y} & c_{y \beta x} & c_{y \beta y} \\
c_{\beta x x} & c_{\beta x y} & c_{\beta x \beta x} & c_{\beta x \beta y} \\
c_{\beta y x} & c_{\beta y y} & c_{\beta y \beta x} & c_{\beta y \beta y}
\end{array}\right]
$$

Entretanto, normalmente apenas os valores de $K_{x x}, K_{x y}, K_{y x}, K_{y y}, C_{x x}, C_{x y}$, $C_{y x}, C_{y y}$ são diferentes de zero e o código utilizado para simular os modelos das bombas permite a inserção destes oitos coeficientes da matriz. A matriz de inércia será desprezada neste trabalho, pois o selo anular não está submetido a pressões elevadas e a razão entre largura e diâmetro $(L / D)$ é menor que 0,5.

Em pose dos coeficientes dinâmicos dos mancais e do selos, da matriz de rigidez e de massa do eixo, a determinação das frequências naturais (autovalores), modo de vibração (autovetores) e a resposta a forças externas podem ser calculadas com o auxílio de softwares de programação e elementos finitos.

Como dito anteriormente, os autovalores informam as frequências naturais e amortecida do sistema mecânico e o coeficiente exponencial de amortecimento, possibilitando desta forma, a elaboração dos seguintes mapas das críticas:

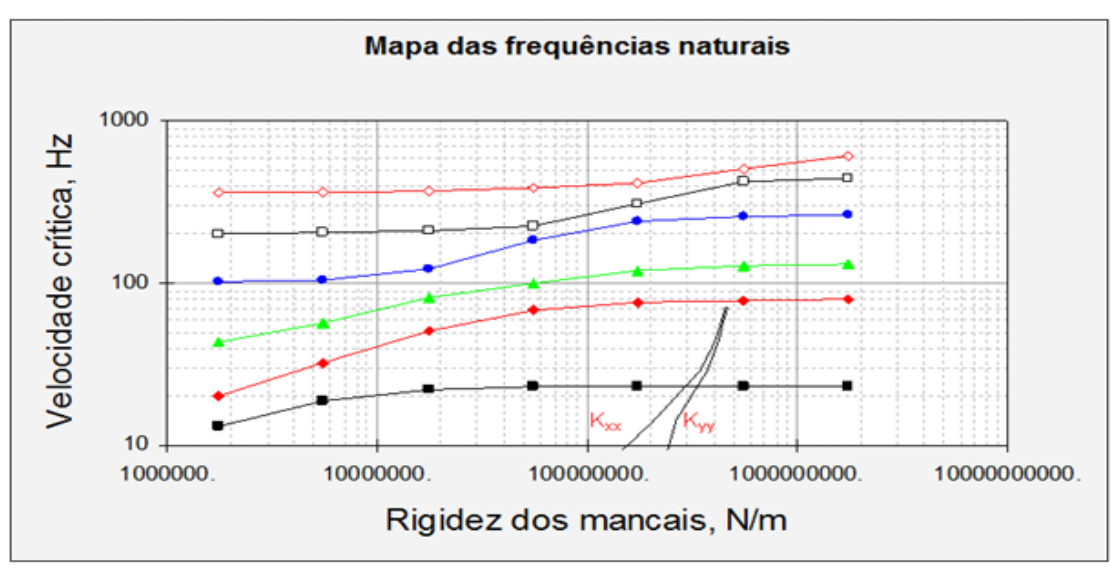

Figura 28 - Mapa das frequências naturais de uma bomba centrífuga 


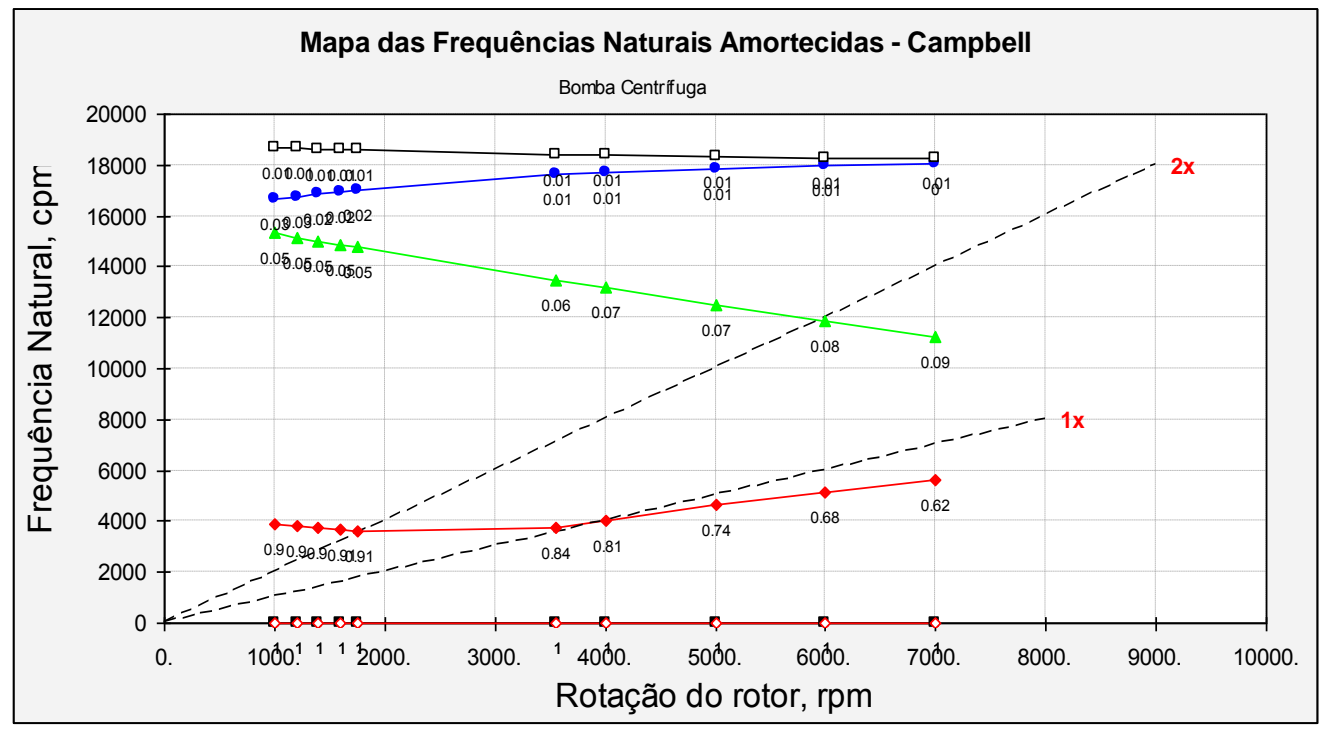

Figura 29 - Diagrama de Campbell - Mapa das frequências naturais

A figura 28 mostra como a frequência natural do sistema varia com o aumento da rigidez dos mancais. Portanto, para obter o valor da frequência natural do conjunto rotativo analisado, basta inserir no diagrama a rigidez dos mancais. Os valores obtidos do cruzamento da linha que representa a rigidez dos mancais com a linha de frequência natural são as frequências naturais não amortecidas do rotor. Cada linha do gráfico representa um modo de vibração que, seguindo de baixo para cima, a primeira linha representa o primeiro modo e a última linha o sexto modo de vibrar.

Já o gráfico representado na figura 29 é conhecido como diagrama de Campbell. Ele indica as frequências naturais amortecidas que podem vir a ser excitada pelas frequências que normalmente aparecem em regime de operação do equipamento, como o desbalanceamento (representado pela reta 1X) e o desalinhamento representado pela reta $2 \mathrm{X}$.

Os valores dos coeficientes de amortecimento, que correspondem à parte real do autovalor referente à frequência natural amortecida calculada, também podem ser inseridos no diagrama de Campbell ou pode ser elaborado um mapa de estabilidade conforme figura 30 abaixo: 


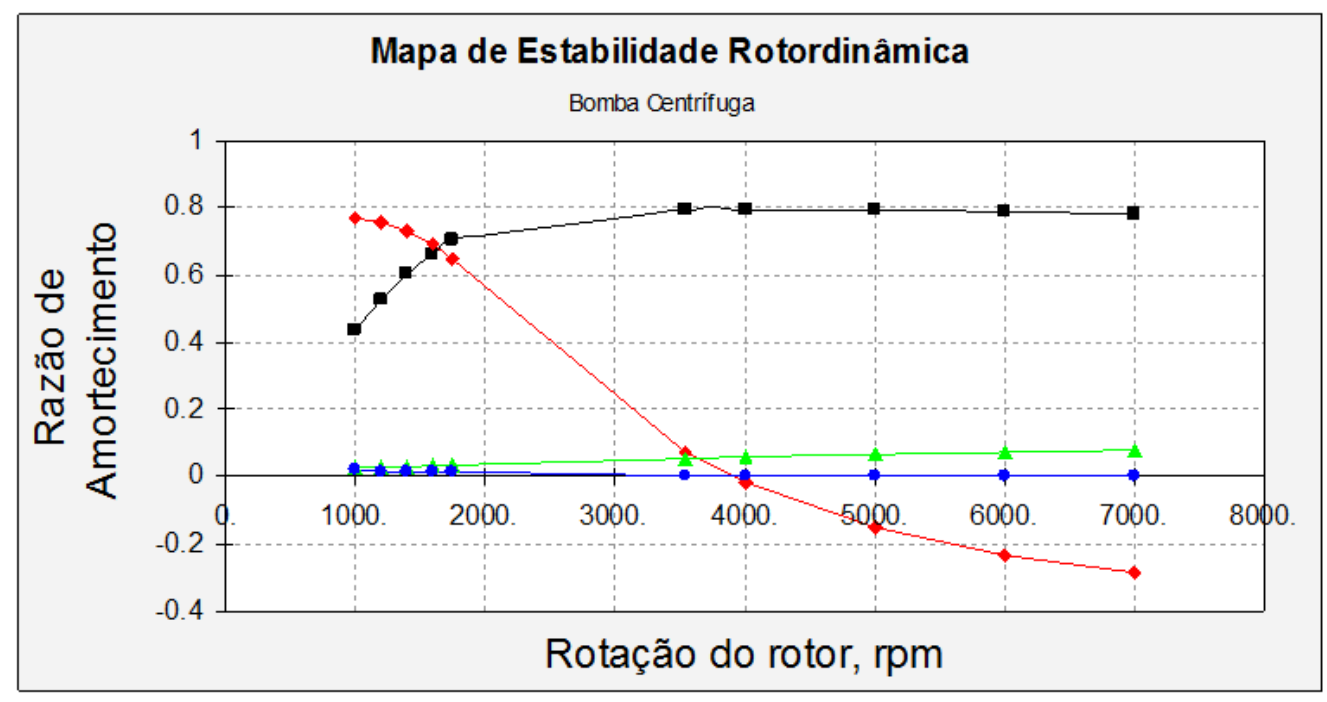

Figura 30 - Mapa de estabilidade rotordinâmica

Conforme mostrado no gráfico acima, o conjunto rotativo apresentaria instabilidade dinâmica no primeiro modo de vibrar forward representado pela linha vermelha, quando a rotação do rotor atingisse o valor de 4000rpm, pois o valor negativo da razão de amortecimento conduz a um modo de vibração divergente. Portanto, a frequência de 4000rpm é chamada de limiar de instabilidade. É usual considerar valores de razão de amortecimento menores que 0.05 ou decremento logarítmico menor que 0.1 como limiar de instabilidade para turbomáquinas como bomba, compressores e turbinas. O mapa de estabilidade também pode ser representado no eixo $Y$ pelo decremento logarítmico ou expoente de amortecimento, sendo que, quando o primeiro for negativo ou o último for positivo obtém uma região de instabilidade.

Já os autovetores, correspondentes aos seus respectivos autovalores, são utilizados para descrever a forma ("shape") que o rotor vibra em um determinado modo (frequência natural). A forma de vibrar do rotor pode ser apresentada em 2D conforme a figura 31 , ou pode ser mostrada em um "falso" $3 \mathrm{D}$ no qual a magnitude de vibração em cada ponto da malha é representado por uma órbita e a interligação dos pontos de amplitude máxima representa a forma de vibrar do rotor, conforme apresentado na figura 32 e 33. 


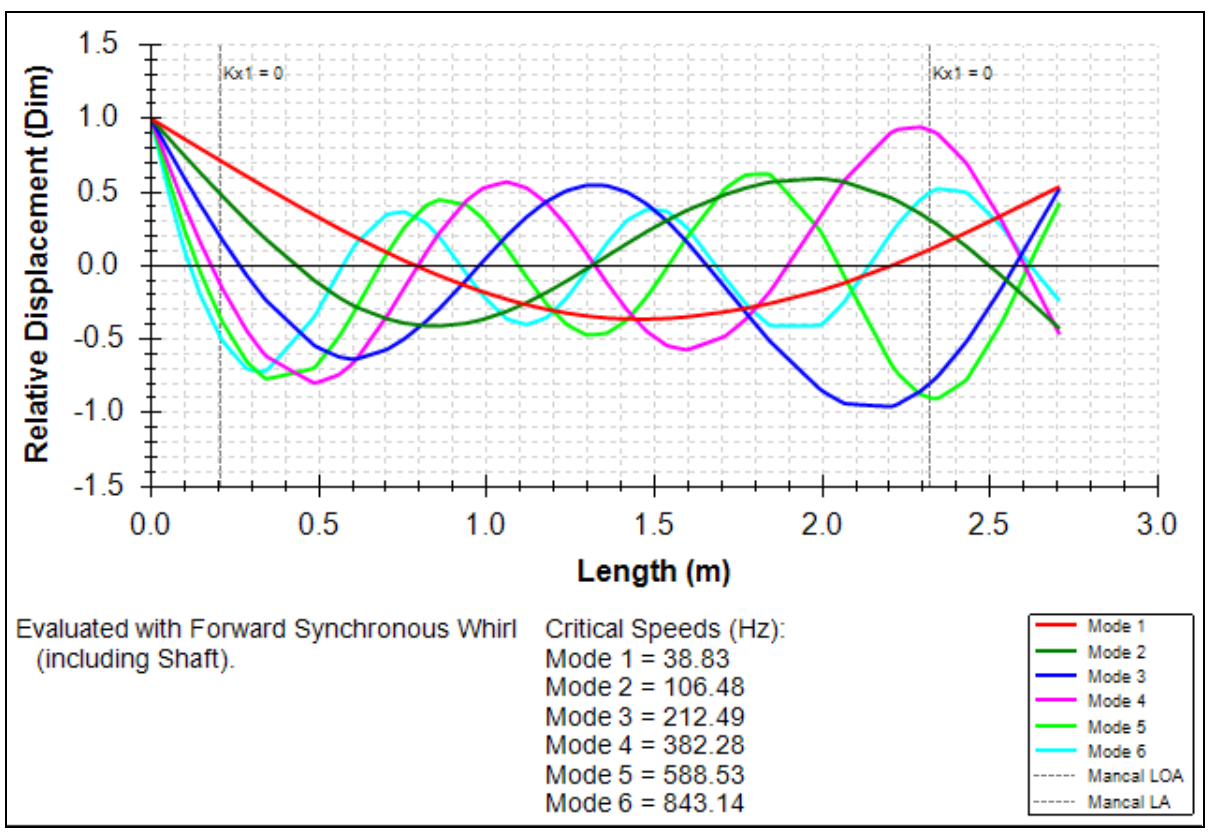

Figura 31 - Simulação dos modos de vibrar de uma bomba centrífuga

\section{Primeiro Modo de Vibrar ("First Mode Shape")}

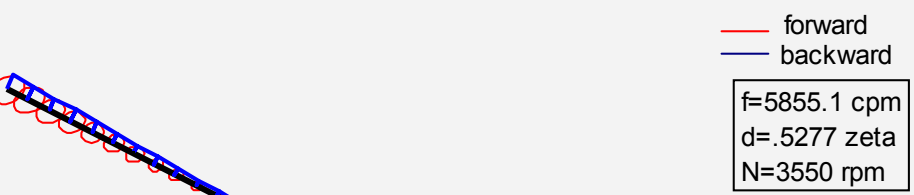

Figura 32 - Representação "3D" do primeiro modo de vibrar de um rotor 


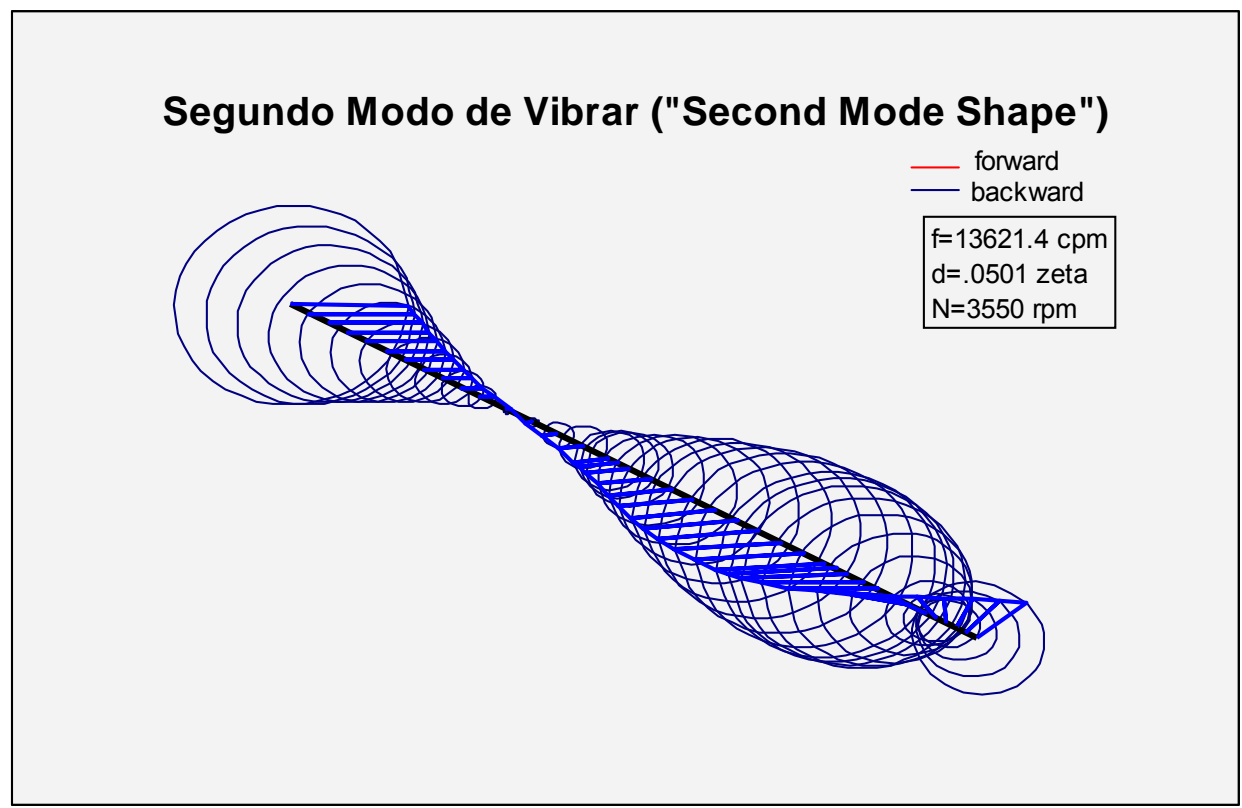

Figura 33 - Representação em "3D" do segundo modo de vibrar de um rotor

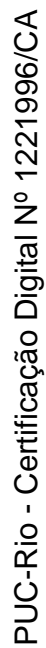




\section{7 \\ Metodologia}

As pesquisas realizadas para elaboração desta dissertação foram focadas em artigos sobre escoamentos em selos anulares de bombas e selo mecânico a óleo de compressores. Os resultados aqui obtidos foram comparados com testes realizados por outros autores, apresentados na referência bibliográfica, a fim de verificar se havia consistência nas considerações feitas.

O principal embasamento para elaboração deste trabalho foi a hipótese que a utilização do anel flutuante em detrimento ao anel estático permite sua instalação com uma folga $50 \%$ menor que o especificado pelo fabricante, sem haver risco de roçamento e travamento como ocorreria com a utilização com anéis fixos. A mesma redução de folga entre os anéis pode ser conseguida através da substituição do anel de desgaste de aço por outro material não metálico, conforme descrito na norma API $610-11^{\circ} \mathrm{Ed}$, pag.38:

"There are published data showing successful applications of nonmetallic wear-rig materials with API clearances reduced by 50\%. Reasonable reductions in clearances are believed to be dependent on the materials applied and other service conditions, such as cleanliness and temperature."

Portanto, todas as análises apresentadas neste trabalho são aplicáveis para utilização de anéis flutuantes ou anéis estáticos com material nãometálico.

Os dois tipos de bomba escolhidos para análise foram uma bomba centrífuga de simples estágio e uma com oito estágios. Para elaboração do modelo da bomba de simples estágio, foi elaborado o dimensional do conjunto rotativo com auxílio dos softwares Autocad e Ansys, de forma a obter as propriedades físicas dos componentes, principalmente a matriz de inércia do impelidor. 
Também foi feita a pesagem dos componentes separadamente para comparar com as informações obtidas no CAD.

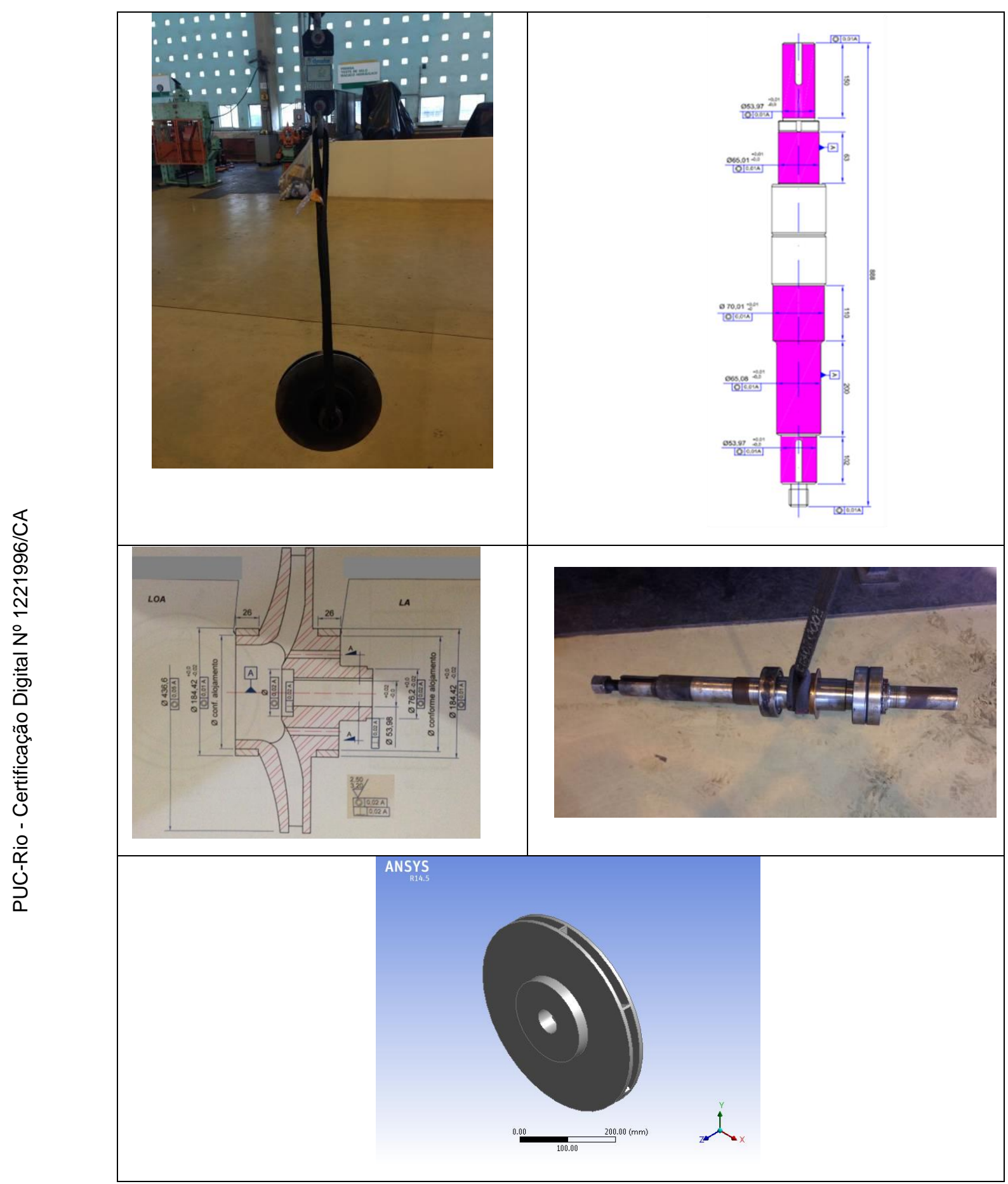

Figura 34 - Etapa do dimensionamento do conjunto rotativo 
Após serem obtidas todas as características físicas do rotor, as informações foram inseridas no programa XLTRC2 para gerar o modelo da bomba em elementos finitos com 38 elementos de malha, que foi definido de modo a obter a razão entre comprimento e diâmetro do elemento menor do que "1". A variação do módulo de elasticidade do eixo com a temperatura foi negligenciada, apesar de a bomba operar com temperaturas acima de $200^{\circ} \mathrm{C}$. Os dados do modelo do eixo e a representação do conjunto rotativo estão apresentados abaixo:

Tabela 2 - Dados de entrada dos elementos da malha do eixo

\begin{tabular}{|c|c|c|c|c|c|c|c|c|}
\hline \multirow{2}{*}{ Shaft } & \multirow{2}{*}{ Element } & \multirow{2}{*}{$\begin{array}{c}\text { Sub- } \\
\text { Element }\end{array}$} & \multirow{2}{*}{ Layer } & \multirow{2}{*}{ Length } & \multicolumn{2}{|c|}{ Left } & \multicolumn{2}{|c|}{ Right } \\
\hline & & & & & OD & ID & OD & ID \\
\hline \# & $\#$ & \# & $\#$ & meters & meters & meters & meters & meters \\
\hline 1 & 1 & 1 & 1 & 0.024892 & 0.053848 & 0 & 0.053848 & 0 \\
\hline 1 & 2 & 1 & 1 & 0.024892 & 0.053848 & 0 & 0.053848 & 0 \\
\hline 1 & 3 & 1 & 1 & 0.024892 & 0.053848 & 0 & 0.053848 & 0 \\
\hline 1 & 4 & 1 & 1 & 0.024892 & 0.053848 & 0 & 0.053848 & 0 \\
\hline 1 & 5 & 1 & 1 & 0.024892 & 0.053848 & 0 & 0.053848 & 0 \\
\hline 1 & 6 & 1 & 1 & 0.024892 & 0.053848 & 0 & 0.053848 & 0 \\
\hline 1 & 7 & 1 & 1 & 0.02413 & 0.06477 & 0 & 0.06477 & 0 \\
\hline 1 & 8 & 1 & 1 & 0.02413 & 0.06477 & 0 & 0.06477 & 0 \\
\hline 1 & 9 & 1 & 1 & 0.02413 & 0.06477 & 0 & 0.06477 & 0 \\
\hline 1 & 10 & 1 & 1 & 0.02413 & 0.06477 & 0 & 0.06477 & 0 \\
\hline 1 & 11 & 1 & 1 & 0.03302 & 0.07366 & 0 & 0.07112 & 0 \\
\hline 1 & 12 & 1 & 1 & 0.03302 & 0.07366 & 0 & 0.07112 & 0 \\
\hline 1 & 13 & 1 & 1 & 0.03302 & 0.07366 & 0 & 0.07112 & 0 \\
\hline 1 & 14 & 1 & 1 & 0.03302 & 0.07366 & 0 & 0.07112 & 0 \\
\hline 1 & 15 & 1 & 1 & 0.03302 & 0.07366 & 0 & 0.07112 & 0 \\
\hline 1 & 16 & 1 & 1 & 0.013716 & 0.069088 & 0 & 0.06985 & 0 \\
\hline 1 & 17 & 1 & 1 & 0.013716 & 0.069088 & 0 & 0.06985 & 0 \\
\hline 1 & 18 & 1 & 1 & 0.027432 & 0.069088 & 0 & 0.06985 & 0 \\
\hline 1 & 19 & 1 & 1 & 0.027432 & 0.069088 & 0 & 0.06985 & 0 \\
\hline 1 & 20 & 1 & 1 & 0.027432 & 0.069088 & 0 & 0.06985 & 0 \\
\hline 1 & 21 & 1 & 1 & 0.028448 & 0.06477 & 0 & 0.06477 & 0 \\
\hline 1 & 22 & 1 & 1 & 0.028448 & 0.06477 & 0 & 0.06477 & 0 \\
\hline 1 & 23 & 1 & 1 & 0.028448 & 0.06477 & 0 & 0.06477 & 0 \\
\hline 1 & 24 & 1 & 1 & 0.028448 & 0.06477 & 0 & 0.06477 & 0 \\
\hline 1 & 25 & 1 & 1 & 0.028448 & 0.06477 & 0 & 0.06477 & 0 \\
\hline 1 & 26 & 1 & 1 & 0.028448 & 0.06477 & 0 & 0.06477 & 0 \\
\hline 1 & 27 & 1 & 1 & 0.014224 & 0.06477 & 0 & 0.06477 & 0 \\
\hline 1 & 28 & 1 & 1 & 0.014224 & 0.06477 & 0 & 0.06477 & 0 \\
\hline 1 & 29 & 1 & 1 & 0.02032 & 0.053848 & 0 & 0.053848 & 0 \\
\hline 1 & 30 & 1 & 1 & 0.02032 & 0.053848 & 0 & 0.053848 & 0 \\
\hline 1 & 31 & 1 & 1 & 0.02032 & 0.053848 & 0 & 0.053848 & 0 \\
\hline 1 & 32 & 1 & 1 & 0.02032 & 0.053848 & 0 & 0.053848 & 0 \\
\hline 1 & 33 & 1 & 1 & 0.02032 & 0.053848 & 0 & 0.053848 & 0 \\
\hline 1 & 34 & 1 & 1 & 0.013462 & 0.0254 & 0 & 0.0254 & 0 \\
\hline 1 & 35 & 1 & 1 & 0.013462 & 0.0254 & 0 & 0.0254 & 0 \\
\hline 1 & 36 & 1 & 1 & 0.013462 & 0.0254 & 0 & 0.0254 & 0 \\
\hline 1 & 37 & 1 & 1 & 0.013462 & 0.0254 & 0 & 0.0254 & 0 \\
\hline 1 & 38 & 1 & 1 & 0.013462 & 0.0254 & 0 & 0.0254 & 0 \\
\hline
\end{tabular}




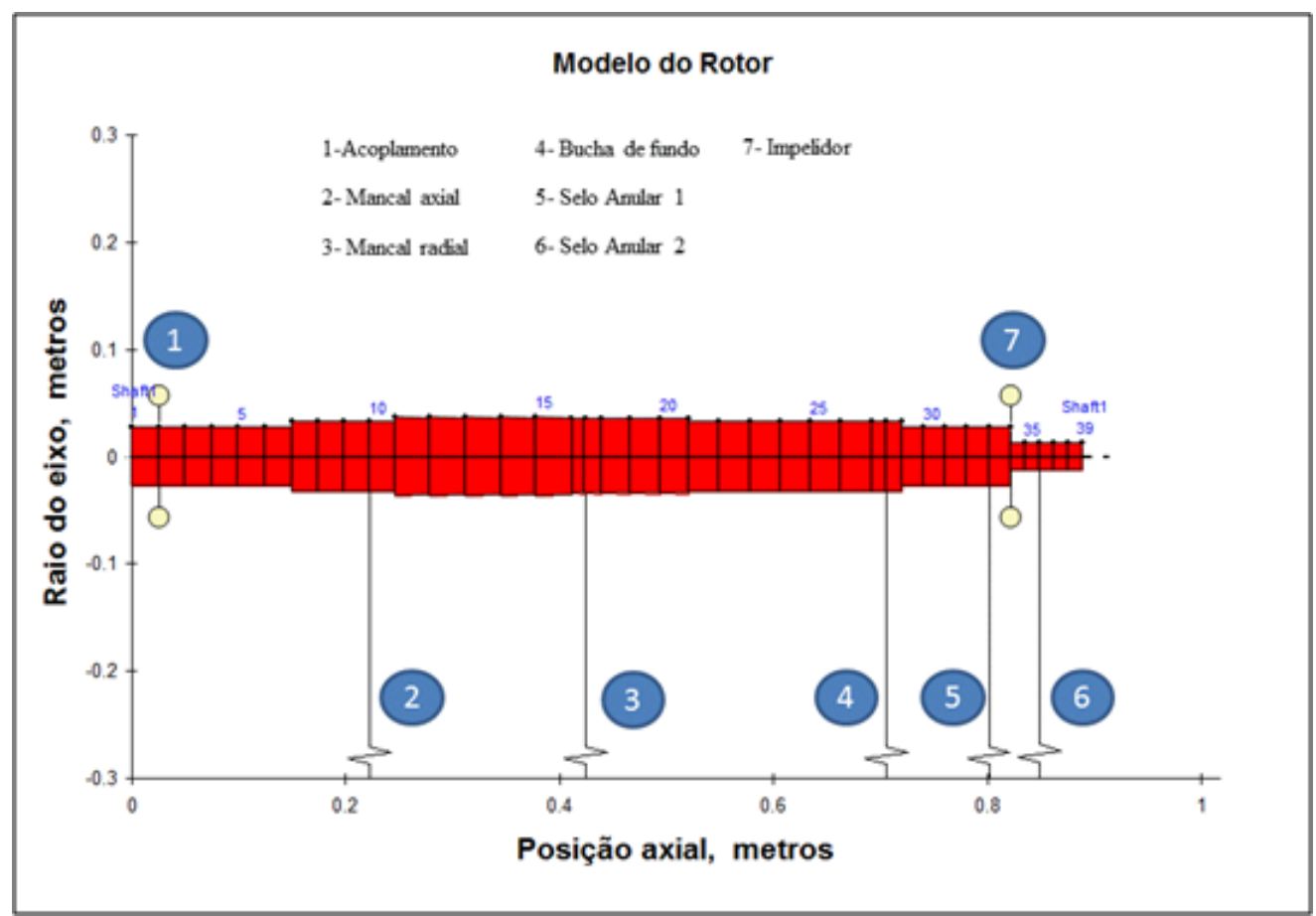

Figura 35 - Representação do modelo do conjunto rotativo

Tabela 3 - Propriedades mecânica do eixo

\begin{tabular}{|c|c|c|c|c|c|}
\hline \multicolumn{6}{|c|}{ Material Properties } \\
\hline Material & $\begin{array}{c}\text { Shear } \\
\text { Const }\end{array}$ & $\begin{array}{c}\text { Axial } \\
\text { Force } \\
\text { Const }\end{array}$ & $\begin{array}{c}\text { Density } \\
\rho\end{array}$ & $\begin{array}{c}\text { Elastic } \\
\text { Modulus } \\
\mathrm{E}\end{array}$ & $\begin{array}{c}\text { Shear } \\
\text { Modulus } \\
\mathrm{G}\end{array}$ \\
\hline$\#$ & $(\mathrm{sc}$ or -1$)$ & $(\mathrm{ax}$ or 0$)$ & $\mathrm{kg} / \mathrm{m}^{3}$ & $\mathrm{~N} / \mathrm{m}^{2}$ & $\mathrm{~N} / \mathrm{m}^{2}$ \\
\hline 1 & -1 & 0 & 7833.412 & $206.8 \mathrm{E}+9$ & $82.7 \mathrm{E}+9$ \\
\hline
\end{tabular}

As rigidezes, $K_{y y}$ e $K_{x x}$, dos mancais de rolamento foram consideradas constantes, pois estes normalmente trabalham sob condições de rotação baixa e estável. Portanto, as forças centrífugas e/ou momentos giroscópios possuem baixa magnitude nestas condições de forma a não influenciar significativamente na distribuição de carga sobre o rolamento. Adicionalmente, as forças de fricção e momentos atuantes nos elementos girantes também foram desprezadas para o caso analisado.

A rigidez de um rolamento de esferas é caracterizada pela magnitude da deformação elástica (deflexão) no rolamento sob carga. Ela é expressa como a relação entre a carga e a deflexão e depende do tipo, projeto e tamanho do rolamento. Os parâmetros mais importantes são: 
- Tipo de corpos rolantes.

- Material dos corpos rolantes

- Número e tamanho de corpos rolantes

- Ângulo de contato

- Classe de pré-carga

De acordo com Harris (2001) a rigidez direta do rolamento pode ser estimada através da seguinte equação:

$$
K=1.174,3 \cdot z^{\frac{2}{3}} \cdot D^{\frac{1}{3}} \cdot(\cos (\alpha))^{\frac{5}{3}} \cdot F_{r}^{\frac{1}{3}}
$$

onde:

$\mathrm{K}(\mathrm{N} / \mathrm{mm})$ : rigidez do rolamento em $X\left(K_{x x}\right)$ e $Y\left(K_{y y}\right)$

z: número de esferas do rolamento

$\alpha$ : ângulo de contato do rolamento em graus

$\mathrm{F}_{\mathrm{r}}$ : Força radial atuando no rolamento em $\mathrm{N}$

D:diâmetro da esfera ( $\mathrm{mm}$ )

De acordo com as informações do fabricante do rolamento, SKF, conforme apresentado no gráfico da figura 36 , a rigidez do rolamento radial de aço possui os seguintes valores conforme o fator de velocidade (A) do rolamento:

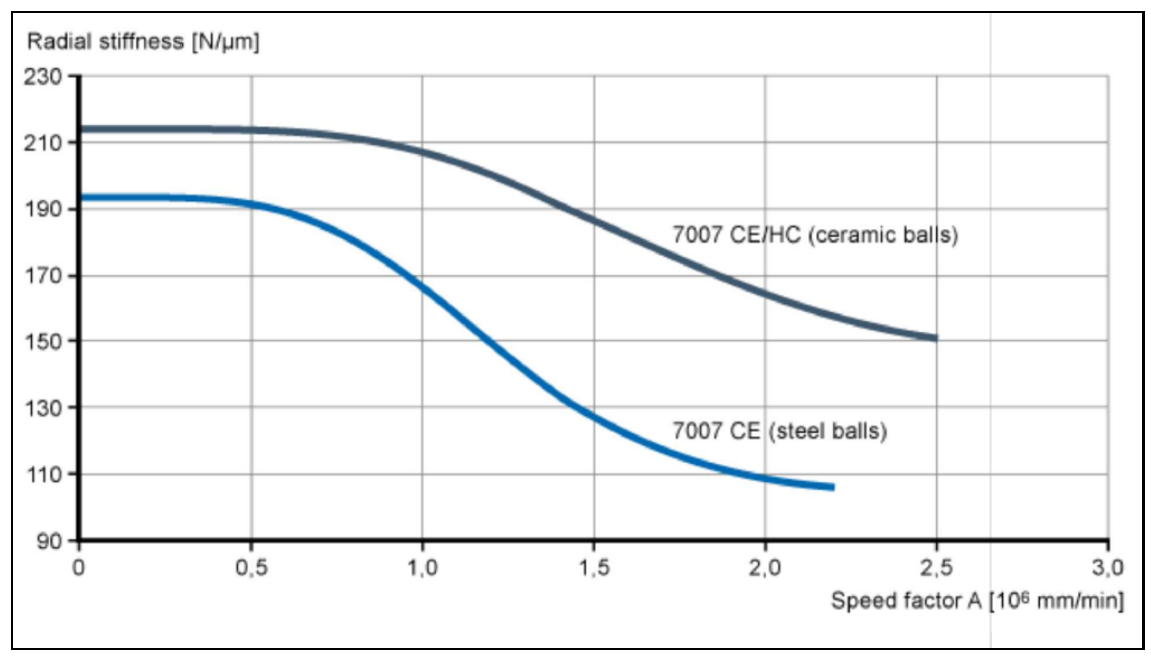

Figura 36 - Variação da rigidez radial com o fator de velocidade - site da SKF 
O fator de velocidade (A) é definido como: $A=\omega . d m$, onde:

$>d m(m m)=0,5 x(d+D)$

> $\omega$ : rotação do rolamento em rpm

$>\quad d$ : diâmetro interno do rolamento

> D: diâmetro externo do rolamento

O valor do fator de velocidade no caso apresentado é de 0.34 , logo, o valor da rigidez do rolamento utilizado na simulação será de $190 \mathrm{~N} / \mu \mathrm{m}$, já que este valor se aproxima ao calculado utilizando a fórmula proposta por Harris. Os coeficientes de rigidez cruzados e de amortecimento do rolamento foram considerados desprezíveis, assim como a influência do suporte da bomba.

Em relação ao impelidor e ao acoplamento (cubo mais a metade do espaçador), estes componentes foram modelados como corpos que possuem massa, momento de inércia polar e transversal e não oferecem rigidez ao sistema (ver tabela 4). Eles foram inseridos no modelo na posição axial dos seus referidos centros de massa. As propriedades físicas do acoplamento foram adquiridas no manual do fabricante.

Tabela 4 - Propriedades físicas do impelidor (34) e acoplamento (2)

\begin{tabular}{|c|c|c|c||}
\hline \multicolumn{5}{|c|}{ Added Mass \& Inertia } \\
\hline STN & $\begin{array}{c}\text { Added } \\
\text { Mass }\end{array}$ & $\begin{array}{c}\text { Added } \\
\text { I }\end{array}$ & $\begin{array}{c}\text { Added } \\
\text { It }\end{array}$ \\
\hline$\#$ & $\mathrm{Kg}$ & $\mathrm{Kg}-\mathrm{m}^{2}$ & $\mathrm{Kg}-\mathrm{m}^{2}$ \\
\hline 34 & 28.12 & 0.537572 & 0.268786 \\
\hline 2 & 3.29 & 0.006278 & 0.005063 \\
\hline \hline
\end{tabular}

O selo mecânico não foi inserido na modelagem, pois massa e rigidez dos componentes rotativos são desprezíveis ao sistema.

O sistema mecânico (rotor, rolamento, anéis de desgaste e bucha de fundo) foi abordado como linear e submetido à carga estática (peso) e dinâmica (desbalanceamento) em regime permanente.

Os coeficientes dinâmicos dos anéis de desgaste e bucha de fundo foram obtidos através do software Romac. Os mesmos não foram obtidos através do XLTRC2, pois o autor não encontrou informações de testes no manual e/ou 
artigos que validassem os dados simulados com os obtidos em testes de bancada para selo anular com o número de Reynolds axial maior que 50.000, como apresentado no manual do Romac. A metodologia para determinação dos coeficientes dos selos anulares está apresentada no capítulo "Escoamento através do selo anular", no qual as informações foram obtidas no manual do código do Romac.

Os coeficientes da bucha de fundo, considerando uma posição concêntrica, obtidos através do Romac foram:

Tabela 5 - Coeficientes dinâmicos da bucha de fundo

\begin{tabular}{|c|l|}
\hline Rigidez & Amortecimento \\
$K x x=4.65 \times 10^{5} \mathrm{~N} / \mathrm{m}$ & $C x x=4.75 \times 10^{3} \mathrm{~N} . \mathrm{s} / \mathrm{m}$ \\
$K x y=5.1 \times 10^{5} \mathrm{~N} / \mathrm{m}$ & $C x y=-4.25 \times 10^{2} \mathrm{~N} . \mathrm{s} / \mathrm{m}$ \\
$K y x=-5.1 \times 10^{5} \mathrm{~N} / \mathrm{m}$ & $C y x=-4.23 \times 10^{2} \mathrm{~N} . \mathrm{s} / \mathrm{m}$ \\
$K y y=4.67 \times 10^{5} \mathrm{~N} / \mathrm{m}$ & $C y y=2.76 \times 10^{3} \mathrm{~N} . \mathrm{s} / \mathrm{m}$ \\
\hline
\end{tabular}

As seguintes propriedades da bomba e fluido de processo foram utilizadas na simulação:

Tabela 6 - Dados de processo da bomba centrífuga simples estágio

\begin{tabular}{|l|l|}
\hline Densidade: $775 \mathrm{~kg} / \mathrm{m}^{3}$ & Vazão de bombeio: $4.872 \mathrm{~m}^{3} / \mathrm{dia}$ \\
Rotação do eixo: $3550 \mathrm{rpm}$ & Temperatura de bombeio: $217^{\circ} \mathrm{C}$ \\
Fluido: óleo leve de reciclo & Diferencial de pressão no selo: $2220 \mathrm{kPa}$ \\
Potência: $196 \mathrm{~kW}$ & Viscosidade dinâmica: $0,000233 \mathrm{~N} . \mathrm{s} / \mathrm{m}^{2}$ \\
\hline
\end{tabular}

Após adquiridas todas as informações para elaboração do modelo que representasse o sistema mecânico da bomba, foram feitas simulações para calcular a resposta ao desbalanceamento, fator de amortecimento e frequências críticas, assim como os coeficientes dinâmicos dos anéis de desgaste para diferentes parâmetros do selo anular como apresentado na tabela 7 abaixo. A folga radial mínima de $0.35 \mathrm{~mm}$ estabelecida para o anel fixo foi devido ao travamento entre selo rotativo e estático na tentativa de operar o equipamento utilizando folgas menores. Para cada folga entre os anéis, foram determinados os coeficientes 
dinâmicos variando a excentricidade do anel rotativo e o tipo de superfície do selo, liso ou ranhurado.

Tabela 7 - Parâmetros do selo anular

\begin{tabular}{|c|c|c|c|c|c|c|c|}
\hline Casos & $\begin{array}{c}\text { Tipo do } \\
\text { Anel }\end{array}$ & $e$ & $\begin{array}{c}\mathrm{h} \\
(\mathrm{mm})\end{array}$ & $\begin{array}{c}\mathrm{L} \\
(\mathrm{mm})\end{array}$ & $\operatorname{Lr}(\mathrm{mm})$ & $\mathrm{G}(\mathrm{mm})$ & NR \\
\hline Caso 1 & fixo & 0 & 0.6 & 0.83 & 2.28 & 1 & 10 \\
\hline Caso 2 & fixo & 0.9 & 0.6 & 0.83 & 2.28 & 1 & 10 \\
\hline Caso 3 & fixo & 0 & 0.6 & 32 & - & - & 0 \\
\hline Caso 4 & fixo & 0.9 & 0.6 & 32 & - & - & 0 \\
\hline Caso 5 & fixo & 0 & 0.35 & 0.83 & 2.28 & 1 & 10 \\
\hline Caso 6 & fixo & 0.9 & 0.35 & 0.83 & 2.28 & 1 & 10 \\
\hline Caso 7 & fixo & 0 & 0.35 & 32 & - & - & 0 \\
\hline Caso 8 & fixo & 0.9 & 0.35 & 32 & - & - & 0 \\
\hline Caso 9 & flutuante & 0 & 0.25 & 0.83 & 2.28 & 1 & 10 \\
\hline Caso 10 & flutuante & 0.9 & 0.25 & 0.83 & 2.28 & 1 & 10 \\
\hline Caso 11 & flutuante & 0 & 0.25 & 32 & - & - & 0 \\
\hline Caso 12 & flutuante & 0.9 & 0.25 & 32 & - & - & 0 \\
\hline Caso 13 & flutuante & 0 & 0.20 & 0.83 & 2.28 & 1 & 10 \\
\hline Caso 14 & flutuante & 0.9 & 0.20 & 0.83 & 2.28 & 1 & 10 \\
\hline Caso 15 & flutuante & 0 & 0.20 & 32 & - & - & 0 \\
\hline Caso 16 & flutuante & 0.9 & 0.20 & 32 & - & - & 0 \\
\hline
\end{tabular}

e: excentricidade; h: folga radial; L: largura do anel; Lr: largura da ranhura;

G: profundidade da ranhura; NR: número de ranhuras

A massa de desbalanceamento, localizada no impelidor, utilizada na simulação foi de $0.00054 \mathrm{~kg} . \mathrm{m}$.

Em relação à bomba centrífuga multiestágios, a metodologia aplicada foi semelhante à aplicada para o rotor de simples estágio, no qual o desenho de corte da bomba, os dados físicos do conjunto rotativo e seu modelo estão representados pelas figuras 25, 26 e 27, respectivamente. As informações com as propriedades dos 34 elementos de malha utilizados para representar o conjunto rotativo estão representados na tabela 7 . Diferentemente da bomba de simples estágio, todas as 
simulações referentes ao conjunto rotativo de oito estágios foram feitas utilizando o Romac.

A terceira coluna da tabela 8 , diâmetro externo $(O D m)$, representa o diâmetro do elemento da malha que contribui para as inércias do sistema. Já o diâmetro externo $O D K$, mostrado na quarta coluna, condizem o diâmetro da malha que contribui para a rigidez do sistema.

Tabela 8 - Dados de entrada dos elementos da malha do eixo da bomba multiestágios

\begin{tabular}{|c|c|c|c|c|c|}
\hline Seção & Largura & $O D m(\mathrm{~m})$ & $O D K(\mathrm{~m})$ & Massa $(\mathrm{kg})$ & $\begin{array}{c}\text { Posição } \\
\text { axial }\end{array}$ \\
\hline$\overline{11}$ & 0.03 & 0.065 & 0.04 & 7.7953E-001 & 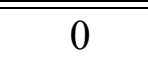 \\
\hline 2 & 0.027 & 0.075 & 0.047 & "9.3405E-001 & 0.03 \\
\hline 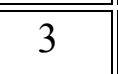 & 0.043 & 0.224 & 0.052 & 13.269 & 0.057 \\
\hline 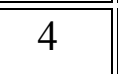 & 0.048 & 0.075 & 0.075 & 1.6605 & 0.1 \\
\hline 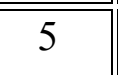 & 0.062 & 0.09 & 0.09 & 3.0886 & 0.148 \\
\hline 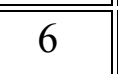 & 0.075 & 0.09 & 0.09 & 3.7362 & 0.21 \\
\hline 7 & 0.058 & 0.095 & 0.095 & 3.2193 & 0.285 \\
\hline 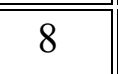 & 0.1425 & 0.107 & 0.095 & 10.034 & 0.343 \\
\hline 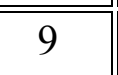 & 0.0725 & 0.095 & 0.095 & 4.0241 & 0.4855 \\
\hline 10 & 0.0345 & 0.12 & 0.095 & 3.0554 & 0.558 \\
\hline 11 & 0.022 & 0.12 & 0.08 & 1.9484 & 0.5925 \\
\hline 12 & 0.0875 & 0.1947 & 0.1 & 20.4 & 0.6145 \\
\hline 13 & 0.0529 & 0.1947 & 0.1 & 12.333 & 0.702 \\
\hline 14 & 0.1043 & 0.1 & 0.1 & 6.4146 & 0.7549 \\
\hline 15 & 0.1297 & "0.1 & 0.1 & 7.9767 & 0.8592 \\
\hline 16 & 0.1297 & 0.1 & 0.1 & 7.9767 & 0.9889 \\
\hline 17 & 0.1197 & 0.1 & 0.1 & 7.3617 & 1.1186 \\
\hline 18 & 0.1197 & 0.1 & 0.1 & 7.3617 & 1.2383 \\
\hline 19 & 0.1197 & 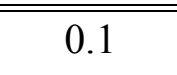 & 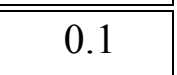 & 7.3617 & 1.358 \\
\hline 20 & 0.1197 & 0.1 & 0.1 & 7.3617 & 1.4777 \\
\hline
\end{tabular}




\begin{tabular}{|r|r|r||c|c|c||}
\hline \multicolumn{1}{|r|}{21} & 0.111 & 0.11 & 0.11 & 8.2602 & 1.5974 \\
\hline \hline 22 & 0.137 & 0.11 & 0.11 & 10.195 & 1.7084 \\
\hline \hline 23 & 0.1485 & 0.1 & 0.1 & 9.133 & 1.8454 \\
\hline \hline 24 & 0.0725 & 0.095 & 0.095 & 4.0241 & 1.9939 \\
\hline \hline 25 & 0.1355 & 0.1065 & 0.095 & 9.452 & 2.0664 \\
\hline \hline 26 & 0.025 & 0.145 & 0.09 & 3.2327 & 2.2019 \\
\hline \hline 28 & 0.063 & 0.095 & 0.095 & 3.4968 & 2.2269 \\
\hline \hline 29 & 0.055 & 0.09 & 0.09 & 2.7399 & 2.2899 \\
\hline \hline 30 & 0.105 & 0.09 & 0.09 & 5.2307 & 2.4299 \\
\hline \hline 31 & 0.0432 & 0.0873 & 0.0873 & 2.0249 & 2.5349 \\
\hline \hline 32 & 0.0237 & 0.0859 & 0.0859 & 1.0755 & 2.5781 \\
\hline \hline 33 & 0.065 & 0.0819 & 0.0819 & 2.6814 & 2.6018 \\
\hline \hline 34 & 0.04 & 0.06 & 0.06 & $8.8562 \mathrm{E}-001$ & 2.6668 \\
\hline \hline
\end{tabular}

Tabela 9 - Propriedades mecânicas do eixo da bomba multiestágios

\begin{tabular}{|l|l|l|l|l}
\hline & Temperature $(\mathrm{K})$ & Density $\left(\mathrm{kg} / \mathrm{m}^{3}\right)$ & Modulus (Pa) & Poisson Ratio \\
\hline & 283.15 & $7,830.6$ & $199,540,000,000$ & 0.29 \\
\hline
\end{tabular}

Para o cálculo dos coeficientes dinâmicos dos anéis de desgaste lisos e fixos presentes na sucção de cada impelidor, foi considerada a folga média durante a meia-vida do anel de desgaste, que representa a média entre a folga do anel novo e a folga máxima estabelecida pelo fabricante. Já para o anel de desgaste flutuante, foi considerada uma folga de $70 \%$ da mínima estabelecida pelo fabricante.

Todos os anéis da bomba multiestágios foram considerados operando em uma posição concêntrica, com o coeficiente de perda na entrada de 0,1 e coeficiente de recuperação de pressão na saída de 0.8. A razão entre a velocidade de rotação do rotor e a de precessão da órbita considerada foi de 0.5 .

A influência dos anéis de desgaste intermediários e das buchas presentes no conjunto rotativo foi negligenciada de forma a deixar o rotor mais flexível, 
fazendo que a resposta ao desbalanceamento do sistema se tornasse mais sensível às condições dos selos anulares da sucção.

Os dados de entrada dos componentes da bomba centrífuga multiestágios são apresentados abaixo:

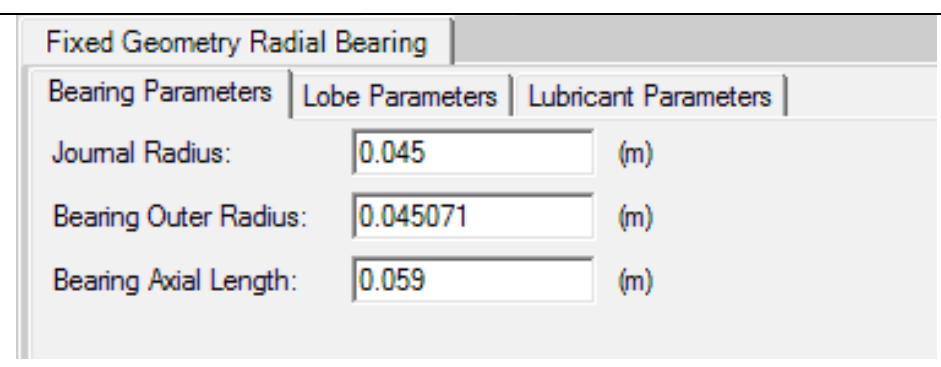

Posição axial do mancal lado acoplado: $0.21 \mathrm{~m}$

Posição axial do mancal lado não acoplado: $2.325 \mathrm{~m}$

Figura 37 - Mancais hidrodinâmicos no lado acoplado e lado desacoplado

\begin{tabular}{|c|c|c|c|}
\hline \multicolumn{4}{|c|}{ Fixed Geometry Radial Bearing } \\
\hline \multicolumn{2}{|c|}{ Bearing Parameters | Lobe Parameters } & Lubricant Parameters & \\
\hline Fluid Density: & 836 & $\left(\mathrm{~kg} / \mathrm{m}^{3}\right)$ & \\
\hline Fluid Specific Heat: & 1.951 & $(\mathrm{~J} / \mathrm{kg}-\mathrm{K})$ & \\
\hline Fluid Thermal Conductivity: & 0.14954 & $(\mathrm{~W} / \mathrm{K}-\mathrm{m})$ & \\
\hline Supply Line Temperature: & 322.04 & $(\mathrm{~K})$ & \\
\hline Viscosity at First Temperature & & 0.01414 & (Pa-sec) \\
\hline
\end{tabular}

Figura 38 - Dados do óleo de lubrificação

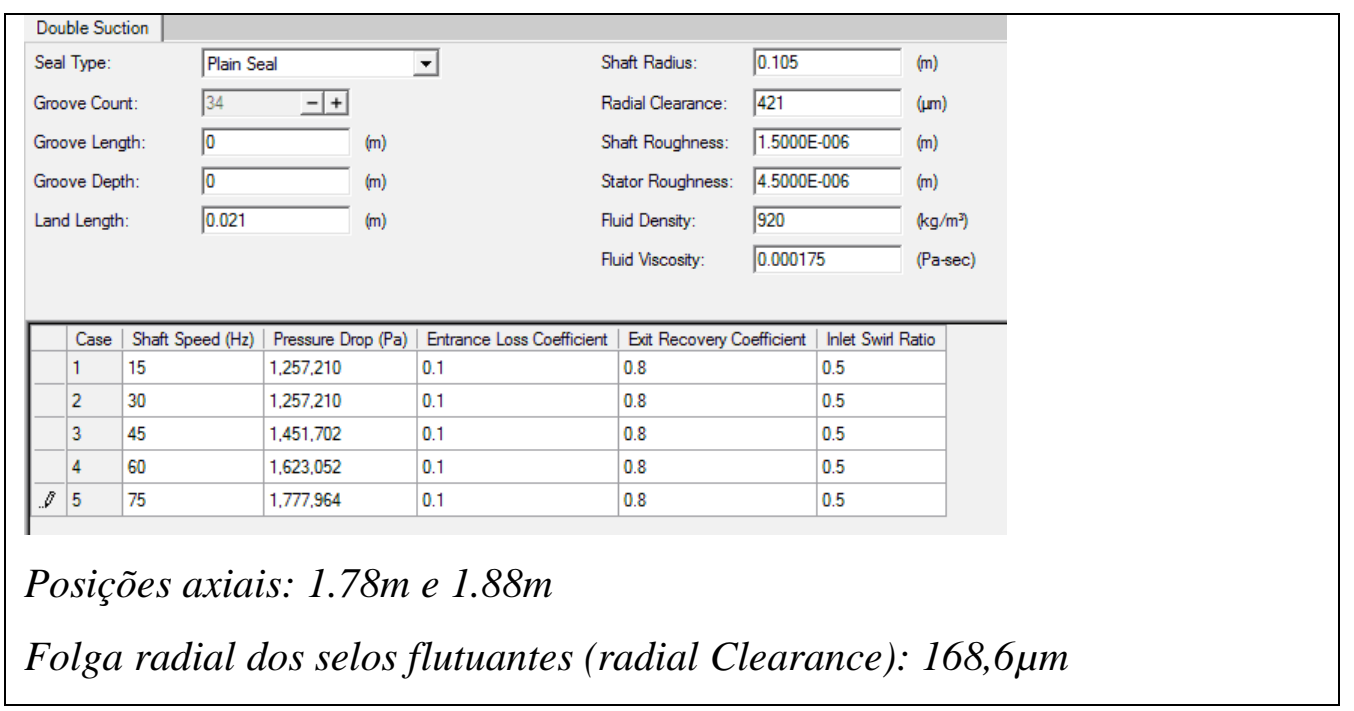

Figura 39 - Selos anulares do rotor do primeiro estágio 


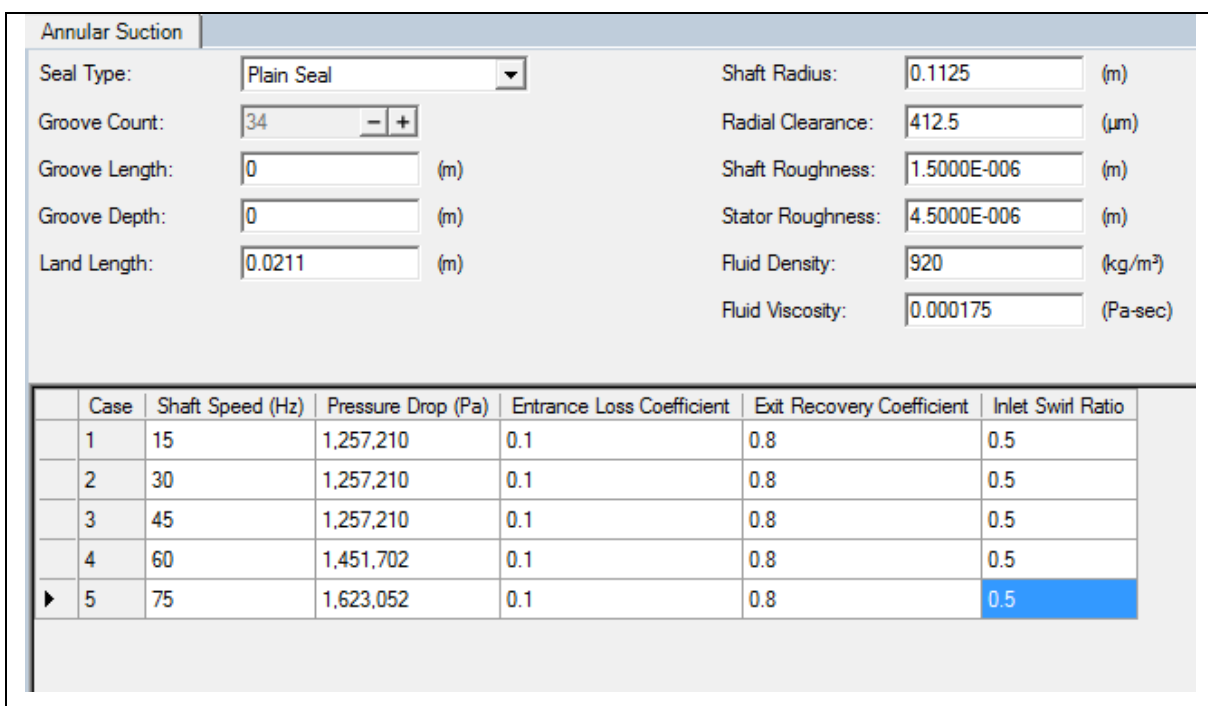

Posições axiais:0.93; 1.05; 1.17; 1.29; 1.41; 1.53; 1.66m

Folga radial dos selos flutuantes (radial Clearance): $165 \mu \mathrm{m}$

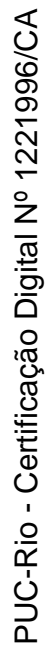

Figura 40 - Dados do selo na sucção do $2^{\circ}$ ao $8^{\circ}$ estágio

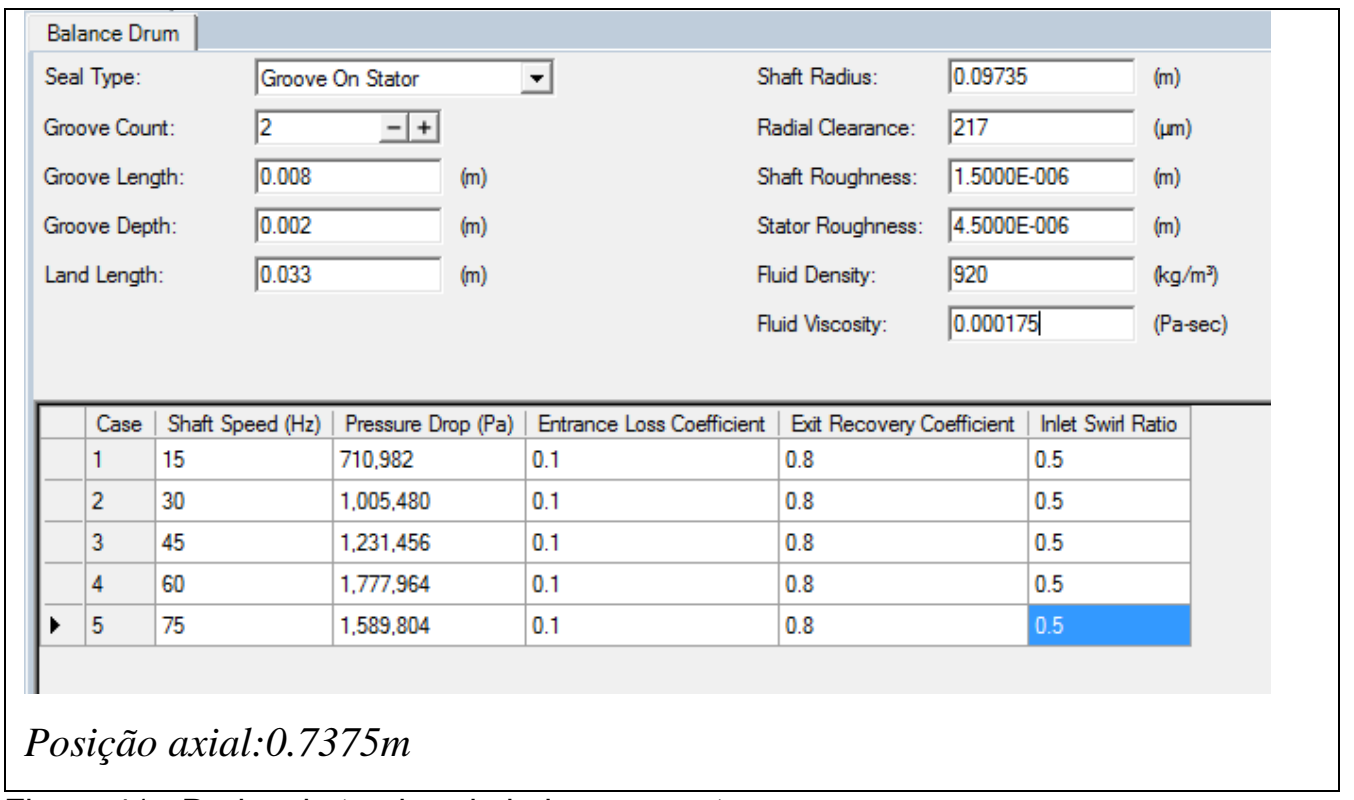

Figura 41 - Dados do tambor de balanceamento 
Tabela 10 - Dados dos impelidores e acoplamento ${ }^{1}$

\begin{tabular}{|c|c|c|c|c|}
\hline Disco & $\begin{array}{c}\text { Posição axial } \\
(\mathrm{m})\end{array}$ & Massa $(\mathrm{kg})$ & $\begin{array}{c}\text { Momento de } \\
\text { Inércia polar } \\
\left(\mathrm{kg}-\mathrm{m}^{2}\right)\end{array}$ & $\begin{array}{c}\text { Momento de } \\
\text { Inércia transversal } \\
\left(\mathrm{kg}-\mathrm{m}^{2}\right)\end{array}$ \\
\hline Acoplamento & 2.647 & 50.5 & 0.398 & 0.3 \\
\hline $1^{\circ}$ impelidor & 1.771 & 17.2 & 0.155 & 0.089 \\
\hline $2^{\circ}$ impelidor & 1,537 & 19.8 & 0.257 & 0.126 \\
\hline $3^{\circ}$ impelidor & 1,418 & 19.8 & 0.257 & 0.126 \\
\hline $4^{\circ}$ impelidor & 1,298 & 19.8 & 0.257 & 0.126 \\
\hline $5^{\circ}$ impelidor & 1,178 & 19.8 & 0.257 & 0.126 \\
\hline $6^{\circ}$ impelidor & 1,059 & 19.8 & 0.257 & 0.126 \\
\hline $7^{\circ}$ impelidor & 0,939 & 19.8 & 0.257 & 0.126 \\
\hline $8^{\circ}$ impelidor & 0,819 & 19.8 & 0.257 & 0.126 \\
\hline
\end{tabular}

1 Informações obtidas na folha de dados do equipamento

Para análise da resposta ao desbalanceamento foi utilizado o critério da norma API 610, no qual foi aplicado um desbalanceamento grau 4 para o acoplamento e grau 10 para os impelidores, sendo que as fases das massas de desbalanceamento foram definidas aleatoriamente, conforme tabela abaixo:

Tabela 11 - Distribuição de massa de desbalanceamento

\begin{tabular}{|c|c|c|}
\hline Disco & $\begin{array}{c}\text { Desbalanceamento } \\
\text { (kg.m) }\end{array}$ & $\begin{array}{c}\text { Fase } \\
\text { (graus) }\end{array}$ \\
\hline Acoplamento & $5.0 \times 10^{-04}$ & 0 \\
\hline $1^{\circ}$ impelidor & $4.0 \times 10^{-04}$ & 30 \\
\hline $2^{\circ}$ impelidor & $2.0 \times 10^{-04}$ & 180 \\
\hline $3^{\circ}$ impelidor & $2.0 \times 10^{-04}$ & 60 \\
\hline $4^{\circ}$ impelidor & $2.0 \times 10^{-04}$ & 75 \\
\hline $5^{\circ}$ impelidor & $2.0 \times 10^{-04}$ & 5 \\
\hline $6^{\circ}$ impelidor & $2.0 \times 10^{-04}$ & 30 \\
\hline $7^{\circ}$ impelidor & $2.0 \times 10^{-04}$ & 130 \\
\hline $8^{\circ}$ impelidor & $2.0 \times 10^{-04}$ & 180 \\
\hline Disco de escora & $3.0 \times 10^{-04}$ & 0 \\
\hline
\end{tabular}

Após obtidos todos os parâmetros para simulação da análise lateral da bomba multiestágios, foram feitas simulações para obtenção da influência dos anéis de desgaste nos valores das três primeiras frequências naturais amortecidas e seus respectivos fatores de amortecimento, amplitude de vibração nos mancais e nas posições axiais das faces dos selos mecânicos e a redução da força nos mancais ao substituir o anel estático pelo flutuante. 


\section{8 \\ Resultados}

\section{1.}

\section{Bomba centrífuga de simples estágio}

Inserindo o valor da rigidez dos mancais no mapa das frequências naturais não amortecidas, identificou-se que a frequência natural seca da bomba é de 4000rpm. Este valor condiz com o medido em "campo". aproximando desta forma do modelo apresentado (ver figuras 42 e 43).

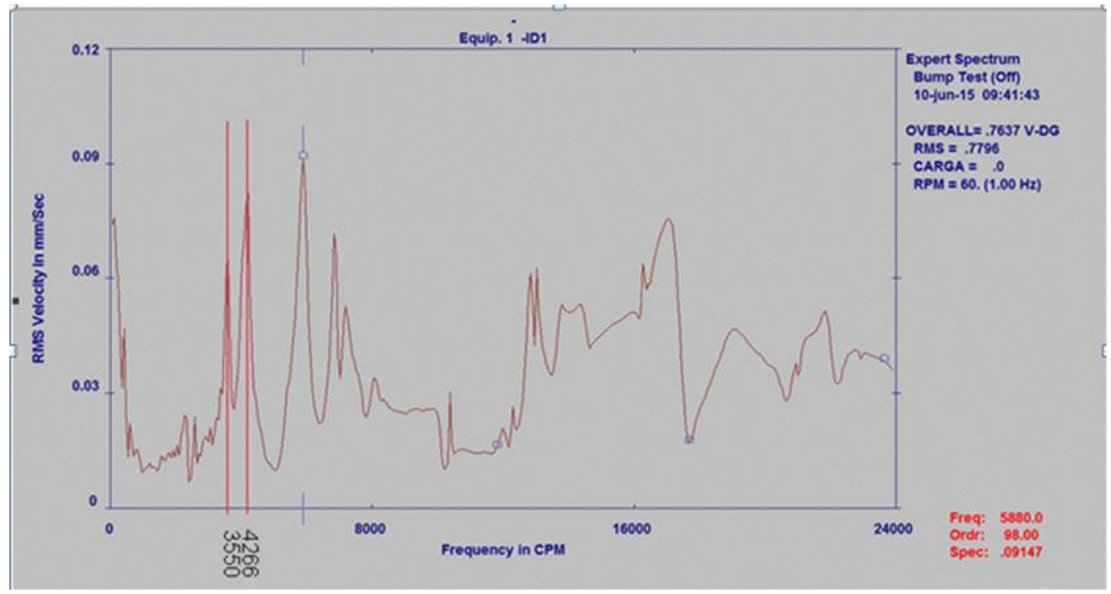

Figura 42 - Medição da frequência natural da bomba com suporte

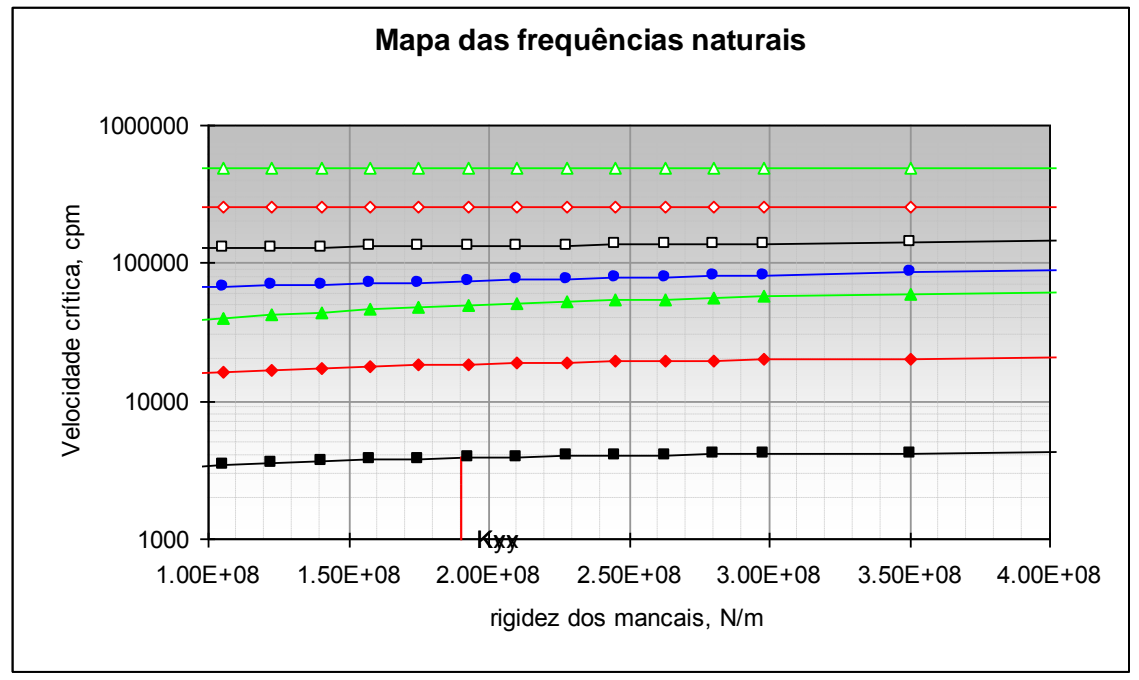

Figura 43 - Mapa das frequências naturais não amortecidas 
Os gráficos apresentados nas figuras 44 a 51 mostram como os valores dos coeficientes dinâmicos obtidos nas simulações variam com a excentricidade, folga e tipo de superfície do selo anular.

Como a excentricidade foi variada alterando a posição do centro do eixo apenas no sentido de ' $y$ ', ou seja, o valor do deslocamento em ' $x$ ' foi mantido constante e igual a zero, os coeficientes tiveram uma variação mais expressiva em ' $y$ '.

A variação dos coeficientes dinâmicos com a excentricidade é significativa apenas quando esta é igual ou maior que 0,8 . Portanto, a resposta do rotor a forças externas não teria alteração considerável em relação à posição excêntrica de operação do anel anular rotativo.

Comparando-se o anel liso com o ranhurado, este último seria mais viável caso a bomba apresente problema de instabilidade fluido-dinâmica, pois este último permite valores de rigidez cruzada consideravelmente menores. Outra forma de reduzir a rigidez $K_{x y}$ e $K_{y x}$ pode ser instalanado aletas (conhecidas como swirl brakes) na entrada do selo anular para que a pré-rotação do fluido seja reduzida. Como mostrado pela figura 14, este dispositivo pode permitir a redução de $K_{y x}$ para valores negativos, eliminando completamente esta fonte de instabilidade.

Diferentemente dos mancais hidrodinâmicos, o valor da rigidez direta é elevado mesmo em uma posição concêntrica. Este fato ocorre porque o escoamento axial que induz esta rigidez, mesmo não havendo rotação, faz com que o selo anular gere uma força de reação radial - fenômeno conhecido como efeito Lomakin.

Em contrapartida ao valor da rigidez cruzada menor, o anel com ranhura oferece um amortecimento direto inferior em comparação ao anel liso (ver figura 47 e 48). Portanto, sua utilização deve ser avaliada com cuidado, pois o problema de instabilidade relacionado ao cross-coupling ( rigidez cruzada) é resolvido, porém pode ocasionar uma redução na frequência natural amortecida que, por sua vez, aproximaria da velocidade de operação do equipamento causando alta amplitude de vibração.

Como mostrado na figura 20, o amortecimento cruzado gera uma força na direção radial ao movimento vibratório do rotor. Entretanto, o gráfico da figura 50 
mostra valores muito baixos deste amortecimento. Portanto, a principal componente da força restauradora do movimento vibratório é a provida pela rigidez direta do fluido. Lembrando que a parcela da força de inércia do fluido foi negligenciada devido à razão entre largura e diâmetro do anel ser menor que 0.5.

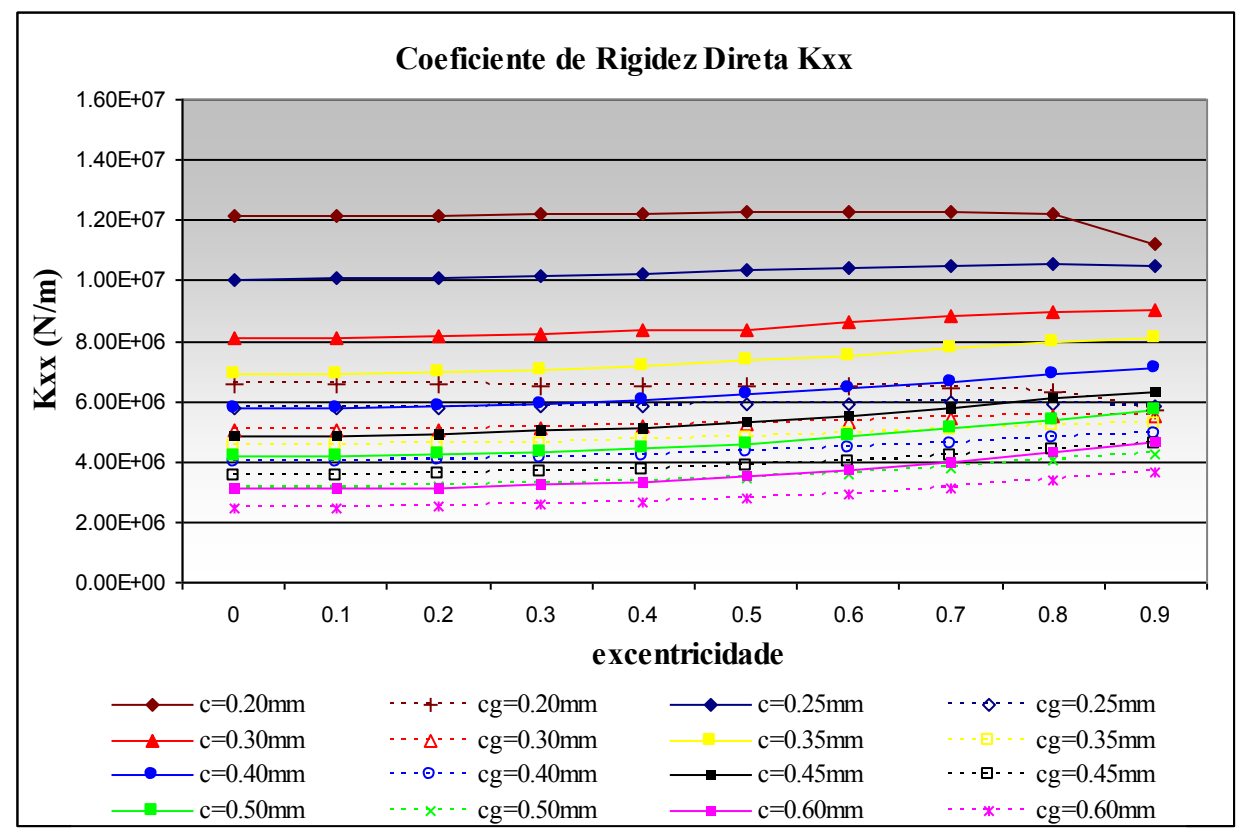

Figura 44 - Variação do coeficiente de rigidez direta $\mathrm{K}_{\mathrm{xx}}$ - ("g" refere-se ao selo com superfície ranhurada)

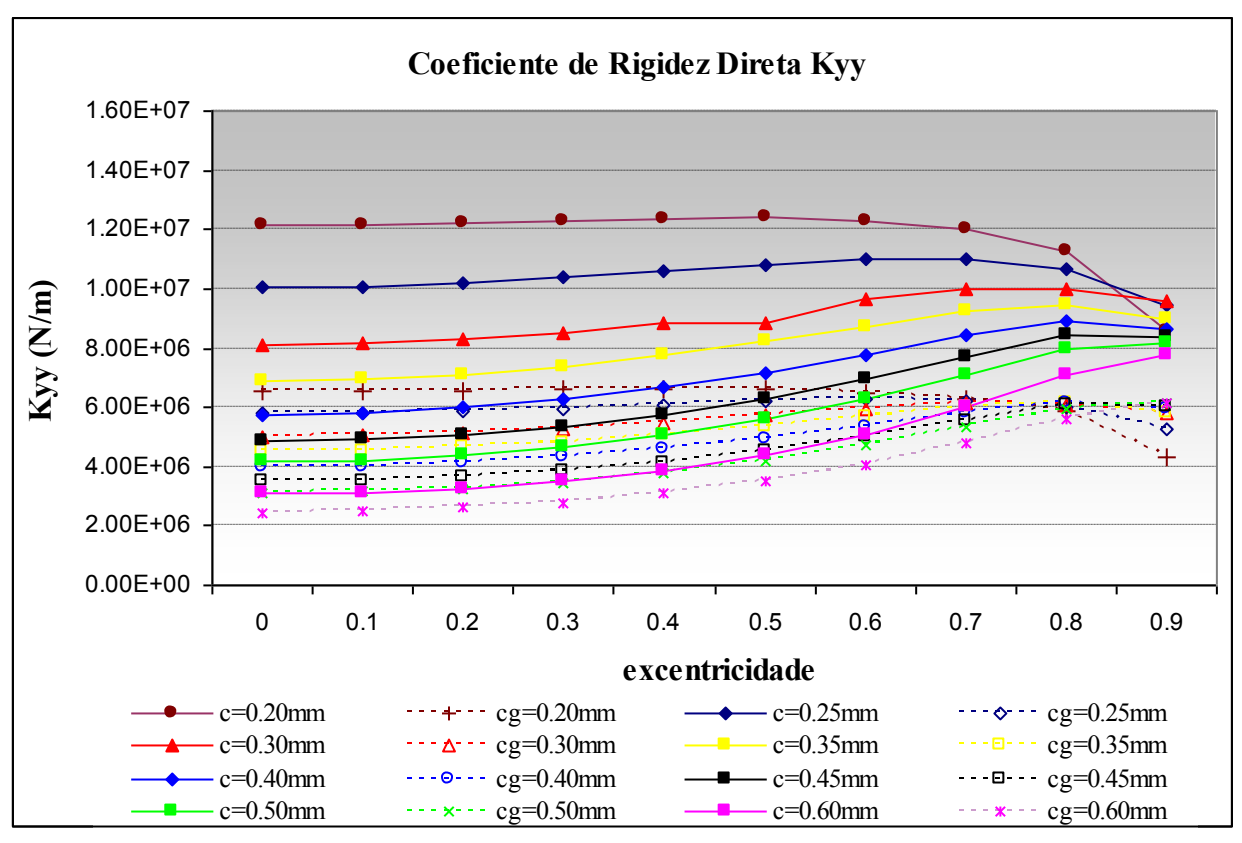

Figura 45 - Variação do coeficiente de rigidez Direta Kyy 


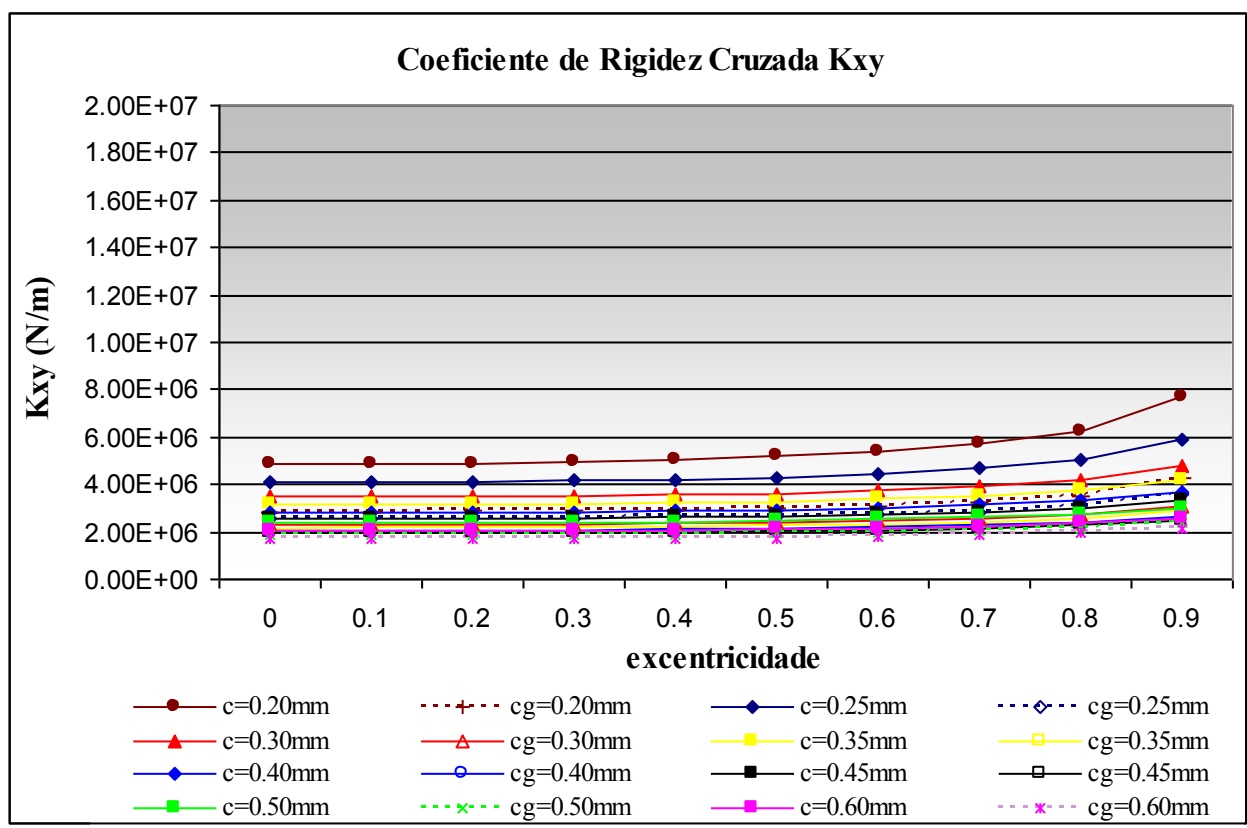

Figura 46 - Variação do coeficiente de rigidez cruzada $\mathrm{K}_{\mathrm{xy}}$

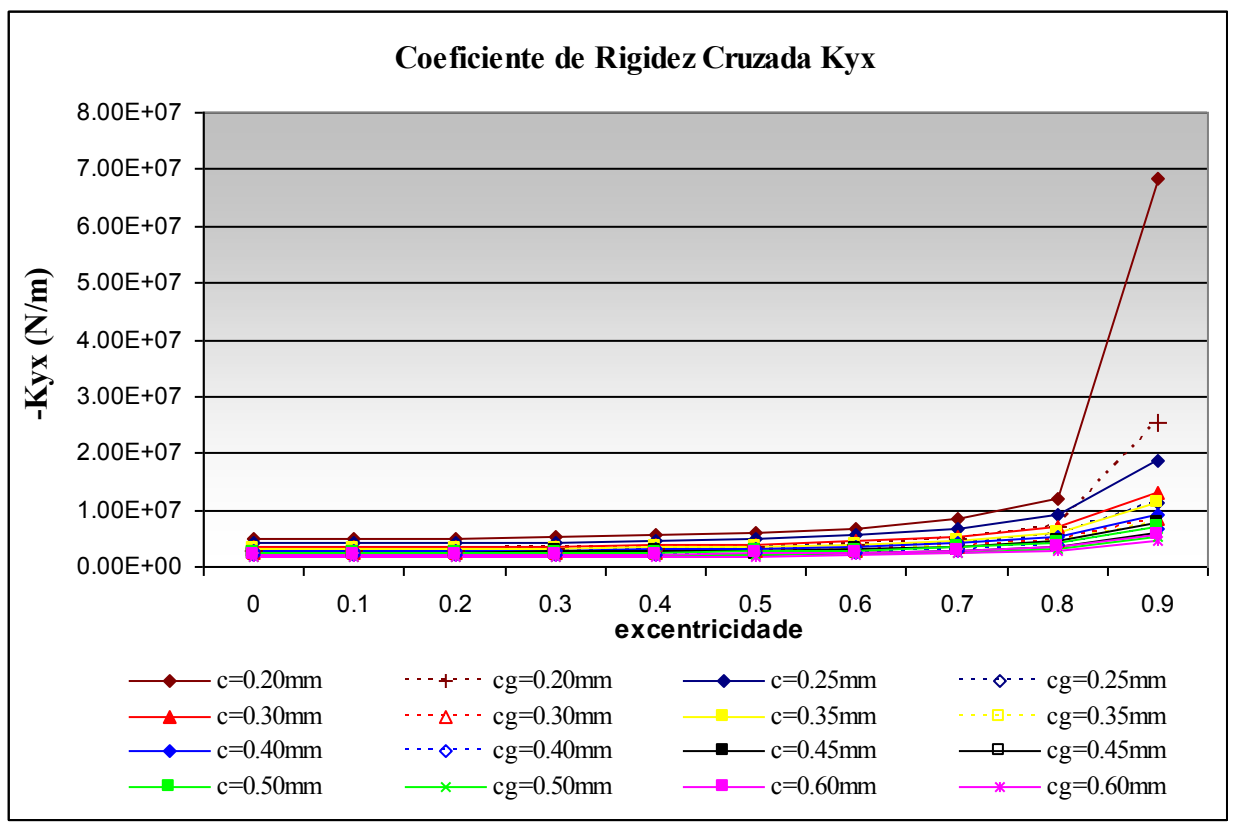

Figura 47 - Variação do coeficiente de rigidez cruzada $\mathrm{K}_{\mathrm{yx}}$ 


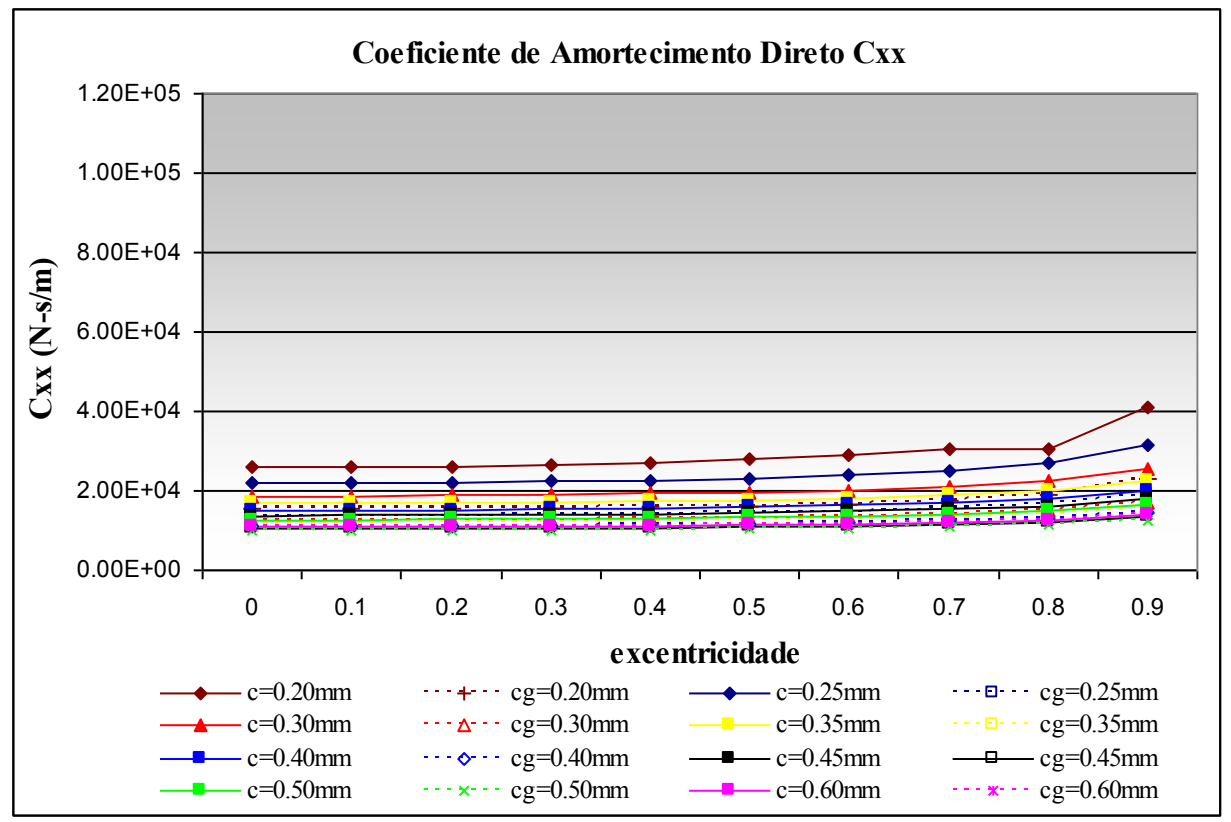

Figura 48 - Variação do coeficiente de amortecimento Direto $C_{x x}$

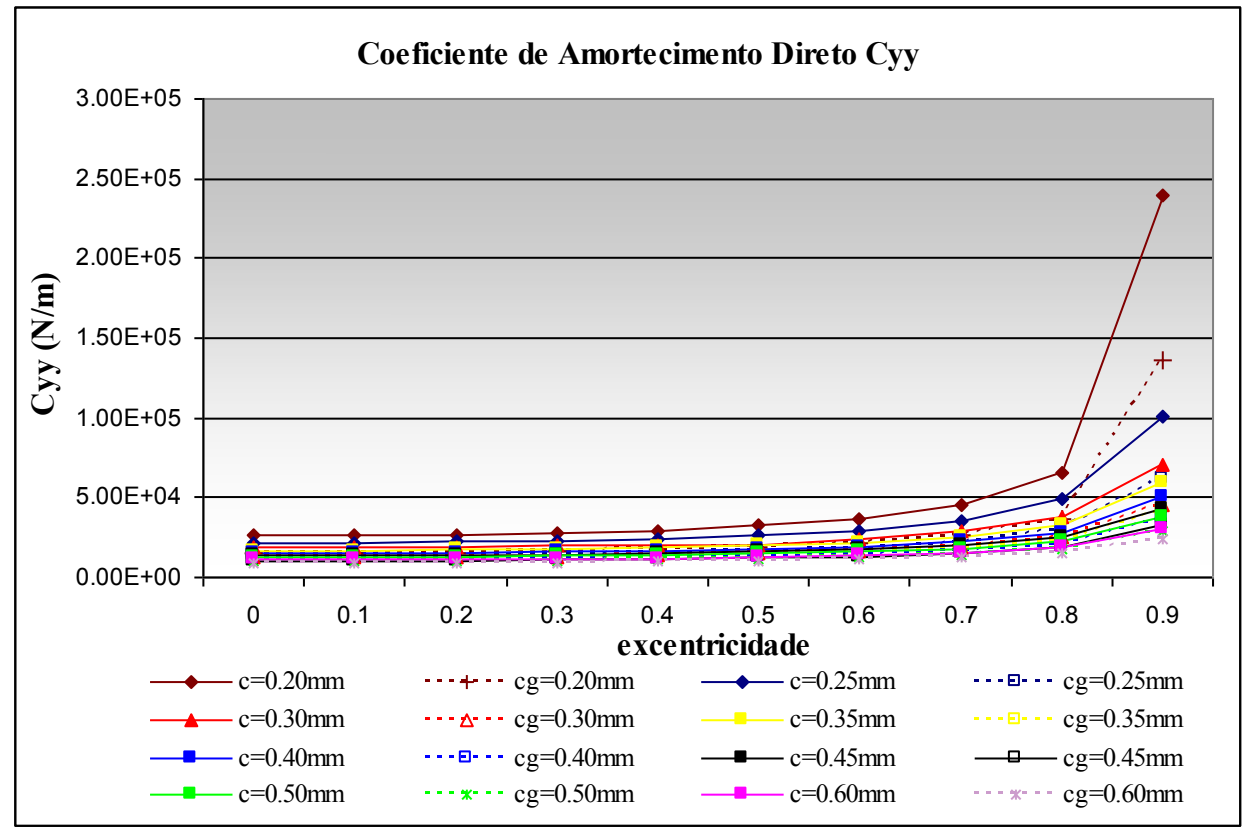

Figura 49 - Variação do coeficiente de amortecimento direto $C_{y y}$ 


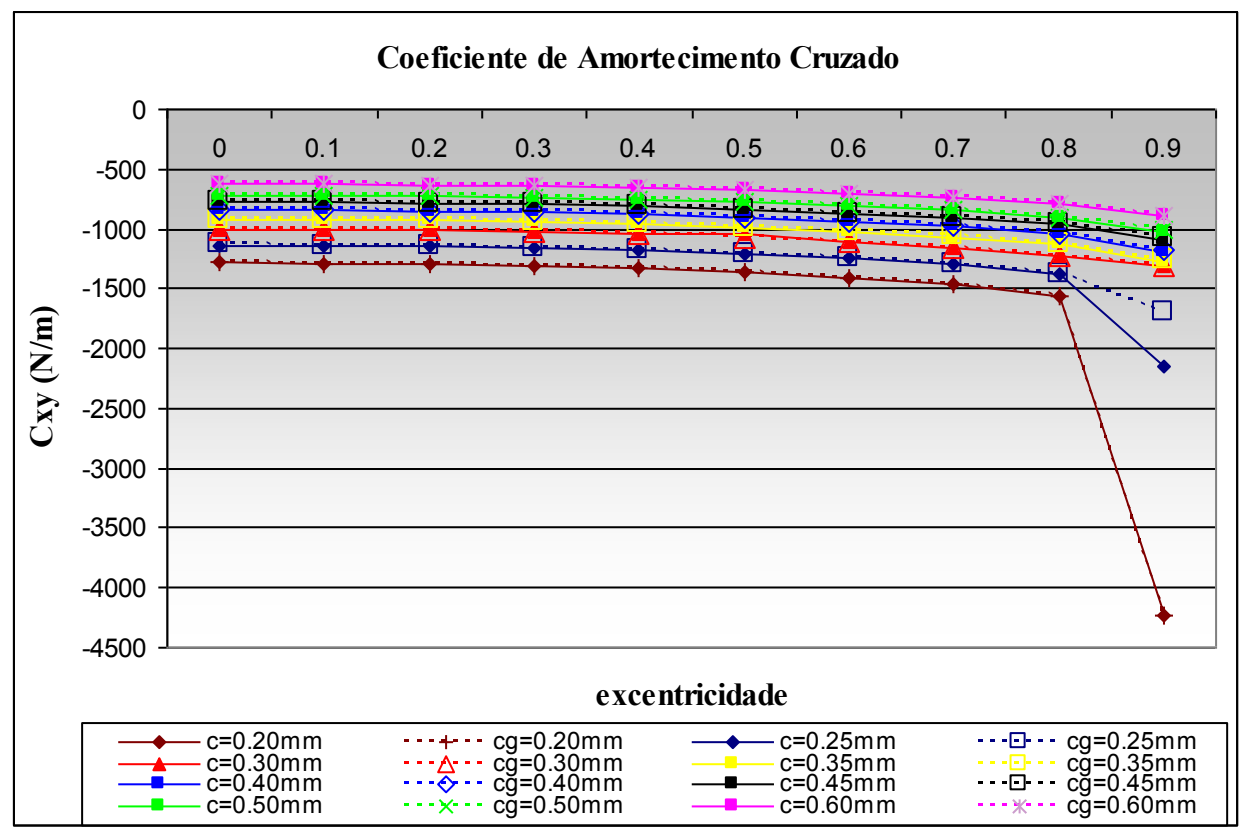

Figura 50 - Variação do coeficiente de amortecimento cruzado

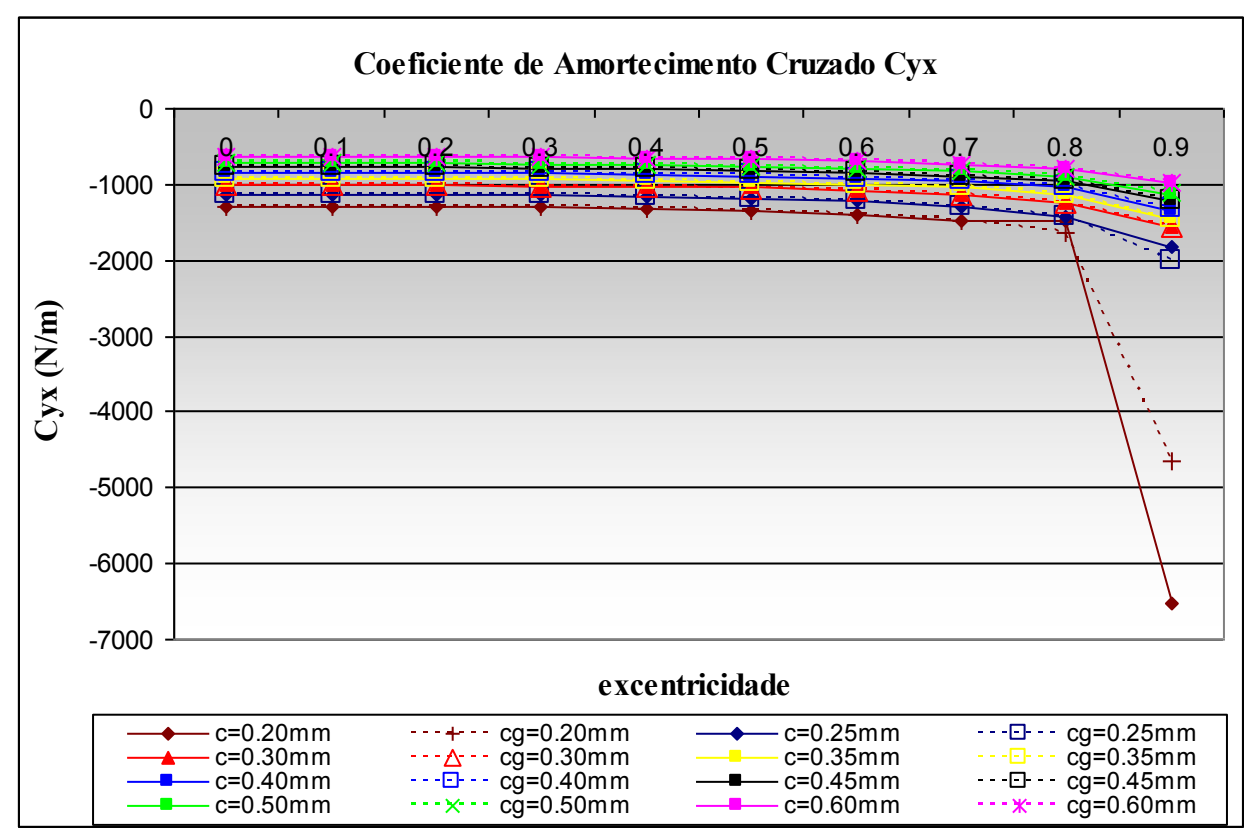

Figura 51 - Variação do coeficiente de amortecimento cruzado

Em relação à força do fluido sobre o anel flutuante, a variação mais relevante é com a excentricidade e o tipo da superfície do anel e menos com a folga radial. Ocorre uma variação quase linear entre a força e a excentricidade, sendo que a posição mais excêntrica oferece uma maior força sobre o rotor - ver figura 52. A força induzida pelo fluido deve ser utilizada para o projeto do selo 
anular, pois esta deve ser equilibrada para que ocorra o travamento do anel flutuante na posição excêntrica desejada.

Caso seja almejada uma menor força do fluido sobre o anel flutuante para tornar mais viável o projeto do anel, a utilização de uma superfície ranhurada seria de melhor escolha, pois a força do fluido pode ter uma redução de até $50 \%$ em relação à superfície lisa.

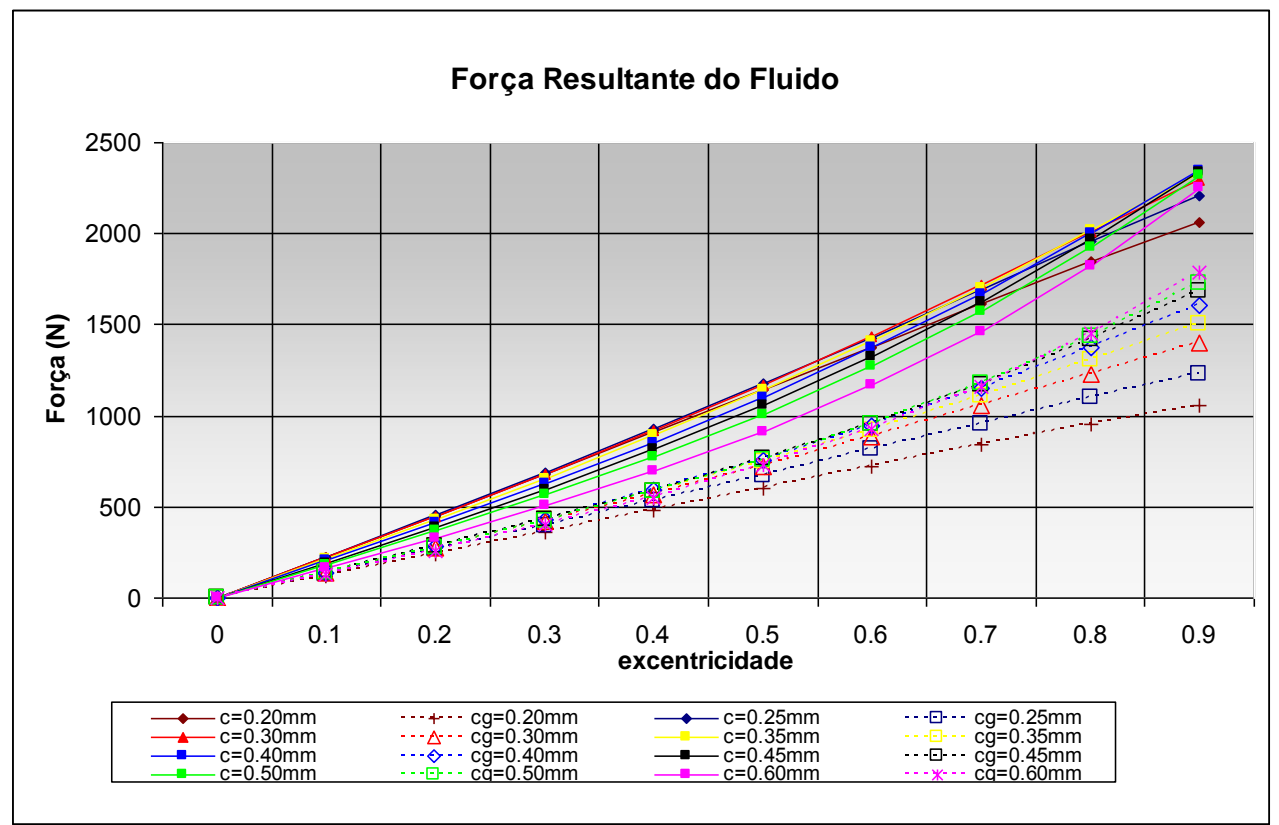

Figura 52 - Força resultante do fluido sobre o anel flutuante

O gráfico da figura 53 apresenta as velocidades críticas e a razão de amortecimento para os 16 casos analisados. Os anéis com superfície lisa possuem maior razão de amortecimento que aqueles com superfície ranhurada considerando a mesma folga radial. O caso 12 apesar de registrar a primeira velocidade crítica $400 \%$ maior que a velocidade de operação, apresenta um valor de amortecimento relativamente baixo, permitindo desta forma sua excitação caso ocorra defeito nos elementos rolantes dos mancais.

Como mencionado anteriormente, devido às condições operacionais e o modelo de bombas, os anéis de desgastes operam com folga radial que variam de 0.35 (quando novo - casos 3 e 4) a 0.6 (quando usado - casos 7 e 8). Adicionalmente, dependendo da folga dos anéis de desgaste, o modelo de bomba estudado apresenta vibração elevada nas frequências entre $4260 \mathrm{rpm}$ e $5325 \mathrm{rpm}$. Portanto, conforme plotado na figura 53, a provável causa desta vibração é a 
excitação da sua frequência natural amortecida. Esta excitação pode ser causada pelo contato entre os anéis de desgaste ou pelo fluido. Entretanto, em ambas as situações espera-se que o anel flutuante elimine esta excitação, pois ele evitaria o contato entre os anéis de desgaste, reduziria o nível de turbulência do fluido (menor número de Reynolds axial) e a rigidez cruzada e permitiria uma operação em uma posição mais concêntrica minimizando a força radial gerada pelo fluxo axial do selo.

A região ótima apresentada no gráfico abaixo é aquela que possui valor de amortecimento e frequência natural elevada. Entretanto, a maioria dos casos apresenta uma frequência entre 4000 e $6000 \mathrm{rpm}$. O caso 15 apresenta o melhor desejado, pois além de apresentar uma frequência natural $45 \%$ acima da frequência de operação, considera o selo operando em uma região concêntrica e fator de amortecimento elevado. $\mathrm{O}$ caso 8 apesar do fator de amortecimento elevado, a frequência crítica coincide com a frequência operacional, tornando-se desta forma indesejável. Já o caso 10 possui alto fator de amortecimento, mas a frequência amortecida é menor que a operacional, contrariando a recomendação da norma API 610.

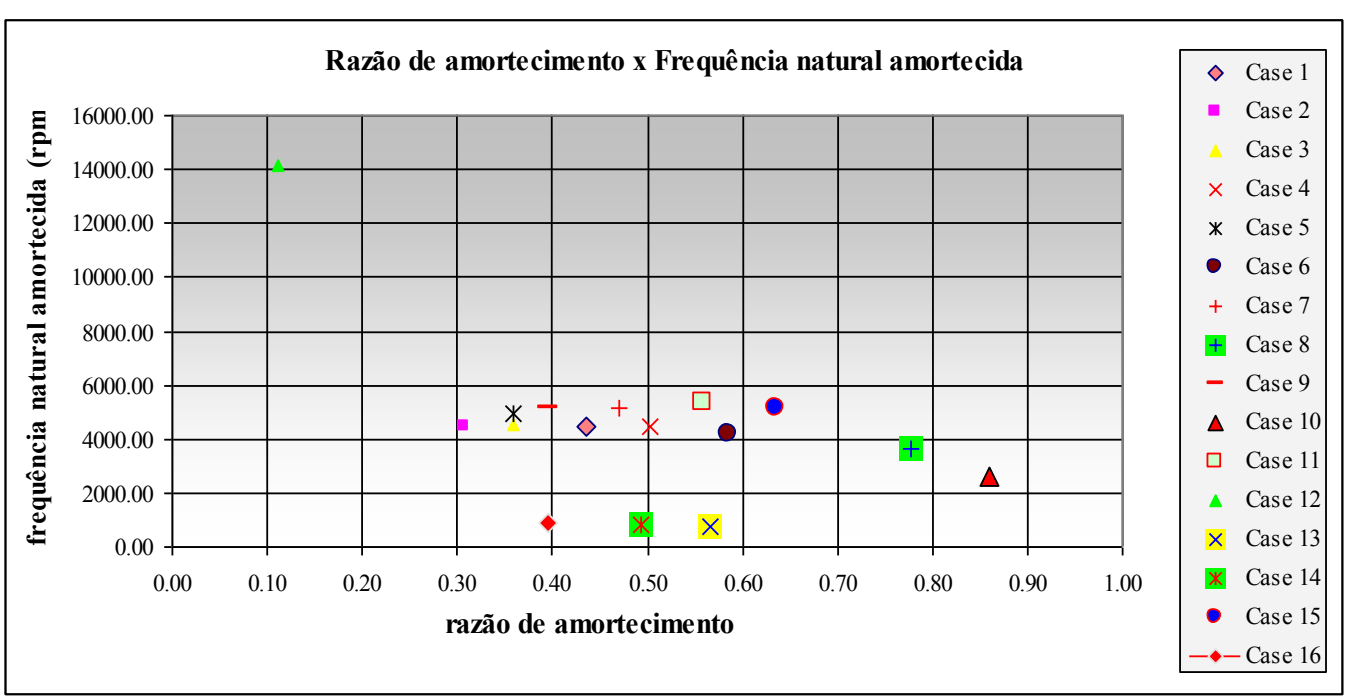

Figura 53 - Razão de amortecimento versus frequência natural amortecida

As figuras 54, 55 e 56 representam a resposta ao desbalanceamento do rotor nas posições do selo anular 1, selo anular 2 e das faces dos anéis do selo mecânico, respectivamente. Através da leitura dos gráficos é possível verificar a grande influência da folga radial dos selos anulares na resposta ao 
desbalanceamento. O deslocamento previsto do rotor nas posições dos anéis variam de 35 micra pico a pico no caso de maior folga $(0.6 \mathrm{~mm})$ para 5 micra pico a pico para o situação de menor folga $(0.2 \mathrm{~mm})$. Na posição das faces do selo mecânico, o deslocamento varia de 10,8 $\mu$ m-pico a pico para o caso de maior folga para 1,4 $\mu \mathrm{m}$-pico a pico para o caso de menor folga, aumentando desta forma a confiabilidade deste componente. Este resultado enfatiza a importância da montagem dos anéis com a menor folga possível, sendo este viabilizado pelo uso do anel flutuante.

$\mathrm{O}$ anel com a superfície lisa permite um deslocamento do rotor menor que o anel com superfície ranhurada, sendo, portanto uma escolha mais vantajosa para reduzir a possibilidade de roçamento.

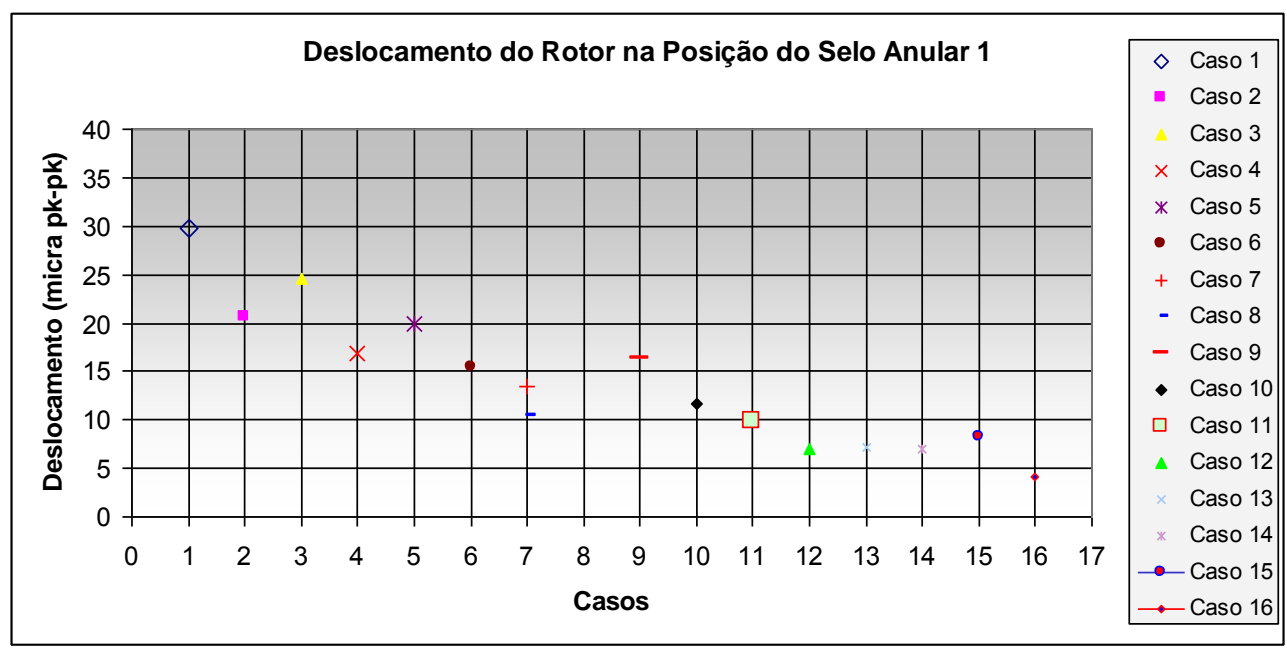

Figura 54 - Deslocamento do rotor na posição do selo anular 1

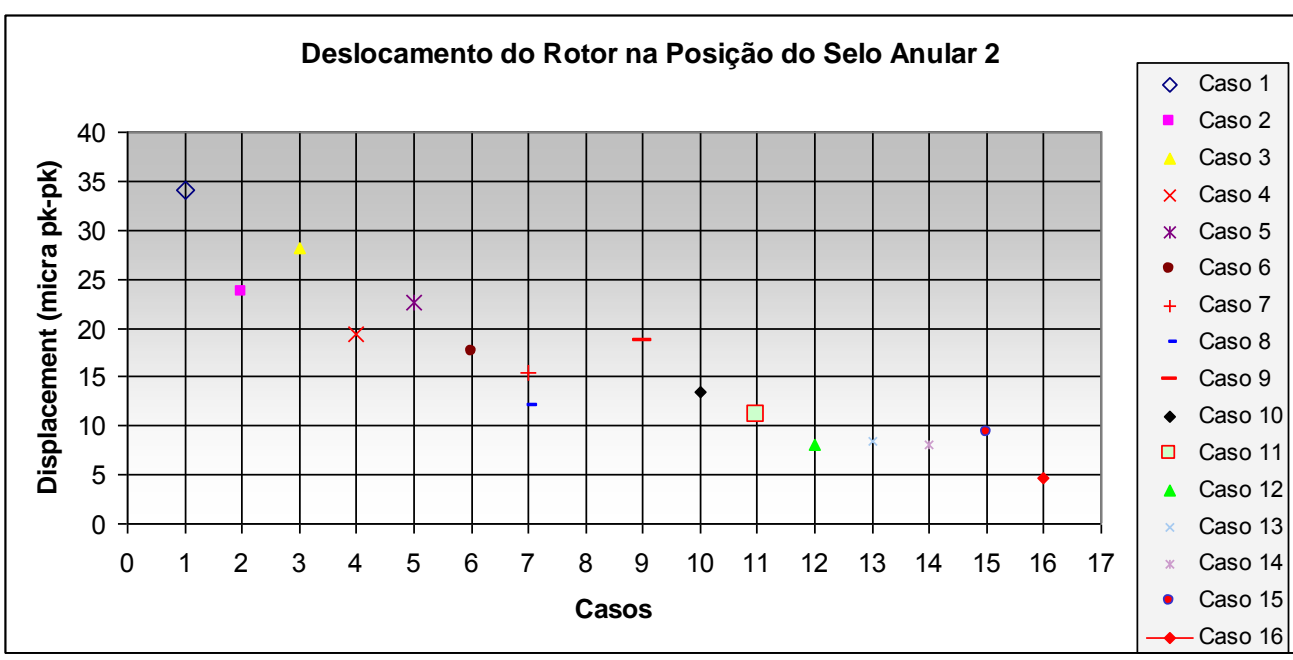

Figura 55 - Deslocamento do rotor na posição do selo anular 2 


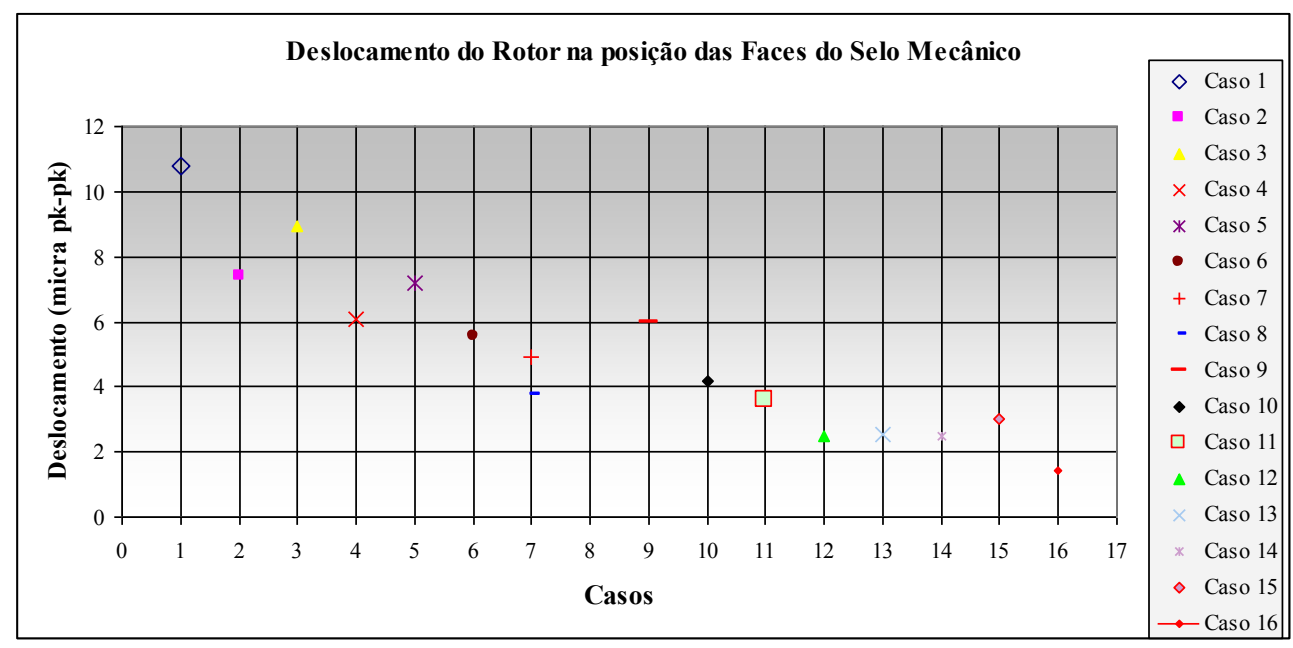

Figura 56 - Deslocamento do rotor na posição do selo mecânico

Em relação à vazão de recirculação pelos selos anulares, a montagem com folga radial de $0.25 \mathrm{~mm}$ utilizando anel flutuante, poderia reduzir a vazão de recirculação em $40 \%$ em relação à montagem com anel fixo com folga radial de $0.35 \mathrm{~mm}$ - ver figura 57 . No fim de sua vida útil, o anel de desgaste fixo com folga radial de $0.6 \mathrm{~mm}$ conduz um aumento da vazão de recirculação em $100 \%$, ocasionando um aumento excessivo da corrente do motor de acionamento da bomba que, por sua vez, induz a parada do sistema de bombeio para evitar danos ao motor elétrico.

A viabilidade da utilização de folgas reduzidas com o uso do anel flutuante reduziria o desgaste por erosão devido à menor vazão e espaço entre os anéis anulares. Portanto, também é esperado o aumento da vida útil dos selos anulares com a substituição dos anéis fixos por flutuantes.

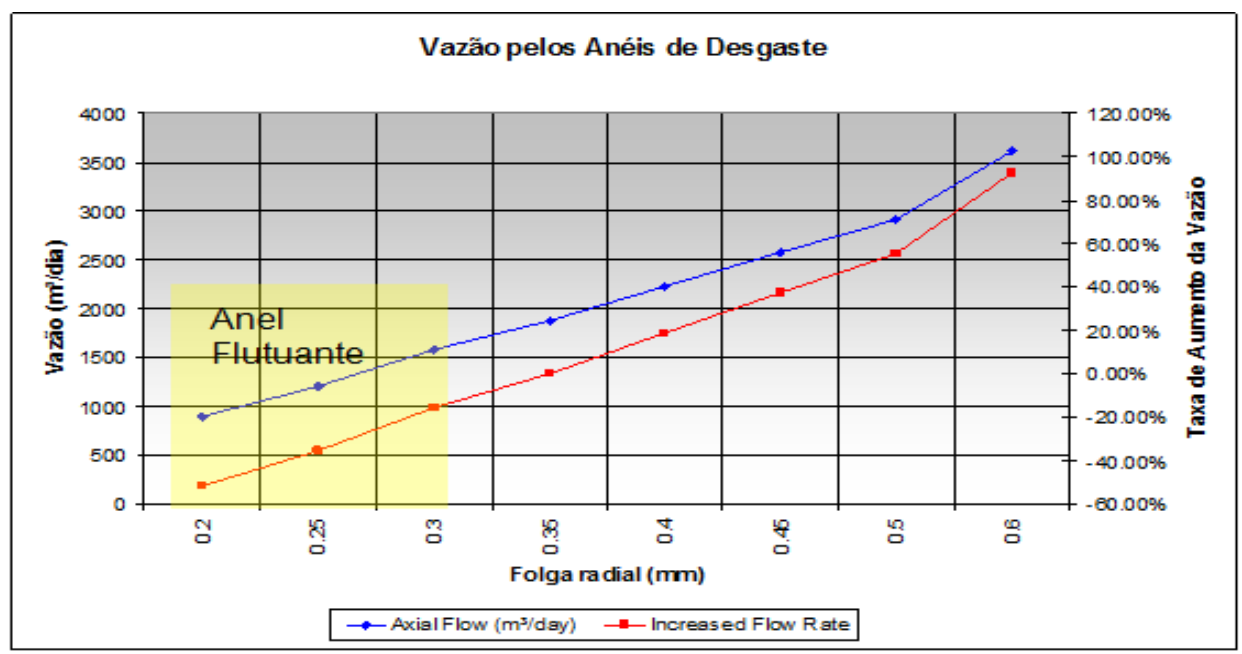

Figura 57 - Vazão pelos anéis de desgaste 
Devido à semelhança, é mostrado nas figuras abaixo apenas o primeiro e segundo modo de vibrar do caso 7. Observa-se que o desbalanceamento do impelidor excita o primeiro modo de vibrar causando maior deslocamento do rotor nas posições dos anéis de desgaste, enfatizando desta forma, a importância destes componentes na análise lateral da bomba centrífuga.

O segundo modo de vibrar poderia ser excitado caso o desbalanceamento ocorresse no acoplamento. Este seria mais prejudicial à bomba, pois a amplitude da vibração nas posições dos anéis de desgaste seria baixa, fazendo com que seu amortecimento fosse pouco efetivo. Entretanto, a frequência do segundo modo é muito elevada, reduzindo, portanto, a probabilidade de ser excitada.

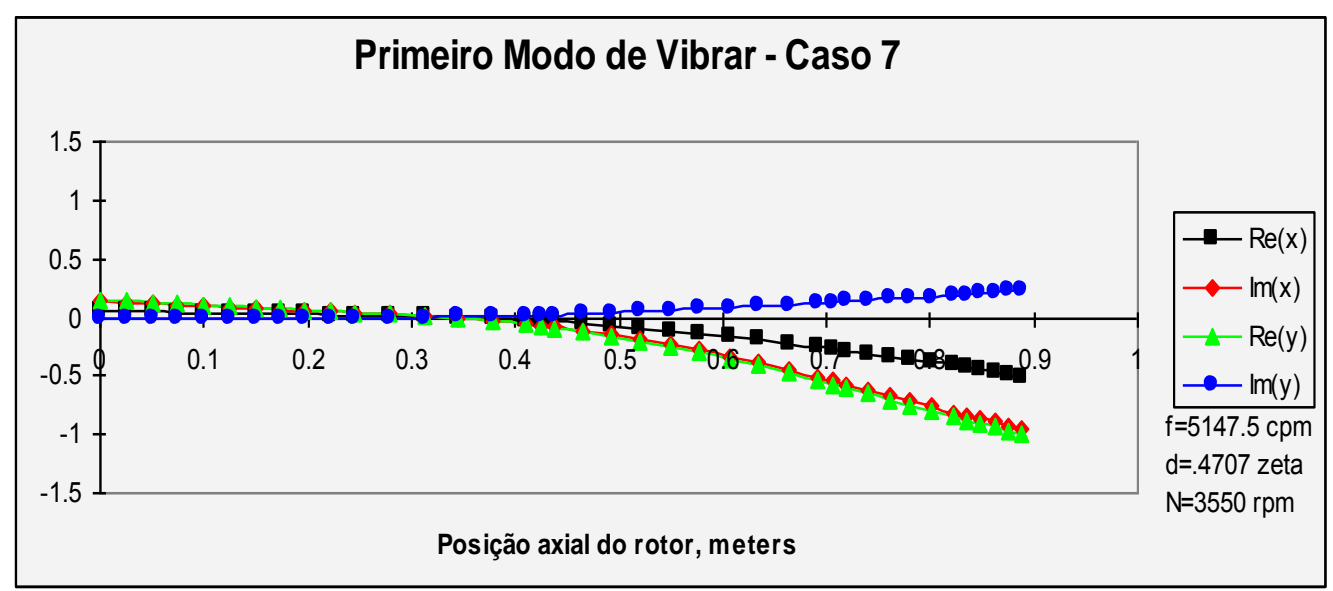

Figura 58 - Primeiro modo de vibrar da bomba centrífuga de simples estágio

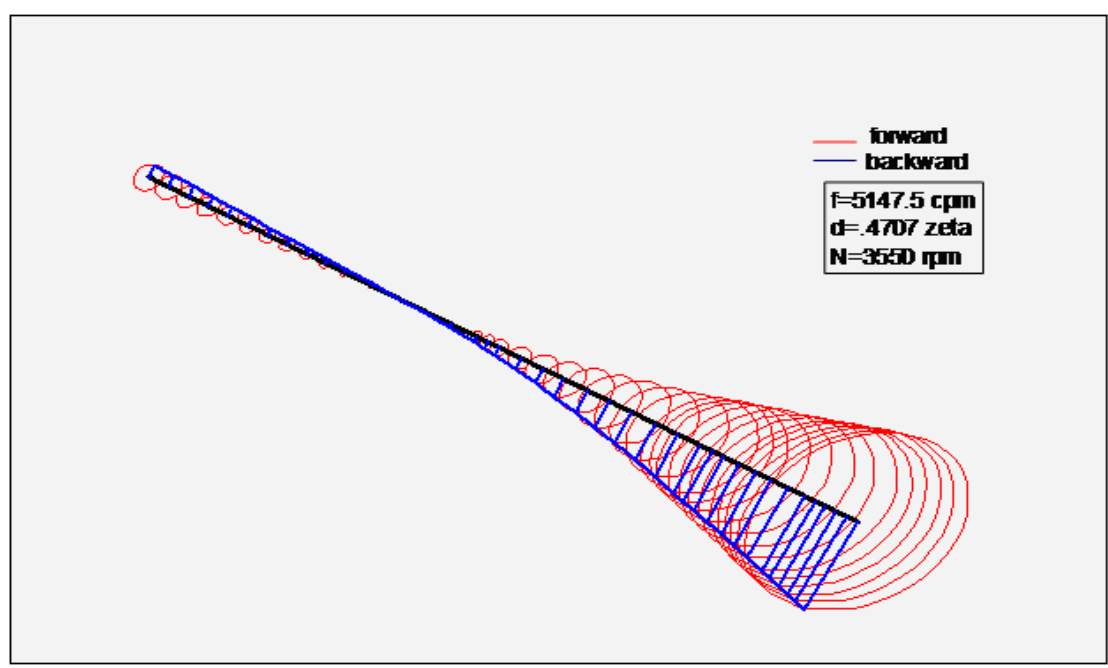

Figura 59 - Primeiro modo de vibrar da bomba centrífuga de simples estágio em "3D" 


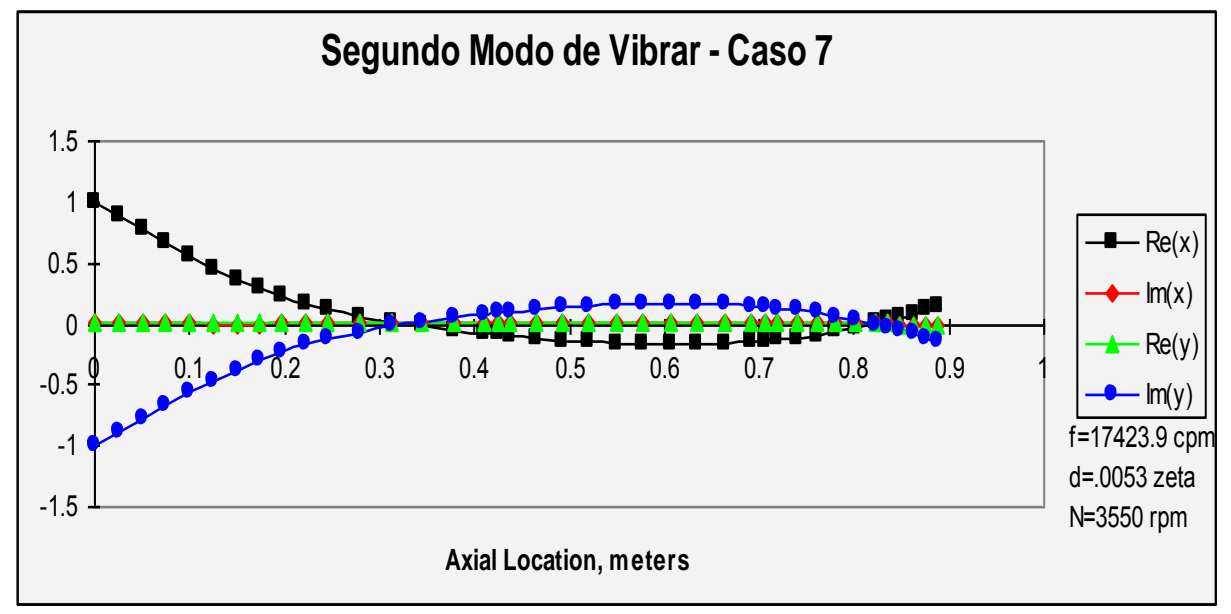

Figura 60 - Segundo modo de vibrar da bomba centrífuga de simples estágio

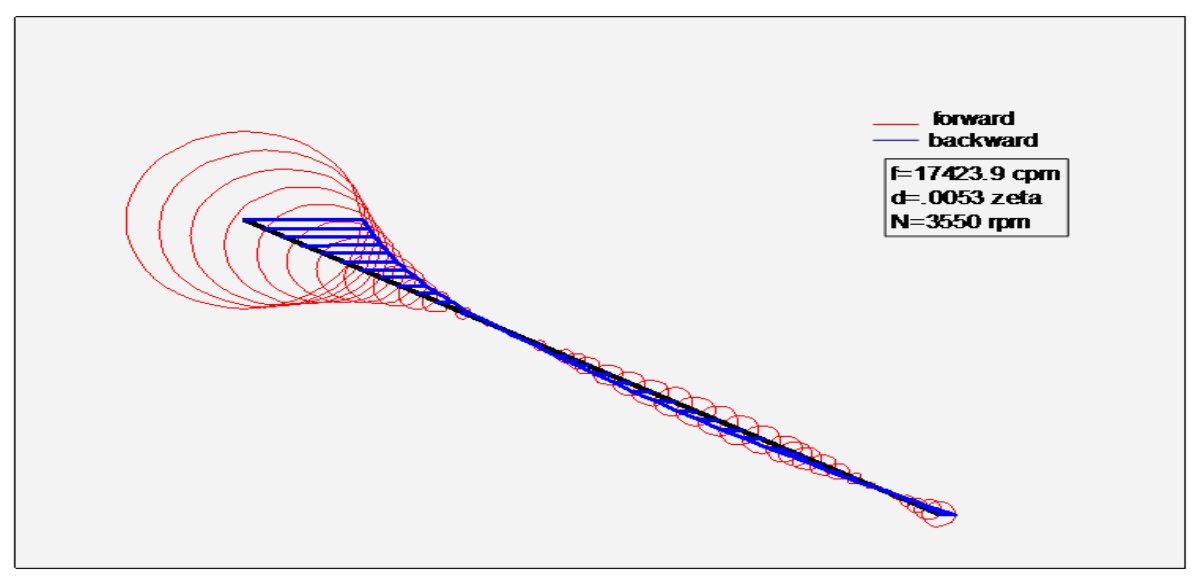

Figura 61 - Segundo modo de vibrar da bomba centrífuga de simples estágio em "3D" 


\section{2.}

\section{Bomba centrífuga de multiestágios}

A tabela abaixo mostra quais seriam os valores previstos das frequências naturais amortecidas e seus respectivos fatores de amortecimento e a redução de força nos mancais ao substituir os anéis estáticos por flutuantes.

Tabela 12 - Comparação dos resultados com anel fixo e flutuante da bomba multiestágios

\begin{tabular}{|c|c|c|}
\hline & Fixo & Flutuante \\
\hline $\begin{array}{c}1^{\circ} \text { Frequência natural } \\
\text { amortecida (rpm) }\end{array}$ & 1894 & 1927 \\
\hline $\begin{array}{c}\text { Decremento } \\
\text { logarítmico }(\mathrm{dec} \log )\end{array}$ & 4.581 & 4.596 \\
\hline $\begin{array}{c}2^{\circ} \text { Frequência natural } \\
\text { amortecida (rpm) }\end{array}$ & 2645 & 2754 \\
\hline $\begin{array}{l}\text { Decremento } \\
\text { logarítmico }\end{array}$ & 3.11 & 3.01 \\
\hline $\begin{array}{c}3^{\circ} \text { Frequência natural } \\
\text { amortecida }(\mathrm{rpm})\end{array}$ & 4762 & 4462 \\
\hline $\begin{array}{l}\text { Decremento } \\
\text { logarítmico }\end{array}$ & 0.543 & 2.77 \\
\hline $\begin{array}{l}\text { Redução da Força } \\
\text { mancal LA (\%) }\end{array}$ & - & $-2,45$ \\
\hline $\begin{array}{c}\text { Redução da Força no } \\
\text { mancal LOA (\%) }\end{array}$ & - & $-10,40$ \\
\hline
\end{tabular}

Como apresentado na tabela acima, não houve variação significativa entre as frequências naturais amortecidas, decrementos logarítmico e das forças atuante sobre os mancais, apesar da redução em $10 \%$ da força no mancal lado oposto acoplado (LOA). Apesar da frequência do terceiro modo, no caso do anel flutuante, apresentar um decremento logarítmico 554\% maior que o caso da utilização do anel fixo, a velocidade crítica é $24 \%$ maior que a velocidade de 
operação de 3600rpm do equipamento. Entretanto, este modo dificilmente seria excitado, pois nenhum caso de excitação super-harmônica como o mencionado para bomba de simples estágio em balanço, não foi encontrada pelo autor.

Os modos de vibrar para ambos os casos foram semelhantes. O primeiro modo dominado pelo tambor de balanceamento e o segundo e terceiro modo dominado pelo acoplamento (ver figura 62 a 67). Este fato explica a pouca influência dos anéis de desgaste apresentado pela tabela 12. Em uma análise lateral cujo modo de vibrar é dominado pelo efeito dos anéis de desgaste, região de maior deslocamento, é esperado uma maior sensibilidade ao alterar os parâmetros físicos dos selos anulares.

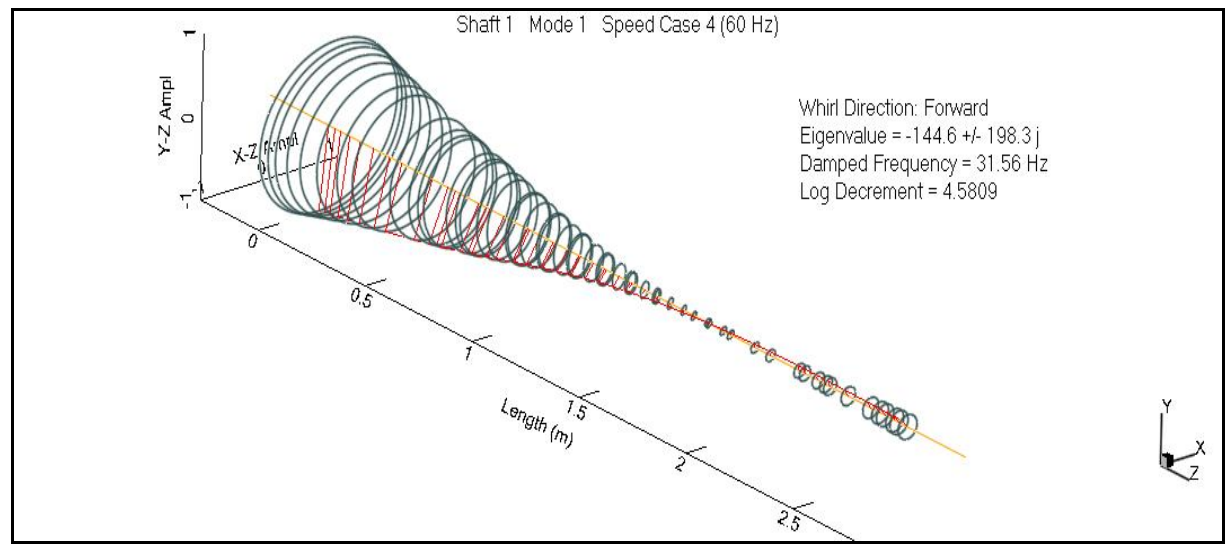

Figura 62 - Primeiro modo de vibrar - anéis fixos

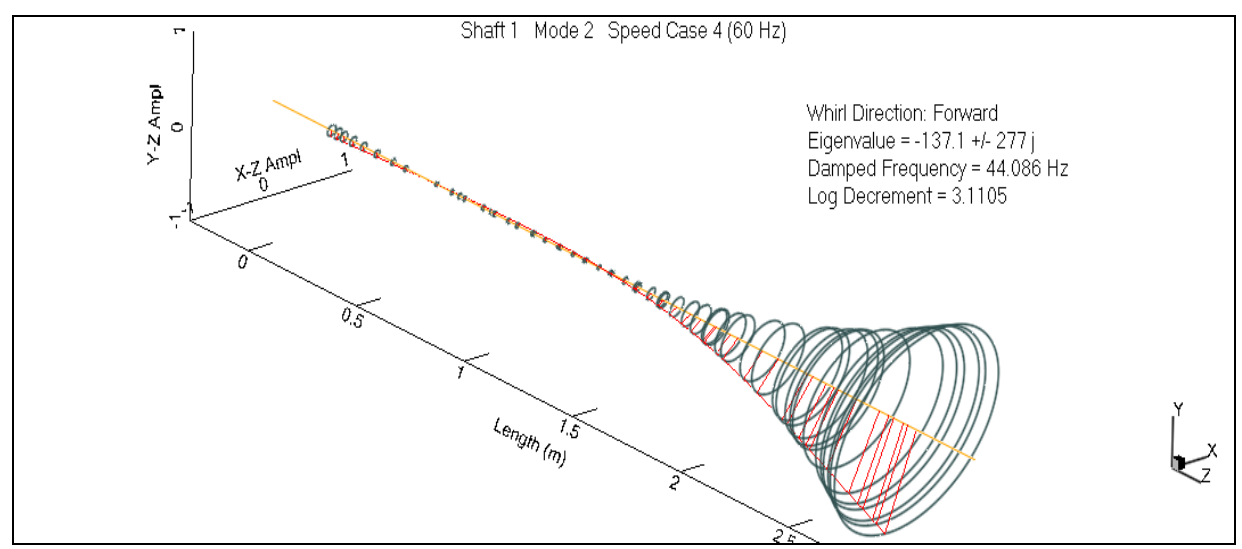

Figura 63 - Segundo modo de vibrar - anéis fixos 


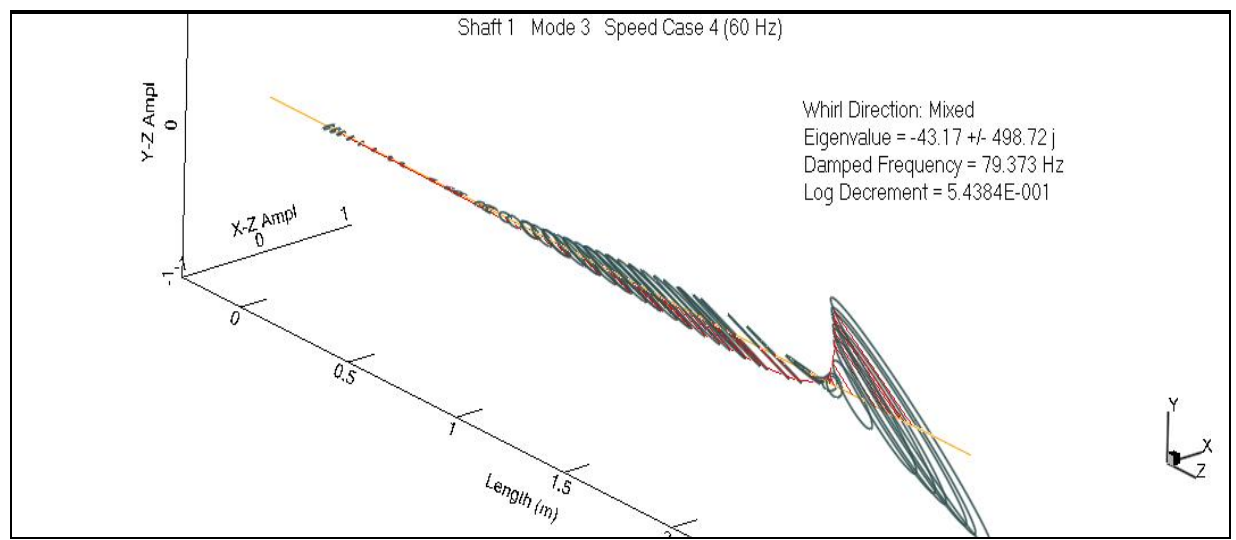

Figura 64 - Terceiro modo de vibrar - anéis fixos

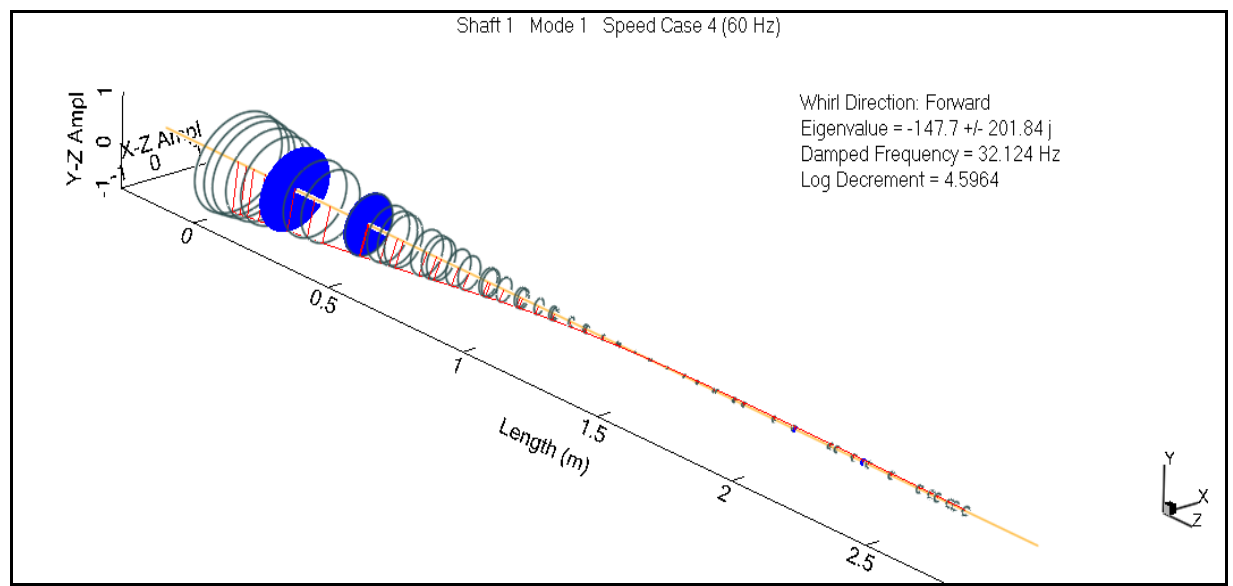

Figura 65 - Primeiro modo de vibrar - anéis flutuantes

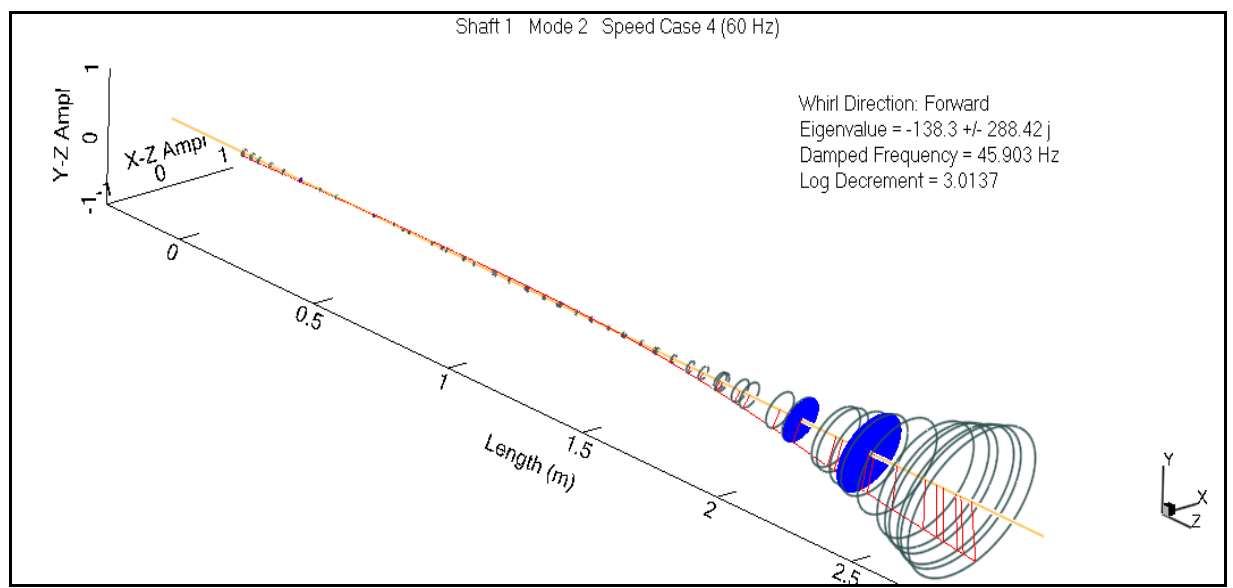

Figura 66 - Segundo modo de vibrar - anéis flutuantes 


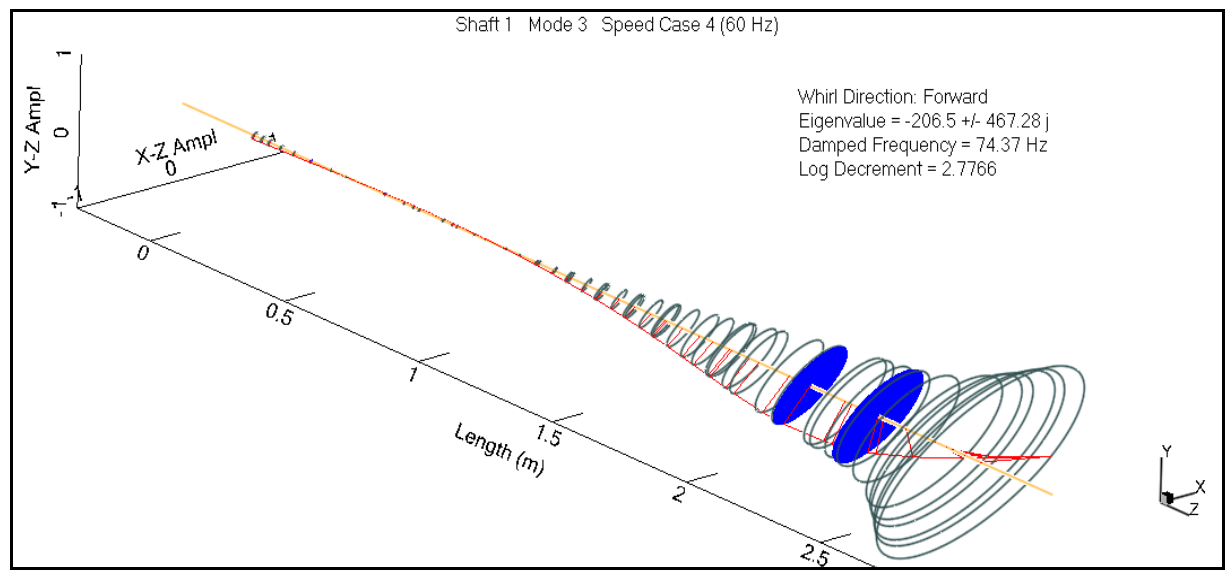

Figura 67 - Terceiro modo de vibrar - anéis flutuantes

Em relação à resposta ao desbalanceamento na velocidade de operação, não houve redução significativa na vibração do rotor, como exposto pelos gráficos de bode plotados nas figuras 68 a 71, que justificasse a utilização do anel flutuante. $\mathrm{O}$ modo de vibração em ambos os casos é dominado pelo acoplamento (ver figura 71 e 72), justificando, conforme informado anteriormente, a baixa sensibilidade à influência dos selos anulares no comportamento dinâmico do rotor.

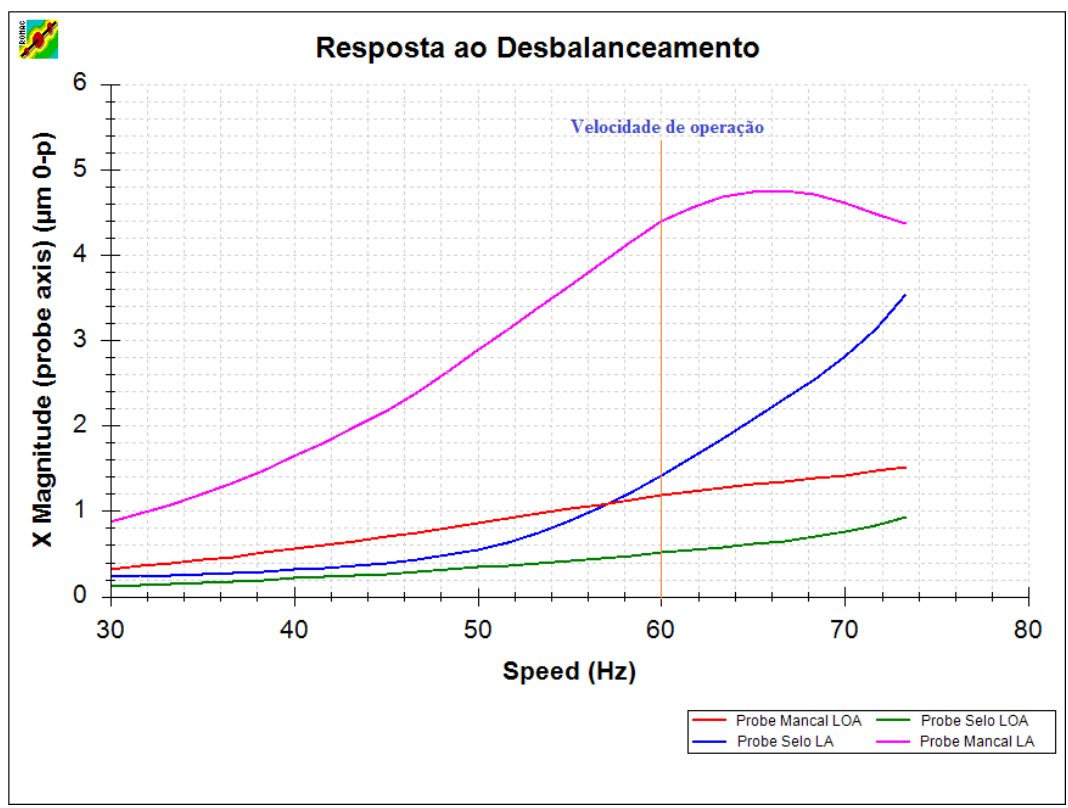

Figura 68 - Bode dos sensores no eixo horizontal 'x' - anéis fixos 


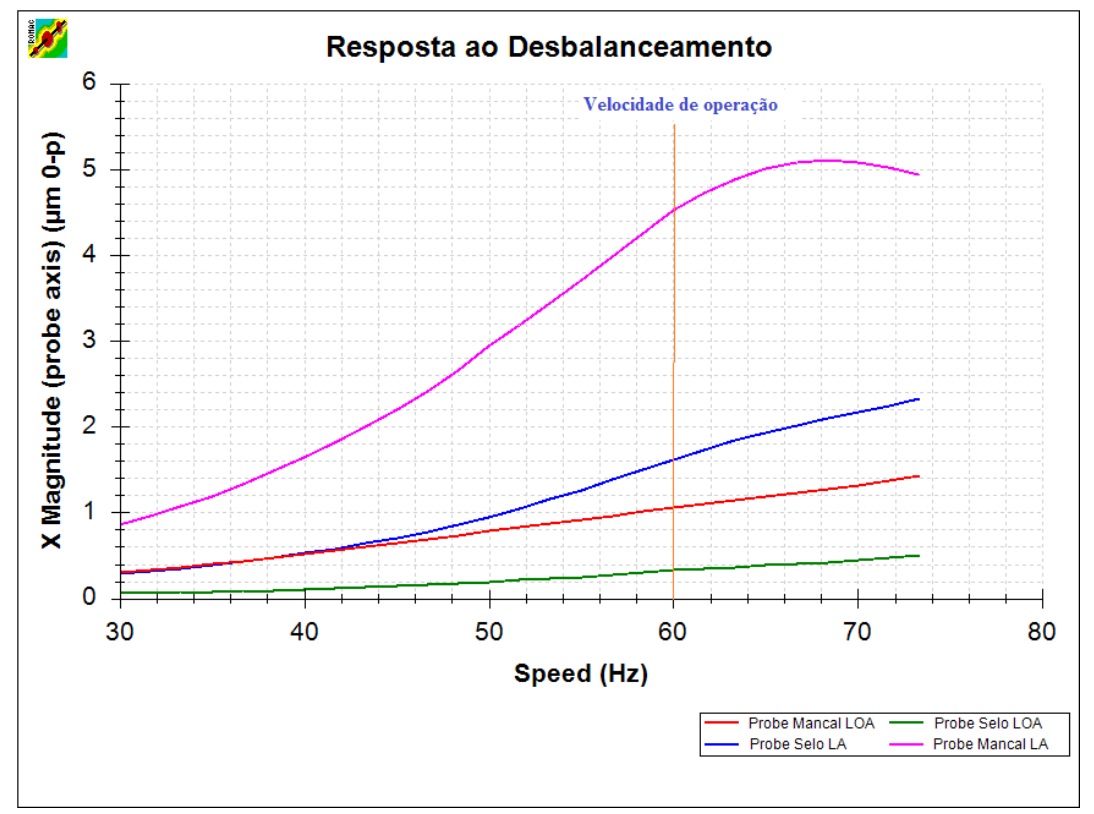

Figura 69 - Bode dos sensores no eixo horizontal 'x' - anéis flutuantes

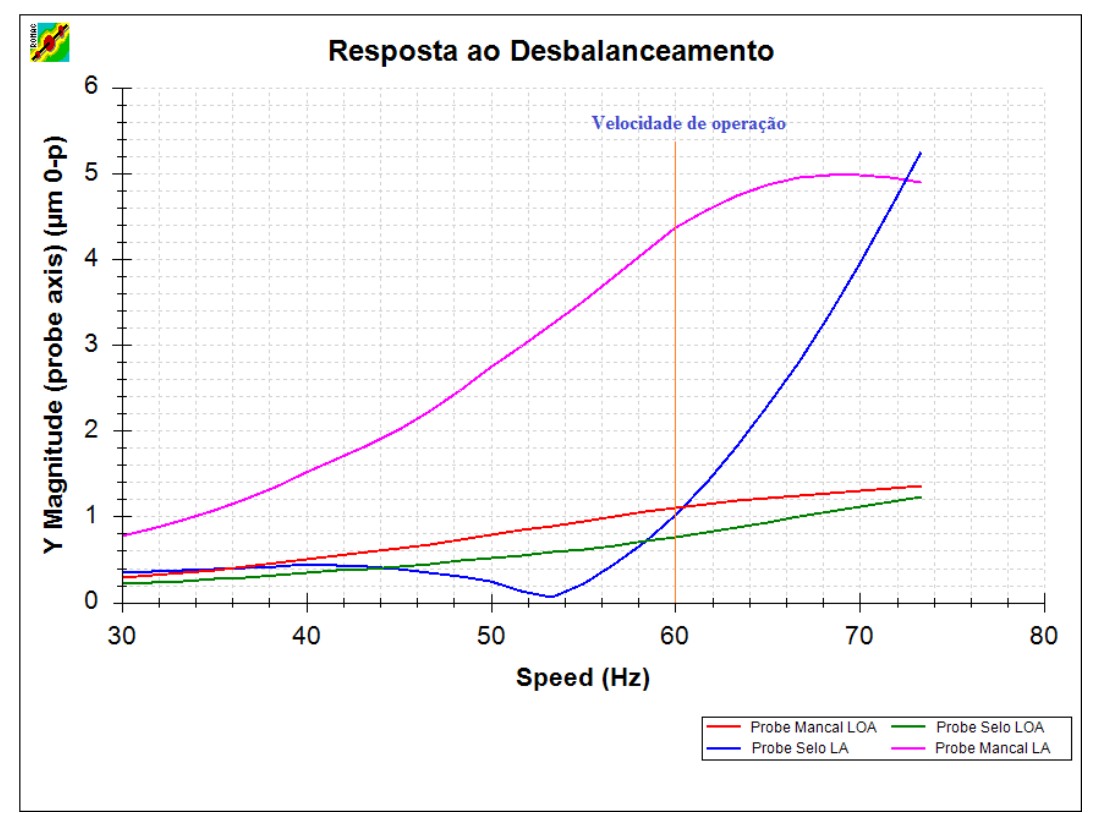

Figura 70 - Bode dos sensores no eixo vertical 'y' - anéis fixos 


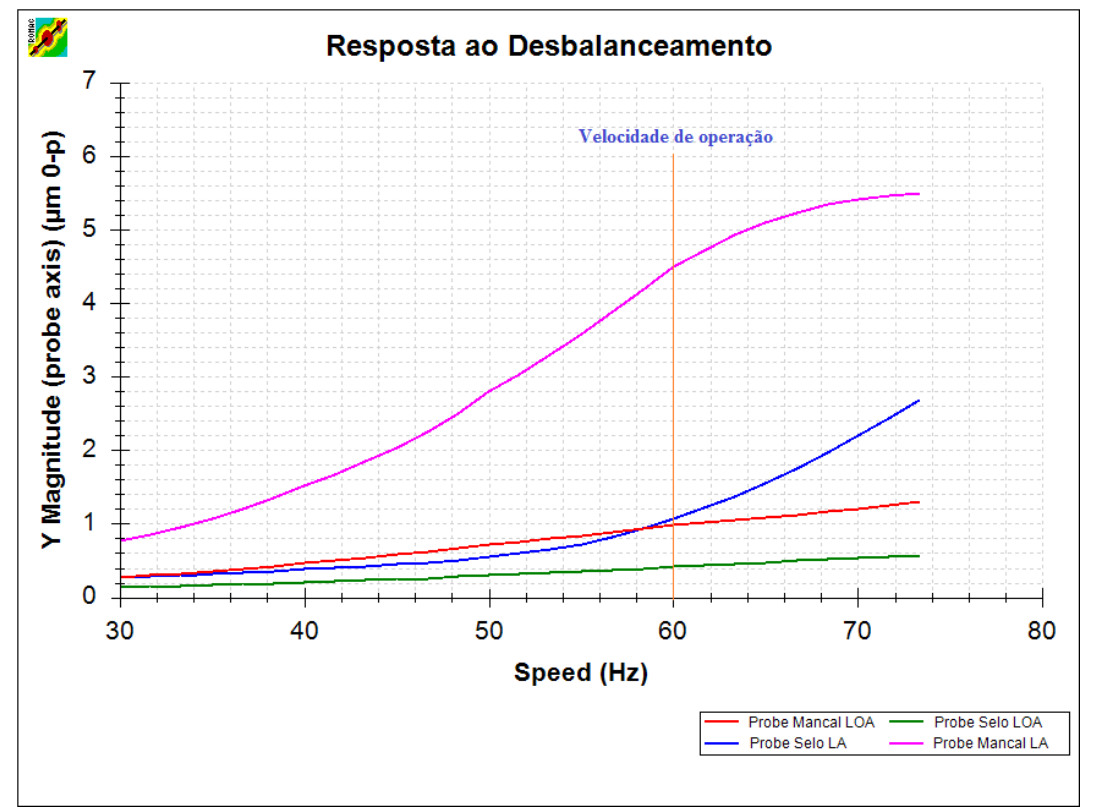

Figura 71 - Bode dos sensores no eixo vertical 'y' - anéis flutuantes

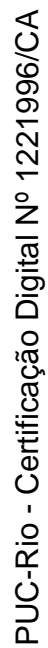




\section{9 \\ Conclusões}

Conforme os resultados expostos, a frequência superharmônica , entre 4.260 a 5500rpm, observada durante as medições de vibração do modelo de bomba analisado é devido à excitação da sua frequência natural amortecida, ou seja, presença de instabilidade. As prováveis causas desta instabilidade são a presença de roçamento dos anéis e/ou excitação fluido-dinâmica. Entretanto, é esperado que a substituição do anel de desgaste fixo pelo flutuante possa anular estas ocorrências, pois este permite uma operação dos selos anulares com menor excentricidade reduzindo o efeito Lomakin, menor turbulência e também evitaria o contato por causa do seu grau de liberdade para se mover radialmente.

Os valores dos coeficientes dinâmicos dos selos anulares permanecem praticamente constantes entre a excentricidade zero a 0.8. Portanto, a análise lateral da bomba operando com o anel flutuante pode ser considerada independente de sua excentricidade, caso este seja projetado para operar em uma posição excêntrica menor ou igual a 0.8 . Este resultado facilita a predição do comportamento dinâmico do rotor devido a linearidade dos coeficientes.

É esperado que a utilização do anel flutuante permita o aumento da eficiência do sistema de bombeio em até $50 \%$, pois a vazão de recirculação reduz significativamente com a folga radial conforme exposto pela figura 56 . Adicionalmente, a vida útil dos selos anulares aumentaria em consequência da redução da erosão propiciada pela menor folga e vazão de fluido de recirculação.

Considerando que a bomba opera em baixa rotação, 3550rpm, a instabilidade causada pela rigidez cruzada possui baixa probabilidade de ocorrência. Portanto, a utilização do anel com superfície lisa em detrimento a superfície ranhurada seria mais viável por introduzir maior amortecimento ao sistema mecânico. Porém, caso seja necessário reduzir a força do fluido sobre o anel flutuante, o uso da superfície ranhurada se tornaria uma boa opção. 
O emprego dos anéis flutuantes na bomba multiestágios não apresentou melhora em relação ao comportamento dinâmico do equipamento. A provável causa seria o domínio da influência do acoplamento na análise lateral do rotor. Em casos em que o rotor mostrasse maior deslocamento nas regiões dos impelidores, prevê-se uma maior viabilidade do emprego dos selos anulares flutuantes em relação ao fixos.

A importância de realizar as simulações apresentadas nesta dissertação é de predizer qual o comportamento dinâmico esperado do sistema mecânico conjunto rotativo/fluido - na sua condição de operação em campo. Como os sistemas de bombeio analisados operam com produtos inflamáveis e temperatura elevada, a gestão de mudança de projeto deve ser estudada e simulada antes de sua aplicação efetiva, a fim de minimizar risco de eventual acidente.

Visto que a aplicação de um material não metálico no anel de desgaste permite uma redução de folga até $50 \%$, todos os resultados das simulações apresentadas também são válidos caso esta alteração seja feita.

Como sugestão de trabalho futuro, propõe-se a realização de testes em campo de bombas centrífugas semelhantes ao modelo analisado operando com anel flutuante em substituição ao estático. As principais variáveis a serem observadas para mensurar a efetividade desta alteração é a taxa de erosão dos anéis de desgaste, amplitude de vibração nos mancais, desaparecimento da frequência super-harmônica e aumento da eficiência de bombeio. 
10

\section{Referências bibliográficas}

ALLAIRE, P. Load Capacity and Dynamic Coefficients for Plain and Grooved Turbulente Annular Seals - A Manual for Computer Program SEAL2VERSION 1.2. Rotating Machinery and Controls. 1983.

ALLAIRE, P.; CASTILHO, A. Instabilidade Rotodinâmica: Fundamentos rotodinâmicos em selos e mancais. Universidade Petrobras. 2011

ALLAIRE, P. et. al. Subsynchronous Vibrations Problem and Solution in Multistage Centrifugal Compressor. Sixteenth Turbomachinery Symposium. pp. 65-75. 1987

ANDRÉS, L. S. Annular Pressure Seals. Lecture Notes (\#12), http://phn.tamu.ed, 2010.

ANDRÉS, L. S. High Pressure Long Oil Seal. Lecture Notes (\#Note 11), ), http://phn.tamu.ed 2014

ANTUNES, J. Dynamics of Rotors Immersed in Eccentric Annular Flow. Part 1: Theory. Journal of Fluids and Structures. 1996 p. 893-918

BASKHARONE, E. A.; HENSEL, S. J. Moment Coefficients of Incompressible-Flow Seals with Conically Whirling Rotors. Mechanical Engineering Department, Texas A\&M University, College Station. 1990.

BENTLY, D. E. Fundamentals of Rotating Machinery Diagnostics. 1.ed. Bently Pressurized Bearing Company. 2002 
BLACK, H. B.; Effects of Hydraulic Forces in Annular Seals on the Vibrations of Centrifugal Pump Rotors. Journal of Mechanical Engineering Science. 1969

BIRD, R. B.; STEWART W. E.; LIGHTFOOT E. N. Transport Phenomena. 2.ed. John Wiley\&Sons, Inc. 2002

CHILDS, D. W. Turbomachinery Rotordynamics: Phenomena, Modeling and Analysis. 1.ed. Wiley. 1993

CHILDS, D. W.; NELSON, C. A Compariron of Experimental and Theoretical Results for Rotordynamics Coefficients of Four Annular Gas Seals. NASA. N85-32332. 2985

CLOUGH, R. W.; PENZIEN J. Dynamics of Structures. 3. ed. Computers \& Structures. 2003.

COLE, M. O. T. On Stability of Rotordynamics Systems with Rotor-Stator Contact Interaction. Mathematical, Physical and Engineering Sciences, Vol. 464. No. 2100. 2008. pp. 3353-3375

CUlotTA, V. G. Theory Versus Experiment of the Rotordynamic and Leakage Characteristics of Smooth Annular Bushing Oil Seals. 2004. Thesis Texas A\&M University

DEKKER, M. Bearing Design in Machinery. 1.ed. Estados Unidos. Headquarters. 2003.

DIETZEN, F. J.; NORDMANN R. A 3-Dimensional Finite-Difference Method for Calculating the Dynamic Coefficients of Seals. University of Kaiserslautern. N89-22903. [19-]. 
DIETZEN, F. J.; NORDMANN R. Calculating Rotordynamic Coefficients of Seals by Finite-Difference Techniques. University of Kaiserslautern. N87-22204 [19-]

DUAN, W. et. al. A bulk-flow analysis of static and dynamic characteristics of floating ring seals. Tribology Internacional 40, pp. 470-478. 2006.

EBRAT, O. et. al. Calculation of journal bearing dynamic characteristics including journal misalignment and bearing structural deformation. Tribology Transactions, 47: 94-102, 2004

EISENMANN, R. C.; EISENMANN R. C. Jr. Machinery malfunction diagnosis and correction: vibration analysis and troubleshooting for the process industries. Hewlett-Packard. 2005

FERREIRA, R. B., Análise numérica de mancais hidrodinâmicos lisos e ranhurados utilizando o método dos volumes finitos. 2009. Dissertação de Mestrado - Faculdade de Engenharia Mecânica, Universidade Estadual de Campinas

GAO, R. Computational Fluid Dynamic and Rotordynamic Study on the Labyrinth Seal. 2012. Dissertation - Faculty of the Virginia Polytechnic Institute and State University.

Gasch R.; Nordmann R.; Pfützner, H. Rotordynamik. 2.ed. Springer. 2002

GUNTER, E. J. Dynamic Stability of Rotor-Bearing Systems. NASA SP-113. Department of Mechanical Engineering, University of Virginia, 1966.

HARRIS, T. A. Rolling Bearing Analysis. 4.ed. Wiley, 2001.

HATCH. M. R. Vibration Simulation Using Matlab and Ansys. 1.ed. Chapman \& Hall/CRC. 2001 
HE, M.; CLOUD, C. H; BYRNE, J. M. Fundamentals of Fluid Film Journal Bearing Operation and Modeling. 34th Turbomachinery Symposium. 2005. pp. $155-175$

HIBBELER, R. C. Dynamics. 12.ed. Prentice Hall. 2010

HIRS, G. G. Fundamentals of a Bulk-Flow Theory for Turbulent Lubricant Films. Diss. TH Delft, Niederlande 1970.

IWATSUBO T.; SHENG B.C.; MATSUMOTO, T. An Experimental Study on the Static and Dynamic Characteristics of Pump Annular Seals. I. Mech. E. C297/84, pp. 159-166, 1984.

IWATSUBO T.; SHENG B.C. Evaluation of Seal Effects on the Stability of

Rotating Fluid Machinery. I. Journal of Rotating Machinery, 1995, Vol.2, No. 2, pp. $85-92$

KIRK, R. G. Oil Seal Dynamics: Considerations for Analysis of Centrifugal Compressors. 15th Turbomachinery Symposium. 1998. pp. 25-34

LEE, Y. B.; SHIN, S. K.; Kim, C. H. Test Results for Leakage and Rotordynamic Coefficients of Floating Ring Seals in a High Pressure, High Speed Turbompump. STLE Tribology Transaction, 2005. Vol. 43, pp.54-60

MERIAM, J. L.; KRAIGE, L. G. Engineering mechanics. 6.ed. Wiley. 2006 SANTOS, I. F. Dinâmica de sistemas mecânicos: modelagem, simulação, visualização, verificação. Makron books. 2001

MUTALIKDESAI, P.; CHANDRAKER, S.; ROY H. Modal Analysis of Damped Rotor using Finite Elements Method. National Conference on "Advances In Modelling and Analysis of Aerodynamic Systems". 2013. pp. 98103

MUSZYNSKA, A. Rotordynamics. 1.ed. Taylor \& Francis Group. 2005 
PATANKAR, S. V. Numerical Heat Transfer and Fluid Flow. 2.ed. Taylor\&Francis. 1980

PONTIFÍCIA UNIVERSIDADE CATÓLICA. Departamento de engenharia mecânica. Raciocinando Dinâmica de Rotação. Weber, H. I. Rio de Janeiro, 2013.

RAJAKUMAR, C. Prediction of Rotordynamic Forces Generated by Labyrinth Seal Clearance Flow. 1985. R. B., Análise numérica de mancais hidrodinâmicos lisos e ranhurados utilizando o método dos volumes finitos. 2009. Thesis - Faculty of the Stevens Institute of Technology

RAO, S. Vibrações Mecânicas. 4.ed. Pearson. 2009

SCHLICHTING, H.; GERSTEN, K. Boundary Layer Theory. 8.ed. Klaus Gersten, 2003.

TIMOSHENKO, S. Vibration problems in engineering. 2.ed. D. Van Nostrand Company, Inc. 1937.

VANCE, J.; COUTO, ZEIDAN F.; BRIAN M. Machinery vibration and rotordynamics. Wiley. 2010

VERSTEEG, H. K.; MLALASEKERA W. Computational Fluid Dynamics: The finite volume method.1.ed. Longman Scientific \& Technical. 1995

VIEIRA, L. C., Análise de mancais axiais sob lubrificação hidrodinâmica. 2011. Dissertação de Mestrado - Faculdade de Engenharia Mecânica, Universidade Estadual de Campinas

WANG, W. Z. et. al. Computation of rotordynamic coefficients associated with leakage steam flow through labyrinth seal. Arch Appl Mech 77: 587-597. 2007 
WILCOX, E. API Centrifugal Compressor Oil Seals and Support Systems Types, Selection, and Field Troubleshooting. 29th Turbomachinery Symposium. 2000. pp. 225-238. 2000

YAMADA, Y. Resistence of Flow Through an Annulus with an Inner Rotating Cylinder. Bull J.S.M.E. 302-310. 1962

ZHAO, L.; ALlAIRE, P. E.; BROWN, D. Manual for Computer Program SEAL3. ROMAC report N0.418. 1998 